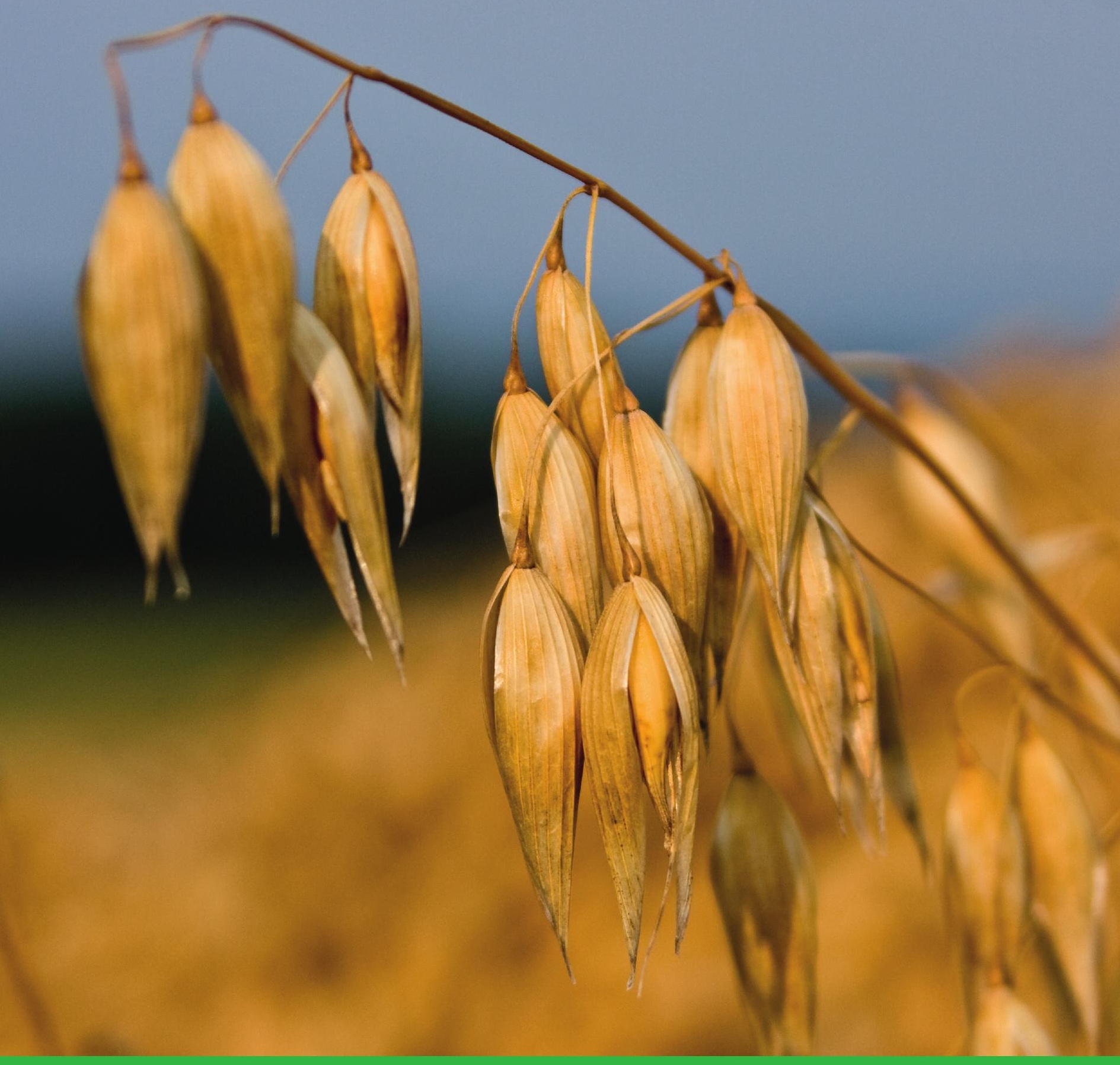

Proficiency test for mycotoxins in oat meal 



\section{Proficiency test for mycotoxins in oat meal}

I.J.W. Elbers, D.P.K.H. Pereboom, J.G.J. Mol and W.C.M. de Nijs

This research has been carried out by Wageningen Food Safety Research, institute within the legal entity Wageningen Research Foundation funded by the Dutch Ministry of Agriculture, Nature and Food Quality, WOT programme Food Safety, theme Animal Feed.

Wageningen, December 2019

WFSR report 2019.012 
Elbers, I.J.W., D.P.K.H. Pereboom, J.G.J. Mol and W.C.M. de Nijs, 2019. Proficiency test for mycotoxins in oat meal. Wageningen, Wageningen Food Safety Research, WFSR report 2019.012. 52 pp.; 0 fig.; 6 tab.; 13 ref.

Project number: 1227248801-WOT BPL

Project title: Borging private laboratoria (WOT-02-004-004)

Coordinator proficiency tests: D.P.K.H. Pereboom/I.J.W. Elbers

Project leader: W.C.M. de Nijs

This report can be downloaded for free at https://doi.org/10.18174/508126 or at www.wur.eu/foodsafety-research (under WFSR publications).

(C) 2019 Wageningen Food Safety Research, institute within the legal entity Wageningen Research Foundation. Hereinafter referred to as WFSR.

The client is allowed to publish or distribute the full report to third parties. Without prior written permission from WFSR it is not allowed to:

a) publish parts of this report;

b) use this report or title of this report in conducting legal procedures, for advertising, acquisition or other commercial purposes;

c) use the name of WFSR other than as the author of this report.

P.O. Box 230, 6700 AA Wageningen, The Netherlands, T +31 (0)317 4802 56, E info.wfsr@wur.nl, www.wur.eu/food-safety-research. WFSR is part of Wageningen University \& Research.

This report from WFSR has been produced with the utmost care. However, WFSR does not accept liability for any claims based on the contents of this report.

WFSR report 2019.012

Distribution list:

- Twenty-three participating laboratories 


\section{Contents}

$\begin{array}{ll}\text { Summary } & 5\end{array}$

$\begin{array}{ll}\text { Introduction } & 7\end{array}$

2

$\begin{array}{ll}\text { Material and methods } & 8\end{array}$

2.1 Scope of the proficiency test $\quad 8$

2.2 Participants $\quad 8$

2.3 Material preparation $\quad 8$

2.4 Logistic procedure $\quad 9$

2.5 Homogeneity study 9

$\begin{array}{ll}2.6 & \text { Stability of the materials } \\ 2.7 & 10\end{array}$

$\begin{array}{ll}2.7 & \text { Interpretation of the results } \\ \end{array}$

3.1 Calculation of the consensus value 12

3.2 Calculation of the uncertainty of the consensus value 12

3.3 Calculation of the standard deviation for proficiency assessment $\left(\sigma_{P}\right) \quad 13$

3.4 Performance characteristics with regard to the accuracy 13

4.1 Participants $\quad 15$

4.2 Methods of analysis applied by participants $\quad 15$

$\begin{array}{lll}4.3 & \text { Performance participants material A } & 15\end{array}$

4.3.1 15-acetyl-Deoxynivalenol 15

4.3.2 3-acetyl-Deoxynivalenol 15

4.3.3 Deoxynivalenol-3-glucoside 16

4.3.4 Deoxynivalenol 16

4.3.5 Aflatoxin B1 16

4.3.6 Enniatin B 16

4.3.7 Enniatin B1 16

4.3.8 Zearalenone 16

$\begin{array}{lll}4.3 .9 & \mathrm{~T}-2 \text { toxin } & 17\end{array}$

4.3.10 HT-2 toxin 17

4.3.11 Sum of T-2 and HT-2 toxins 17

4.3.12 Other mycotoxins 17

$\begin{array}{lll}4.4 & \text { Performance results participants material B } & 17\end{array}$

$\begin{array}{lll}4.4 .1 & 15 \text {-acetyl-Deoxynivalenol } & 17\end{array}$

$\begin{array}{lll}4.4 .2 & 3-a c e t y l-D e o x y n i v a l e n o l & 17\end{array}$

4.4.3 Deoxynivalenol-3-glucoside 18

4.4.4 Deoxynivalenol 18

4.4.5 Aflatoxin B1 18

4.4.6 Enniatin B 18

4.4.7 Enniatin B1 18

4.4.8 Zearalenone 18

4.4.9 T-2 toxin 19

4.4.10 HT-2 toxin 19

4.4.11 Sum of T-2 and HT-2 toxins 19

4.4.12 Other mycotoxins 19 
Annex 1 Codification of the samples

Annex 2 Instruction letter

Annex 3 Statistical evaluation of homogeneity data

Annex 4 Statistical evaluation of stability data

Annex 5 Overview of the applied methods 36

Annex 6 Results material A 38

Annex 7 Results material B 44

Annex 8 False positive and false negative results 50

Annex 9 Overview performance per laboratory 


\section{Summary}

In April 2019 a proficiency test for mycotoxins in oat meal was organised by Wageningen Food Safety Research (WFSR), Wageningen University \& Research in accordance with ISO 17043. WFSR, part of Wageningen University \& Research is accredited for the organisation of proficiency tests in the field of contaminants, pesticides, mycotoxins, plant toxins and veterinary drugs in feed and feed ingredients according to ISO/IEC 17043 (R013). The primary goal of this proficiency test was to give participants the opportunity to evaluate or demonstrate their competence for the analysis of mycotoxins in oat meal.

Two materials were prepared and dispatched on dry-ice to the participants. The consensus values of the mycotoxins in each material are given in Table 1.

Table 1 Consensus values of the mycotoxins in the proficiency materials.

\begin{tabular}{lcc} 
& Material A & Material B \\
\hline Compound & Consensus value & Consensus value \\
& $\mu g / \mathrm{kg}$ & 152 \\
15-acetyl-Deoxynivalenol & 161 & 645 \\
\hline 3-acetyl-Deoxynivalenol & 613 & 1144 \\
\hline Deoxynivalenol-3-glucoside & 1143 & 4268 \\
\hline Deoxynivalenol & 4174 & 10.3 \\
\hline Aflatoxin B1 & 25 & 115 \\
\hline Enniatin B & 121 & 65 \\
\hline Enniatin B1 & 65 & 24 \\
\hline T-2 toxin & 133 & 61 \\
\hline HT-2 toxin & 185 & 289 \\
\hline Zearalenone & 293 & 83 \\
\hline Sum of T-2 and HT-2 toxin & 319 & \\
\hline
\end{tabular}

Material A was prepared by spiking a solution of aflatoxin B1, T-2 toxin and HT-2 toxin to an incurred oat meal to the required target concentrations. Material B was prepared by spiking a solution of aflatoxin B1 to the same incurred oat meal. The materials were mixed with water and the slurry was freeze-dried. The materials were homogenized afterwards.

Homogeneity assessment showed that both materials were sufficiently homogeneous for proficiency testing. The stability test demonstrated no statistically significant loss of the mycotoxins, except for HT-2 toxin in material B. This decrease was accounted for in the calculation of the z-scores.

Twenty-three participants subscribed for the participation in this proficiency test. For calculating of the accuracy $z$-scores in this test a target standard deviation of $25 \%$ was taken to assess proficiency of the participants.

Not all compounds could be statistically evaluated since the number of results submitted by the participants was too low. In both material A and B seven statistical evaluations were possible.

A total of 249 z-scores could be calculated from the submitted results of which thirteen questionable $z$-scores and four unsatisfactory z-scores were reported. In addition, two false positive and four false negative results were reported. Five participants showed optimal performance by detecting the mycotoxins with a correct quantification/qualification (14 satisfactory z-scores) and the absence of false positive and false negative results. Another ten participants showed suboptimal performance 
within their scope by reporting thirteen or less satisfactory z-scores. Eight participants reported qualitative, false negative, false positive, questionable or unsatisfactory z-scores.

Based on the results of this test it can be concluded that all quantitative results for aflatoxin B1 show optimal performance. The performance of deoxynivalenol, 3-acetyl-deoxynivalenol, T-2 toxin and HT-2 toxin needs improvement; satisfactory results vary from 70 to $89 \%$. Only nine participants included one or more of the metabolites of deoxynivalenol in their method, despite the recommendation of the European Commission for monitoring of these mycotoxins. 


\section{Introduction}

Proficiency testing is conducted to provide participants with a powerful tool to evaluate and demonstrate the reliability of the data that are produced by the laboratory. Proficiency testing is an important requirement and demanded by ISO/IEC 17025:2017 [1].

The preparation of the materials, including the homogeneity and stability testing of the materials, and the evaluation of the quantitative results were carried out under accreditation according to ISO/IEC 17043:2010 [3] accreditation by the Dutch Accreditation Board (R013).

There is EU harmonised regulation for aflatoxin B1 in animal feed materials at a limit of $0.02 \mathrm{mg} / \mathrm{kg}$ (Directive 2002/32/DC and its amendments) [11]. Guidance values for deoxynivalenol and zearalenone in animal feed are laid down in recommendation 2006/576/EC and amendments [12] at, respective $8 \mathrm{mg} \mathrm{DON} / \mathrm{kg}$ and $2 \mathrm{mg} Z \mathrm{EN} / \mathrm{kg}$ cereals and cereal products with the exception of maize by-products. For the sum of T2/HT2 indicative levels have been set in recommendation 2013/165/EU of $0.5 \mathrm{mg} / \mathrm{kg}$ in cereals and $2 \mathrm{mg} / \mathrm{kg}$ for oat milling products (husks).

The aim of this proficiency test was to give participants the opportunity to evaluate or demonstrate their competence for the analysis of mycotoxins in oat meal. 


\section{Material and methods}

\subsection{Scope of the proficiency test}

This proficiency test (PT) focused on the mycotoxins aflatoxin B1, deoxynivalenol, 3-acetyldeoxynivalenol, 15-acaetyl-deoxynivalenol, deoxynivalenol-3-glucoside, zearalenone, T-2 toxin, HT-2 toxin, enniatin A, enniatin A1, enniatin B and enniatin B1 in oat meal. The target concentrations for the mycotoxins in this PT are presented in Table 3.

\subsection{Participants}

Twenty-three participants registered for the participation in the PT and all reported their results. All of these participants are situated in Europe. Each participant was asked a priori, to indicate which compounds were included in the scope of their method. The participants were asked to report the results through a web application designed for PTs.

\subsection{Material preparation}

Two spiked/contaminated oat meals, material A and material B, were prepared for the PT. The starting material was an oat meal which was contaminated with several compounds (Table 3). For material A levels of T-2 toxin and HT-2 toxin were artificially increased and aflatoxin B1 was added by spiking an acetonitrile-solution containing aflatoxin B1, T-2 toxin and HT-2 toxin and material B by adding an acetonitrile-solution containing aflatoxin B1 at levels presented in Table 2. The oat meal samples $(2 \mathrm{~kg})$ were mixed with three litres of water and homogenized using a concrete mixer according to inhouse standard operating procedures [4]. The fortified slurry was freeze-dried, homogenized and stored in the freezer until use.

Table 2 Target concentrations of mycotoxins in the proficiency materials.

\begin{tabular}{|c|c|c|c|c|}
\hline & Abbreviation & Oat meal material & Material A & Material B \\
\hline Compound & & $\begin{array}{l}\text { Contains } \\
(\mu \mathrm{g} / \mathrm{kg})\end{array}$ & $\begin{array}{c}\text { Target concentration } \\
(\mu g / k g)\end{array}$ & $\begin{array}{c}\text { Target concentration } \\
(\mu \mathrm{g} / \mathrm{kg})\end{array}$ \\
\hline 3-acetyl-Deoxynivalenol & 3-Ac-DON & 600 & 600 & 600 \\
\hline Deoxynivalenol & DON & 3600 & 3600 & 3600 \\
\hline Aflatoxin B1 & AFLA & & 25 & 10 \\
\hline Enniatin B & ENN B & 110 & 110 & 110 \\
\hline Enniatin B1 & ENN B1 & 60 & 60 & 60 \\
\hline Zearalenone & ZEN & 350 & 350 & 350 \\
\hline
\end{tabular}




\subsection{Logistic procedure}

After homogenization, the samples for the participants were randomly selected and coded using a web application designed for PTs (Annex 1). The code used was 2019/mycotoxins/oats/000, in which the three digit number at the end of the code was automatically generated by the WFSR Laboratory Quality Services web application. In addition, the samples for homogeneity and stability testing were also randomly selected.

Each of the participating participants received a randomly assigned laboratory code, generated by the web application. The sample sets with the corresponding numbers were sent to the participants on April 8, 2019. The sample sets were packed in an insulating box with dry-ice and were dispatched to the participants immediately by courier. The samples were accompanied by a letter describing the requested analysis (Annex 2) and an acknowledgement of receipt form. By e-mail the participants received instructions on how to use the web application to report the results.

The participants were asked to store the samples in the freezer and to analyse the samples according to their routine method. A single analysis result for the mycotoxins in each sample was requested. The deadline for submitting the quantitative results was May 20, 2019, allowing the participants at least five weeks for the analysis.

Results should be reported for mycotoxins as $\mu \mathrm{g} / \mathrm{kg}$ product (no correction for moisture). Participants were asked to provide information on their analytical method (extraction solvent, clean-up procedure, internal standards used, detection technique, limit of detection, limit of quantification).

\subsection{Homogeneity study}

The homogeneity of the materials was tested according to The International Harmonized Protocol for Proficiency Testing of Analytical Laboratories [7] and ISO 13528:2015 [5]. For homogeneity a target standard deviation for proficiency assessment $\left(\sigma_{P}\right)$ of $25 \%$ was used as a fit-for-purpose standard deviation, in line with the target RSD used in proficiency tests on mycotoxins as organised by the EURL mycotoxins \& plant toxins [13]. With this procedure the between-sample standard deviation ( $s_{s}$ ) and the within-sample standard deviation $\left(\mathrm{S}_{\mathrm{w}}\right)$ were compared with the standard deviation for proficiency assessment. The method applied for homogeneity testing is considered suitable if $s_{w}$ $<0.5^{*} \sigma_{\mathrm{p}}$ and a material is considered adequately homogeneous if $\mathrm{s}_{\mathrm{s}}<0.3^{*} \sigma_{\mathrm{p}}$. The results of the homogeneity study, the grand mean with the corresponding RSD are presented in Table 4 and the statistical evaluation of material A and material B are presented in Annex 3.

Ten containers of materials $A$ and $B$ were analysed in duplicate for ten mycotoxins (Table 3 ). All mycotoxins in material A fulfilled the homogeneity-criterion. T-2 toxin in material B was the only analyte for which the criteria did not comply with the criterion for the within-sample standard deviation. Despite the deviation of this compound, material B was considered to be homogeneous, since the other nine mycotoxins fulfilled the homogeneity requirements and were spiked in the same solution.

The mycotoxins in material A and material B demonstrated to be sufficiently homogeneous for use in the proficiency test. 


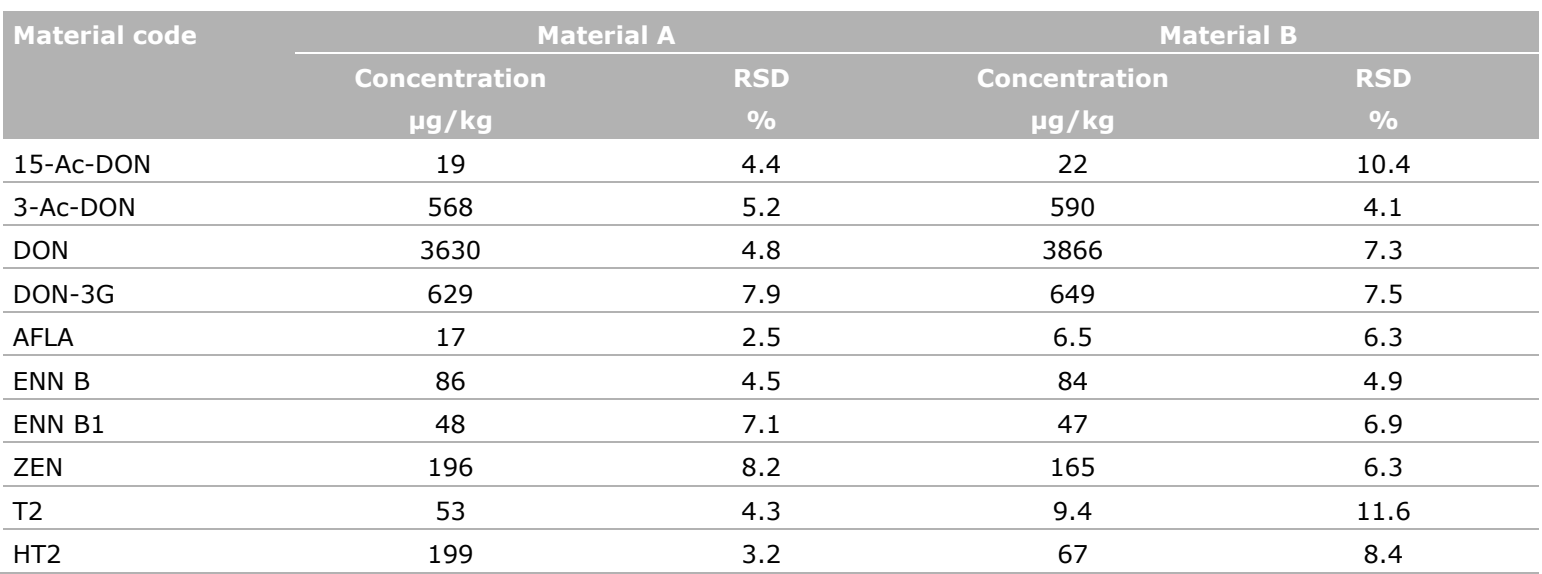

\subsection{Stability of the materials}

On April 8, 2019, the day the materials were distributed to the participants, six randomly selected samples of both materials were stored at $<-70^{\circ} \mathrm{C}$. It is assumed that the mycotoxins are stable at these storage conditions. Another 12 containers remained stored in the freezer. In addition, to mimic a possible thaw situation during transport, six containers were stored at room temperature for two days and then stored again in the freezer.

On May 21, 2019, 43 days after distribution of the samples, six samples of both materials $B$ that were stored at <-70, in the freezer and for two days at room temperature were analysed for mycotoxins. For each set of test samples, the average of the results and the standard deviation were calculated.

It was determined whether a consequential instability of the analytes occur [5, 7]. A consequential instability is observed when the average value of an analyte in the samples stored in the freezer or at room temperature for two days is more than $0.3 \sigma_{p}$ below the average value of the analyte in the samples stored at $<-70^{\circ} \mathrm{C}$. If so, the instability has a significant influence on the calculated z-scores.

For the mycotoxins in material A no consequential instability was observed and therefore, they are considered stable for the duration of the proficiency test. In material B only AFLA, T2 and HT2 were evaluated for stability and a consequential instability was observed for HT2. A decrease of $15 \%$ was observed between samples stored at $<-70^{\circ} \mathrm{C}$ and in the freezer/two days at room temperature. This instability was taken into account in the calculation of the z-scores. The results of the stability test are presented in Annex 4.

\subsection{Interpretation of the results}

A result was assigned as false negative result if a compound was not detected, taking into account the reported scope of the participant, the consensus value and the reported LOQ for the compound by the participant.

For example: the consensus value of compound $A$ is $70 \mu \mathrm{g} / \mathrm{kg}$ and the participant reported an $L O Q=$ $20 \mu \mathrm{g} / \mathrm{kg}$ for this compound. Taken into account the $25 \%$ target standard deviation in this test, the $2 z$ threshold would be at $35 \mu \mathrm{g} / \mathrm{kg}(70-(2 * 25 \%$ of 70$))$. Since the LOQ of this participant is lower than the $-2 z$ value, this participant should be able to detect the presence. If the LOQ would have been $40 \mu \mathrm{g} / \mathrm{kg}$ no false negative result would be assigned. 
Also, when no LOQ values were reported by the participants and the compound was reported as not detected (nd), or the compound was not reported but was within the participants' scope, a false negative (FN) result was assigned.

For false positive results it was decided to apply a cut-off level of $2 \mu \mathrm{g} / \mathrm{kg}$ for ochratoxin A, $50 \mu \mathrm{g} / \mathrm{kg}$ or enniatin $A(1)$ and $100 \mu \mathrm{g} / \mathrm{kg}$ for fumonisin $B 1$ and concentrations below these levels were not assigned as false positive results. 


\section{Statistical evaluation}

The statistical evaluation was carried out according to the International Harmonized Protocol for the Proficiency Testing of Analytical Laboratories [7], elaborated by ISO, IUPAC and AOAC and ISO 13528:2015 [5] in combination with the insights published by the Analytical Methods Committee [8,9] regarding robust statistics.

For the evaluation of the quantitative results, the consensus value, the uncertainty of the consensus value, the standard deviation for proficiency assessment and z-scores were calculated.

\subsection{Calculation of the consensus value}

The consensus value $(X)$ was determined using robust statistics $[5,8,9]$. The advantage of robust statistics is that all values are taken into account: outlying observations are retained, but given less weight. Furthermore, it is not expected to receive normally distributed data in a proficiency test. When using robust statistics, the data do not have to be normally distributed in contrast to conventional outlier elimination methods.

The robust mean of the reported results of all participants, calculated from an iterative process that starts at the median of the reported results using a cut-off value depending on the number of results, was used as the consensus value $[5,8]$.

\subsection{Calculation of the uncertainty of the consensus value}

The uncertainty of the consensus value is calculated to determine the influence of this uncertainty on the evaluation of the participants. A high uncertainty of the consensus value will lead to a high uncertainty of the calculated participants $z_{a}$-scores. If the uncertainty of the consensus value and thus the uncertainty of the $z_{a}$-score is high, the evaluation could indicate unsatisfactory method performance without any cause within the laboratory. In other words, illegitimate conclusions could be drawn regarding the performance of the participating participants from the calculated $z_{a}$-scores if the uncertainty of the consensus value is not taken into account.

The uncertainty of the consensus value (the robust mean) is calculated from the estimation of the standard deviation of the consensus value and the number of values used for the calculation of the consensus value [5]:

$\mathrm{u}=1.25 * \frac{\hat{\sigma}}{\sqrt{\mathrm{n}}}$

where:

$\mathrm{u}=$ Uncertainty of the consensus value;

$\mathrm{n}=$ Number of values used to calculate the consensus value;

$\hat{\sigma}=$ The estimate of the standard deviation of the consensus value resulting from robust statistics.

According to ISO 13528:2015 [5] the uncertainty of the consensus value (u) is negligible and therefore does not have to be included in the statistical evaluation if:

$u \leq 0.3 \sigma_{\mathrm{P}}$ 
where:

$\mathrm{u}=$ The uncertainty of the consensus value;

$\sigma_{\mathrm{P}}=$ Standard deviation for proficiency assessment (§3.3).

In case the uncertainty of the consensus value does not comply with this criterion, the uncertainty of the consensus value should be taken into account when evaluating the performance of the participants regarding the accuracy ( $\S 3.4)$. In case the uncertainty is $>0.7 \sigma_{\mathrm{p}}$ the calculated $z$-scores should not be used for evaluation of participants performance and are presented for information only.

\subsection{Calculation of the standard deviation for proficiency assessment $\left(\sigma_{P}\right)$}

A target standard deviation for proficiency assessment $\left(\sigma_{\mathrm{P}}\right)$ of $25 \%$ was used as a fit-for-purpose standard deviation which is in line with the target RSD used in proficiency tests on mycotoxins as organised by the EURL.

$\sigma_{\mathrm{P}}=0.25 \mathrm{C}$

where:

$\sigma_{\mathrm{P}}=$ Expected standard deviation in proficiency tests for animal feed;

$c=$ Concentration of the analyte $(\mu \mathrm{g} / \mathrm{kg})$.

\subsection{Performance characteristics with regard to the accuracy}

For illustrating the performance of the participating participants with regard to the accuracy a $z_{a}$-score is calculated. For the evaluation of the performance of the participants, ISO 13528:2015 [5] is applied. According to these guidelines $\mathrm{z}_{\mathrm{a}}$-scores are classified as presented in Table 4 .

Table 4 Classification of $z_{a}$-scores.

\begin{tabular}{cc}
\hline$\left|z_{a}\right| \leq 2$ & Satisfactory \\
\hline $2<\left|z_{a}\right|<3$ & Questionable \\
\hline$\left|z_{a}\right| \geq 3$ & Unsatisfactory
\end{tabular}

If the calculated uncertainty of the consensus value complies with the criterion mentioned in $\S 3.2$, the uncertainty is negligible. In this case the accuracy z-score is calculated from:

$z_{a}=\frac{X-X}{\sigma_{p}}$

where:

$\mathrm{z}_{\mathrm{a}}=$ Accuracy $\mathrm{z}$-score;

$\bar{x}=$ The average result of the laboratory;

$\mathrm{X}=$ Consensus value;

$\sigma_{\mathrm{P}}=$ Standard deviation for proficiency assessment. 
However, if the uncertainty of the consensus value does not comply with the criterion mentioned in $\S 3.2$, it could influence the evaluation of the participants. Although, according to ISO 13528 in this case no z-scores can be calculated, we feel that evaluation of the participating participants is of main importance justifying the participating participants' effort. Therefore in this case, the uncertainty is taken into account by calculating the accuracy z-score [5]:

$z_{a}^{\prime}=\frac{x-X}{\sqrt{\sigma_{p}^{2}+u^{2}}}$

Equation II

where:

$\mathrm{z}_{\mathrm{a}}^{\prime}=$ Accuracy $z$-score taking into account the uncertainty of the consensus value;

$\bar{x}=$ The average result of the laboratory;

$\mathrm{X}=$ Consensus value;

$\sigma_{\mathrm{P}}=$ Standard deviation for proficiency assessment;

$\mathrm{u}=$ Uncertainty of the consensus value.

A consequential instability of the proficiency materials can influence the evaluation of the laboratory performance. Therefore, in that case the consequential instability is taken into account when calculating z-scores. Because instability only regards one side of the confidence interval (a decrease of the concentration) this correction only applies to the lower $2 \mathrm{~s}$ limit and results in an asymmetrical confidence interval.

In the case of a consequential instability the accuracy z-score for the participants that reported an amount below the consensus value is corrected for this instability by:

$z_{\mathrm{ai}}=\frac{\bar{X}-X}{\sqrt{\sigma_{\mathrm{p}}^{2}+\Delta^{2}}}$

Equation III

where:

$\mathrm{z}_{\overline{\mathrm{ai}}}=$ Accuracy $z$-score taking into account the instability of the consensus value;

$\bar{x}=$ The average result of the laboratory;

$\mathrm{X}=$ Consensus value;

$\sigma_{\mathrm{P}}=$ Standard deviation for proficiency assessment;

$\Delta=$ Difference between average concentration of compound stored at $<-70{ }^{\circ} \mathrm{C},<-18{ }^{\circ} \mathrm{C}$ and average concentration at room temperature for two days.

In some cases the uncertainty of the consensus value does not comply with the criterion in $\S 3.2$ and a consequential instability is observed. In this case the $\mathrm{z}_{\mathrm{a}}{ }_{\mathrm{a}}$-score for the participants that reported an amount below the consensus value is corrected for this instability by:

$Z^{\prime}{ }_{a i}=\frac{X-X}{\sqrt{\sigma_{p}^{2}+\Delta^{2}+u^{2}}}$

Equation IV

where:

$z^{\prime}{ }_{a i}=$ Accuracy $z$-score taking into account the uncertainty and instability of the consensus value;

$\bar{x}=$ The average result of the laboratory;

$\mathrm{X}=$ Consensus value;

$\sigma_{\mathrm{P}} \quad=$ Standard deviation for proficiency assessment;

$\Delta=$ Difference between average concentration of compound stored at $<-70{ }^{\circ} \mathrm{C},<-18{ }^{\circ} \mathrm{C}$ and average concentration at room temperature for two days;

$\mathrm{u}=$ Uncertainty of the consensus value. 


\section{$4 \quad$ Methods and results}

\subsection{Participants}

Twenty-three participants registered for the PT. All participants reported that the samples were received in good order and all participants submitted the results. The performance of individual participants is summarized in Annex 9.

\subsection{Methods of analysis applied by participants}

An overview of the information provided by the participants regarding the methods applied in this PT is presented in Annex 5. The samples were analysed using various extraction methods, purification steps and detection techniques.

Ranges for the reported limits of detection (LODs) and limits of quantification (LOQs) for the mycotoxins are presented in Table 5.

Table 5 Overview of reported $L O D$ and $L O Q$ reported by the participants.

\begin{tabular}{lcr} 
Compound & LOD $(\mu \mathrm{g} / \mathrm{kg})$ & LOQ $(\mu \mathrm{g} / \mathrm{kg})$ \\
15-AC-DON & $1-100$ & $2-500$ \\
\hline 3-AC-DON & $1-100$ & $2-500$ \\
\hline DON & $2-151.5$ & $10-500$ \\
\hline DON-3-G & $61-100$ & $20-500$ \\
\hline AFLA & $0.07-10$ & $0.2-10$ \\
\hline ENN B & $0.2-3$ & $2-10$ \\
\hline ENN B1 & $0.2-3$ & $1-10$ \\
\hline ZON & $0.4-70$ & $2-140$ \\
\hline T2 & $0.4-21$ & $2-50$ \\
\hline HT2 & $1.5-20$ & $4-60$
\end{tabular}

\subsection{Performance participants material A}

\subsubsection{5-acetyl-Deoxynivalenol}

Five participants reported quantitative results for 15-Ac-DON. Two participants (PT9615 and PT9618) reported the sum of $15-\mathrm{Ac}-\mathrm{DON}$ and 3-Ac-DON.

The lowest concentration reported was $93.6 \mu \mathrm{g} / \mathrm{kg}$ and the highest was $494 \mu \mathrm{g} / \mathrm{kg}$. The consensus value is $161 \mu \mathrm{g} / \mathrm{kg}$ with a robust standard deviation of $67 \mu \mathrm{g} / \mathrm{kg}$ (resulting in an $\mathrm{RSD}_{\mathrm{R}}$ of $42 \%$ ) expressing the reproducibility within this PT. The robust standard deviation of $67 \mu \mathrm{g} / \mathrm{kg}$ is more than 1.5 times higher than the target standard deviation $\sigma_{\mathrm{p}}$ of $40 \mu \mathrm{g} / \mathrm{kg}$ ( $25 \%$ of the consensus value) suggested in $\$ 3.3$ for feed material. With only five laboratories reporting quantitative results, statistic evaluation is not appropriate.

\subsubsection{3-acetyl-Deoxynivalenol}

Seven participants reported quantitative results for 3-Ac-DON. Two participants (PT9615 and PT9618) reported the sum of $15-\mathrm{Ac}-\mathrm{DON}$ and 3-Ac-DON.

The lowest concentration reported is $415 \mu \mathrm{g} / \mathrm{kg}$ and the highest is $664 \mu \mathrm{g} / \mathrm{kg}$. The consensus value is $613 \mu \mathrm{g} / \mathrm{kg}$ with a robust standard deviation of $56 \mu \mathrm{g} / \mathrm{kg}$ (resulting in an $\mathrm{RSD}_{\mathrm{R}}$ of $9.1 \%$ ) expressing the 
reproducibility within this PT. The robust standard deviation of $56 \mu \mathrm{g} / \mathrm{kg}$ is almost 3 times lower than the target standard deviation $\sigma_{\mathrm{P}}$ of $153 \mu \mathrm{g} / \mathrm{kg}$. The uncertainty of the consensus value is $26 \mu \mathrm{g} / \mathrm{kg}$, which does not exceed $0.3 \sigma_{\mathrm{P}}(\S 3.2)$. With respect to the accuracy all results are satisfactory.

\subsubsection{Deoxynivalenol-3-glucoside}

Four participants reported quantitative results for DON-3G.

The lowest concentration reported is $569 \mu \mathrm{g} / \mathrm{kg}$ and the highest is $1413 \mu \mathrm{g} / \mathrm{kg}$. The consensus value is $1143 \mu \mathrm{g} / \mathrm{kg}$ with a robust standard deviation of $290 \mu \mathrm{g} / \mathrm{kg}$ (resulting in an RSD $\mathrm{R}_{\mathrm{R}}$ of $25 \%$ ) expressing the reproducibility within this PT. The robust standard deviation of $290 \mu \mathrm{g} / \mathrm{kg}$ is comparable to the target standard deviation $\sigma_{\mathrm{P}}$ of $286 \mu \mathrm{g} / \mathrm{kg}$. With only four laboratories reporting quantitative results, statistic evaluation is not appropriate.

\subsubsection{Deoxynivalenol}

Twenty participants reported quantitative results for DON. Participant PT9609 failed to detect the presence of DON and reported a false negative result.

The lowest concentration reported is $2572 \mu \mathrm{g} / \mathrm{kg}$ and the highest is $6860 \mu \mathrm{g} / \mathrm{kg}$. The consensus value is $4174 \mu \mathrm{g} / \mathrm{kg}$ with a robust standard deviation of $629 \mu \mathrm{g} / \mathrm{kg}$ (resulting in an $\mathrm{RSD}_{\mathrm{R}}$ of $15 \%$ ) expressing the reproducibility within this PT. The robust standard deviation of $629 \mu \mathrm{g} / \mathrm{kg}$ is almost 2 times lower than the target standard deviation $\sigma_{\mathrm{P}}$ of $1044 \mu \mathrm{g} / \mathrm{kg}$. The uncertainty of the consensus value is $176 \mu \mathrm{g} / \mathrm{kg}$, which does not exceed $0.3 \sigma_{\mathrm{P}}$ (§3.2). With respect to the accuracy two laboratories reported questionable results (PT9625 and PT9628).

\subsubsection{Aflatoxin B1}

Twenty-two of the 23 participants reported quantitative results for AFLA.

The lowest concentration reported is $12.4 \mu \mathrm{g} / \mathrm{kg}$ and the highest is $33.0 \mu \mathrm{g} / \mathrm{kg}$. The consensus value is $25 \mu \mathrm{g} / \mathrm{kg}$ with a robust standard deviation of $5.5 \mu \mathrm{g} / \mathrm{kg}$ (resulting in an $\mathrm{RSD}_{\mathrm{R}}$ of $22 \%$ ) expressing the reproducibility within this PT. The robust standard deviation of $5.5 \mu \mathrm{g} / \mathrm{kg}$ is comparable to the target standard deviation $\sigma_{\mathrm{P}}$ of $6.2 \mu \mathrm{g} / \mathrm{kg}$. The uncertainty of the consensus value is $1.5 \mu \mathrm{g} / \mathrm{kg}$, which does not exceed $0.3 \sigma_{\mathrm{P}}(\S 3.2)$. With respect to the accuracy all results are satisfactory.

\subsubsection{Enniatin B}

Four participants reported quantitative results for ENN B.

The lowest concentration reported is $75 \mu \mathrm{g} / \mathrm{kg}$ and the highest is $197 \mu \mathrm{g} / \mathrm{kg}$. The consensus value is $121 \mu \mathrm{g} / \mathrm{kg}$ with a robust standard deviation of $56 \mu \mathrm{g} / \mathrm{kg}$ (resulting in an $\mathrm{RSD}_{\mathrm{R}}$ of $38 \%$ ) expressing the reproducibility within this PT. The robust standard deviation of $46 \mu \mathrm{g} / \mathrm{kg}$ is 1.5 times higher than the target standard deviation $\sigma_{\mathrm{p}}$ of $30 \mu \mathrm{g} / \mathrm{kg}$ ( $25 \%$ of the consensus value). With only four laboratories reporting quantitative results, statistic evaluation is not appropriate.

\subsubsection{Enniatin B1}

Four participants reported quantitative results for ENN B1.

The lowest concentration reported is $35.4 \mu \mathrm{g} / \mathrm{kg}$ and the highest is $100.4 \mu \mathrm{g} / \mathrm{kg}$. The consensus value is $65 \mu \mathrm{g} / \mathrm{kg}$ with a robust standard deviation of $31 \mu \mathrm{g} / \mathrm{kg}$ (resulting in an $\mathrm{RSD}_{\mathrm{R}}$ of $48 \%$ ) expressing the reproducibility within this PT. The robust standard deviation of $31 \mu \mathrm{g} / \mathrm{kg}$ is almost two times higher than the target standard deviation $\sigma_{\mathrm{p}}$ of $16.2 \mu \mathrm{g} / \mathrm{kg}$ ( $25 \%$ of the consensus value). With only four laboratories reporting quantitative results, statistic evaluation is not appropriate.

\subsubsection{Zearalenone}

Twenty-one participants reported quantitative results for ZEN.

The lowest concentration reported is $177 \mu \mathrm{g} / \mathrm{kg}$ and the highest is $692 \mu \mathrm{g} / \mathrm{kg}$. The consensus value is $293 \mu \mathrm{g} / \mathrm{kg}$ with a robust standard deviation of $41 \mu \mathrm{g} / \mathrm{kg}$ (resulting in an $\mathrm{RSD}_{\mathrm{R}}$ of $14 \%$ ) expressing the reproducibility within this PT. The robust standard deviation of $41 \mu \mathrm{g} / \mathrm{kg}$ is almost two times lower 
than the target standard deviation $\sigma_{\mathrm{P}}$ of $73 \mu \mathrm{g} / \mathrm{kg}$. The uncertainty of the consensus value is $11.3 \mu \mathrm{g} / \mathrm{kg}$, which does not exceed $0.3 \sigma_{\mathrm{P}}(\S 3.2)$. With respect to the accuracy one result is unsatisfactory (PT9628).

\subsubsection{T-2 toxin}

Nineteen participants reported quantitative results for T-2 toxin.

The lowest concentration reported is $26.0 \mu \mathrm{g} / \mathrm{kg}$ and the highest is $221 \mu \mathrm{g} / \mathrm{kg}$. The consensus value is $133 \mu \mathrm{g} / \mathrm{kg}$ with a robust standard deviation of $25 \mu \mathrm{g} / \mathrm{kg}$ (resulting in an $\mathrm{RSD}_{\mathrm{R}}$ of $19 \%$ ) expressing the reproducibility within this $\mathrm{PT}$. The robust standard deviation of $25 \mu \mathrm{g} / \mathrm{kg}$ is comparable to the target standard deviation $\sigma_{\mathrm{P}}$ of $33 \mu \mathrm{g} / \mathrm{kg}$. The uncertainty of the consensus value is $7.1 \mu \mathrm{g} / \mathrm{kg}$, which does not exceed $0.3 \sigma_{\mathrm{P}}(\S 3.2)$. With respect to the accuracy one result is questionable (PT9620) and one is unsatisfactory (PT9627).

\subsubsection{HT-2 toxin}

Nineteen participants reported quantitative results for HT-2 toxin.

The lowest concentration reported is $71.1 \mu \mathrm{g} / \mathrm{kg}$ and the highest is $259 \mu \mathrm{g} / \mathrm{kg}$. The consensus value is $185 \mu \mathrm{g} / \mathrm{kg}$ with a robust standard deviation of $42 \mu \mathrm{g} / \mathrm{kg}$ (resulting in an $\mathrm{RSD}_{\mathrm{R}}$ of $23 \%$ ) expressing the reproducibility within this PT. The robust standard deviation of $42 \mu \mathrm{g} / \mathrm{kg}$ is comparable to the target standard deviation $\sigma_{\mathrm{P}}$ of $46 \mu \mathrm{g} / \mathrm{kg}$. The uncertainty of the consensus value is $12.1 \mu \mathrm{g} / \mathrm{kg}$, which does not exceed $0.3 \sigma_{\mathrm{P}}(\S 3.2)$. With respect to the accuracy two results are questionable (PT9609 and PT9627).

\subsubsection{Sum of T-2 and HT-2 toxins}

Nineteen participants reported quantitative results for T-2 and/or HT-2 toxin. Sum-concentrations were calculated by adding the concentrations.

The lowest sum-concentration reported is $97.1 \mu \mathrm{g} / \mathrm{kg}$ and the highest is $452 \mu \mathrm{g} / \mathrm{kg}$. The consensus value is $319 \mu \mathrm{g} / \mathrm{kg}$ with a robust standard deviation of $62 \mu \mathrm{g} / \mathrm{kg}$ (resulting in an $\mathrm{RSD}_{\mathrm{R}}$ of $19 \%$ ) expressing the reproducibility within this PT. The robust standard deviation of $62 \mu \mathrm{g} / \mathrm{kg}$ is comparable to the target standard deviation $\sigma_{\mathrm{P}}$ of $80 \mu \mathrm{g} / \mathrm{kg}$. The uncertainty of the consensus value is $17.9 \mu \mathrm{g} / \mathrm{kg}$, which does not exceed $0.3 \sigma_{\mathrm{P}}(\S 3.2)$. With respect to the accuracy one result is questionable (PT9627).

\subsubsection{Other mycotoxins}

Participant PT9627 reported a false positive result by detecting the presence of $2.8 \mu \mathrm{g} / \mathrm{kg}$ ochratoxin A.

\subsection{Performance results participants material B}

\subsubsection{5-acetyl-Deoxynivalenol}

Five participants reported quantitative results for 15-Ac-DON. Two participants (PT9615 and PT9618) reported the sum of $15-\mathrm{Ac}-\mathrm{DON}$ and 3-Ac-DON.

The lowest concentration reported is $106 \mu \mathrm{g} / \mathrm{kg}$ and the highest is $514 \mu \mathrm{g} / \mathrm{kg}$. The consensus value is $152 \mu \mathrm{g} / \mathrm{kg}$ with a robust standard deviation of $48 \mu \mathrm{g} / \mathrm{kg}$ (resulting in an $\mathrm{RSD}_{\mathrm{R}}$ of $32 \%$ ) expressing the reproducibility within this PT. The robust standard deviation of $48 \mu \mathrm{g} / \mathrm{kg}$ is comparable to the target standard deviation $\sigma_{\mathrm{p}}$ of $38 \mu \mathrm{g} / \mathrm{kg}$ suggested in $\S 3.3$ for feed material. With only five laboratories reporting quantitative results, statistic evaluation is not appropriate.

\subsubsection{3-acetyl-Deoxynivalenol}

Seven participants reported quantitative results for 3-Ac-DON. Two participants (PT9615 and PT9618) reported the sum of $15-$ Ac-DON and 3-Ac-DON.

The lowest concentration reported is $432 \mu \mathrm{g} / \mathrm{kg}$ and the highest is $713 \mu \mathrm{g} / \mathrm{kg}$. The consensus value is $645 \mu \mathrm{g} / \mathrm{kg}$ with a robust standard deviation of $69 \mu \mathrm{g} / \mathrm{kg}$ (resulting in an RSD $\mathrm{R}$ of $11 \%$ ) expressing the reproducibility within this PT. The robust standard deviation of $69 \mu \mathrm{g} / \mathrm{kg}$ is almost 2 times lower than 
the target standard deviation $\sigma_{\mathrm{P}}$ of $161 \mu \mathrm{g} / \mathrm{kg}$. The uncertainty of the consensus value is $33 \mu \mathrm{g} / \mathrm{kg}$, which does not exceed $0.3 \sigma_{\mathrm{P}}(\S 3.2)$. With respect to the accuracy all results are satisfactory.

\subsubsection{Deoxynivalenol-3-glucoside}

Four participants reported quantitative results for DON-3G.

The lowest concentration reported is $726 \mu \mathrm{g} / \mathrm{kg}$ and the highest is $1517 \mu \mathrm{g} / \mathrm{kg}$. The consensus value is $1144 \mu \mathrm{g} / \mathrm{kg}$ with a robust standard deviation of $418 \mu \mathrm{g} / \mathrm{kg}$ (resulting in an $\mathrm{RSD}_{\mathrm{R}}$ of $37 \%$ ) expressing the reproducibility within this PT. The robust standard deviation of $418 \mu \mathrm{g} / \mathrm{kg}$ is almost 1.5 times higher than the target standard deviation $\sigma_{\mathrm{p}}$ of $286 \mu \mathrm{g} / \mathrm{kg}$. With only four laboratories reporting quantitative results, statistic evaluation is not appropriate.

\subsubsection{Deoxynivalenol}

Nineteen participants reported quantitative results for DON. Participant PT9609 failed to detect the presence of DON and reported a false negative result.

The lowest concentration reported is $2627 \mu \mathrm{g} / \mathrm{kg}$ and the highest is $5682 \mu \mathrm{g} / \mathrm{kg}$. The consensus value is $4268 \mu \mathrm{g} / \mathrm{kg}$ with a robust standard deviation of $729 \mu \mathrm{g} / \mathrm{kg}$ (resulting in an $\mathrm{RSD}_{\mathrm{R}}$ of $17 \%$ ) expressing the reproducibility within this PT. The robust standard deviation of $729 \mu \mathrm{g} / \mathrm{kg}$ is higher to the target standard deviation $\sigma_{\mathrm{P}}$ of $549 \mu \mathrm{g} / \mathrm{kg}$. The uncertainty of the consensus value is $209 \mu \mathrm{g} / \mathrm{kg}$, which exceeds $0.3 \sigma_{\mathrm{P}}(\S 3.2)$, so the uncertainty is included in the calculation of the $z^{\prime}$-scores (Equation II is used). With respect to the accuracy four laboratories reported questionable results (PT9610, PT9624, PT9625 and PT9628).

\subsubsection{Aflatoxin B1}

Twenty-one of the 23 participants reported quantitative results for AFLA. The lowest concentration reported is $5.45 \mu \mathrm{g} / \mathrm{kg}$ and the highest is $12.6 \mu \mathrm{g} / \mathrm{kg}$. The consensus value is $10.3 \mu \mathrm{g} / \mathrm{kg}$ with a robust standard deviation of $1.6 \mu \mathrm{g} / \mathrm{kg}$ (resulting in an $\mathrm{RSD}_{\mathrm{R}}$ of $15 \%$ ) expressing the reproducibility within this PT. The robust standard deviation of $1.6 \mu \mathrm{g} / \mathrm{kg}$ is almost two times lower than the target standard deviation $\sigma_{\mathrm{p}}$ of $2.6 \mu \mathrm{g} / \mathrm{kg}$. The uncertainty of the consensus value is $0.43 \mu \mathrm{g} / \mathrm{kg}$, which does not exceed $0.3 \sigma_{\mathrm{P}}(\S 3.2)$. With respect to the accuracy all results are satisfactory.

\subsubsection{Enniatin B}

Four participants reported quantitative results for ENN B.

The lowest concentration reported is $74.2 \mu \mathrm{g} / \mathrm{kg}$ and the highest is $211 \mu \mathrm{g} / \mathrm{kg}$. The consensus value is $115 \mu \mathrm{g} / \mathrm{kg}$ with a robust standard deviation of $39 \mu \mathrm{g} / \mathrm{kg}$ (resulting in an $\mathrm{RSD}_{\mathrm{R}}$ of $34 \%$ ) expressing the reproducibility within this PT. The robust standard deviation of $39 \mu \mathrm{g} / \mathrm{kg}$ is higher than the target standard deviation $\sigma_{\mathrm{P}}$ of $29 \mu \mathrm{g} / \mathrm{kg}$ ( $25 \%$ of the consensus value). With only four laboratories reporting quantitative results, statistic evaluation is not appropriate.

\subsubsection{Enniatin B1}

Four participants reported quantitative results for ENN B1.

The lowest concentration reported is $31.4 \mu \mathrm{g} / \mathrm{kg}$ and the highest is $110.3 \mu \mathrm{g} / \mathrm{kg}$. The consensus value is $65 \mu \mathrm{g} / \mathrm{kg}$ with a robust standard deviation of $35 \mu \mathrm{g} / \mathrm{kg}$ (resulting in an $\mathrm{RSD}_{\mathrm{R}}$ of $48 \%$ ) expressing the reproducibility within this $\mathrm{PT}$. The robust standard deviation of $35 \mu \mathrm{g} / \mathrm{kg}$ is two times higher than the target standard deviation $\sigma_{\mathrm{p}}$ of $16.2 \mu \mathrm{g} / \mathrm{kg}$. With only four laboratories reporting quantitative results, statistic evaluation is not appropriate.

\subsubsection{Zearalenone}

Twenty-two participants reported quantitative results for ZEN.

The lowest concentration reported is $172 \mu \mathrm{g} / \mathrm{kg}$ and the highest is $390 \mu \mathrm{g} / \mathrm{kg}$. The consensus value is $289 \mu \mathrm{g} / \mathrm{kg}$ with a robust standard deviation of $38 \mu \mathrm{g} / \mathrm{kg}$ (resulting in an RSD $\mathrm{R}_{\mathrm{R}}$ of $13 \%$ ) expressing the reproducibility within this PT. The robust standard deviation of $38 \mu \mathrm{g} / \mathrm{kg}$ is almost two times lower than 
the target standard deviation $\sigma_{\mathrm{p}}$ of $72 \mu \mathrm{g} / \mathrm{kg}$. The uncertainty of the consensus value is $10.2 \mu \mathrm{g} / \mathrm{kg}$, which does not exceed $0.3 \sigma_{\mathrm{P}}(\S 3.2)$. With respect to the accuracy all results are satisfactory.

\subsubsection{T-2 toxin}

Sixteen participants reported quantitative results for T-2 toxin. Three participants reported '< ...' values of which lab PT9627 reported ' $<10 \mu \mathrm{g} / \mathrm{kg}^{\prime}$. This is considered a false negative result (see explanation in §2.7).

The lowest concentration reported is $21 \mu \mathrm{g} / \mathrm{kg}$ and the highest is $78.9 \mu \mathrm{g} / \mathrm{kg}$. The consensus value is $24 \mu \mathrm{g} / \mathrm{kg}$ with a robust standard deviation of $2.4 \mu \mathrm{g} / \mathrm{kg}$ (resulting in an $\mathrm{RSD}_{\mathrm{R}}$ of $10 \%$ ) expressing the reproducibility within this PT. The robust standard deviation of $2.4 \mu \mathrm{g} / \mathrm{kg}$ is more than two times lower than the target standard deviation $\sigma_{\mathrm{p}}$ of $6.1 \mu \mathrm{g} / \mathrm{kg}$. The uncertainty of the consensus value is $0.74 \mu \mathrm{g} / \mathrm{kg}$, which does not exceed $0.3 \sigma_{\mathrm{P}}(\S 3.2)$. With respect to the accuracy two results are unsatisfactory (PT9620 and PT9625).

\subsubsection{HT-2 toxin}

Eighteen participants reported quantitative results for HT-2 toxin. Participant PT9625 failed to detect the presence of HT-2 toxin and reported a false negative result.

The lowest concentration reported is $23.8 \mu \mathrm{g} / \mathrm{kg}$ and the highest is $90 \mu \mathrm{g} / \mathrm{kg}$. The consensus value is $61 \mu \mathrm{g} / \mathrm{kg}$ with a robust standard deviation of $9.2 \mu \mathrm{g} / \mathrm{kg}$ (resulting in an $\mathrm{RSD}_{\mathrm{R}}$ of $15 \%$ ) expressing the reproducibility within this PT. The robust standard deviation of $9.2 \mu \mathrm{g} / \mathrm{kg}$ is almost tow times lower than the target standard deviation $\sigma_{\mathrm{P}}$ of $15.2 \mu \mathrm{g} / \mathrm{kg}$. The uncertainty of the consensus value is $2.7 \mu \mathrm{g} / \mathrm{kg}$, which does not exceed $0.3 \sigma_{\mathrm{P}}(\S 3.2)$.). A consequential instability (15\% decrease) for HT-2 toxin during storage was observed. With respect to the accuracy one result is questionable (PT9627).

\subsubsection{Sum of $\mathrm{T}-2$ and $\mathrm{HT}-2$ toxins}

Nineteen participants reported quantitative results for T-2 and/or HT-2 toxin. Sum-concentrations were calculated ('< values' were not taken into account) by adding the concentrations. The lowest sum-concentration reported is $23.8 \mu \mathrm{g} / \mathrm{kg}$ and the highest is $144.3 \mu \mathrm{g} / \mathrm{kg}$. The consensus value is $83 \mu \mathrm{g} / \mathrm{kg}$ with a robust standard deviation of $15.0 \mu \mathrm{g} / \mathrm{kg}$ (resulting in an $\mathrm{RSD}_{\mathrm{R}}$ of $18 \%$ ) expressing the reproducibility within this PT. The robust standard deviation of $15.0 \mu \mathrm{g} / \mathrm{kg}$ is lower than the target standard deviation $\sigma_{P}$ of $21 \mu \mathrm{g} / \mathrm{kg}$. The uncertainty of the consensus value is $4.3 \mu \mathrm{g} / \mathrm{kg}$, which does not exceed $0.3 \sigma_{\mathrm{P}}$ (§3.2). A consequential instability (15\% decrease) for HT-2 toxin during storage was observed. With respect to the accuracy two participants reported questionable results (PT9620 and PT9627). In case no instability of HT-2 toxin occurred, the z-score for participant PT9627 would still be questionable.

\subsubsection{Other mycotoxins}

Participant PT9627 reported a false positive result by detecting the presence of $3.5 \mu \mathrm{g} / \mathrm{kg}$ ochratoxin A. 


\section{Discussion and conclusions}

Twenty-three participants subscribed for the proficiency test on mycotoxins in oat meal and all reported results. Each participant was asked to indicate a priori which compounds were included in their scope. This allowed the evaluation of the results which regard to the participants' scope.

Two materials were sent to the participants. The mycotoxins were homogeneously distributed in the materials. An overview of each participant's performance is shown in Annex 9 and a summary of the results is presented in Table 6.

Table $6 \quad$ Summarized performance of participants reporting results.

\begin{tabular}{|c|c|c|c|c|c|c|c|}
\hline Compound & $\begin{array}{c}\text { \# } \\
\text { results }\end{array}$ & $\begin{array}{c}\text { quantitative } \\
\text { result }\end{array}$ & FN & $\begin{array}{c}\mathbf{q} \\
\mathbf{z} \text {-score }\end{array}$ & $\begin{array}{c}\text { u } \\
\text { z-score }\end{array}$ & $\begin{array}{c}\text { used } \\
\text { z-score }\end{array}$ & correct results ( $\%)$ \\
\hline \multicolumn{8}{|l|}{ Material A } \\
\hline 3-Ac-DON & 9 & 7 & & & & $\mathrm{za}_{\mathrm{a}}$ & 78 \\
\hline DON-3G & 4 & 4 & & & & not possible & \\
\hline AFLA & 22 & 22 & & & & $\mathrm{Za}$ & 100 \\
\hline ENN B & 4 & 4 & & & & not possible & \\
\hline ENN B1 & 4 & 4 & & & & not possible & \\
\hline ZEN & 21 & 21 & & & 1 & $\mathrm{z}_{\mathrm{a}}$ & 95 \\
\hline $\mathrm{T} 2$ & 19 & 19 & & 1 & 1 & $\mathrm{za}_{\mathrm{a}}$ & 89 \\
\hline \multicolumn{8}{|l|}{ Material B } \\
\hline 15-Ac-DON & 7 & 5 & & & & not possible & \\
\hline 3-Ac-DON & 9 & 7 & & & & $\mathrm{Za}$ & 78 \\
\hline DON-3G & 4 & 4 & & & & not possible & \\
\hline DON & 22 & 19 & 1 & 4 & & $z_{a}^{\prime}$ & 75 \\
\hline AFLA & 21 & 21 & & & & $\mathrm{z}_{\mathrm{a}}$ & 100 \\
\hline ENN B & 4 & 4 & & & & not possible & \\
\hline ENN B1 & 4 & 4 & & & & not possible & \\
\hline \multicolumn{8}{|c|}{ FN false negatives } \\
\hline \multicolumn{8}{|c|}{ q questionable $z$-score } \\
\hline u unsatisf & y z-score & & & & & & \\
\hline
\end{tabular}

Two participants failed to submit results for aflatoxin B1, the regulated mycotoxin in animal feed. Maximum three participants did not submit results for ZEN and DON, which have a guidance value in EU legislation. Four participants analysed for all three DON conjugates, as advised by the Commission. Five participants analysed for 3- and 15-AC-DON, besides DON, and two laboratories analysed for 3-AC-DON and DON-3G.

Five participants showed optimal performance by detecting the mycotoxins with a correct quantification/qualification (14 satisfactory z-scores), the absence of false positive and false negative results and reporting within the deadline. Another ten showed suboptimal performance within their 
scope by reporting thirteen or less satisfactory z-scores. Eight participants reported FN, FP, questionable or unsatisfactory z-scores. A total of thirteen questionable z-scores, four unsatisfactory $z$-score, four false positive and two false negative results were reported.

Based on the results of this proficiency test it was concluded that:

- The optimal quantification for the mycotoxins in oat meal varied from $70-100 \%$ in this proficiency test. T-2 toxin in material B was the most difficult compound to quantify; all quantitative results for AFLA in both materials were satisfactory.

- The determination of DON, ZEN and T-2/HT-2 toxin should be included in the scope of all participants since guideline values/indicative levels have been set at an EU-level.

- The determination of 15-Ac-DON, 3-Ac-DON and DON-3G should be included in the scope of all participants due to the advice of the Commission and because it is foreseen that these forms of DON will be included in future legislation. 


\section{References}

1 ISO/IEC 17025:2017 (E). 2017. General Requirements for the Competence of Calibration and Testing Laboratories.

2 ISO/IEC 17043:2010. 2010. Conformity assessment - General requirements for proficiency testing.

3 SOPA0989 - De bereiding van referentiematerialen en referentiemonsters - WFSR.

4 ISO 13528:2015, IDT. 2015. Statistical methods for use in proficiency testing by inter-laboratory comparison, 1st edition.

5 Thompson M. 2000. Recent trends in inter-laboratory precision at $\mu \mathrm{g} / \mathrm{kg}$ and sub- $\mu \mathrm{g} / \mathrm{kg}$ concentrations in relation to fitness for purpose criteria in proficiency testing. Analyst. 125: 385-386.

6 Thompson M, Ellison SL, Wood R. 2006. The International Harmonized Protocol for the Proficiency Testing of Analytical Chemistry Laboratories. Pure Appl. Chem. 78(1):145-196.

7 Analytical Methods Committee. 1989. Robust statistics - How not to reject outliers Part 1. Basic concepts. Analyst 114:1693-1697.

8 Analytical Methods Committee. 1989. Robust statistics - How not to reject outliers Part 2. Interlaboratory trials. Analyst. 114:1699-1702.

9 Regulation (EC) No 396/2005 of 23 February 2005 on maximum residue levels of mycotoxins in or on food and feed of plant and animal origin and amending Council 91/414/EEC.

10 EC 2014. Compilation of agreed monitoring recommendations as regards the presence of mycotoxins and plant toxins in food. Summary report of the standing committee on plants, animals, food and feed, held in Brussels on 1 JULY 2014 (Section Toxicological Safety of the Food chain, https://ec.europa.eu/food/safety/chemical_safety/contaminants/catalogue/mycotoxins_en)

11 EC. 2002. Directive 2002/32/EC of the European Parliament and of the council of 7 May 2002 on undesirable substances in animal feed (https://eur-lex.europa.eu/legalcontent/EN/TXT/?qid=1572259187508\&uri=CELEX:02002L0032-20171225)

12 EC. 2006. Commission Recommendation of 17 August 2006 on the presence of deoxynivalenol, zearalenone, ochratoxin A, T-2 and HT-2 and fumonisins in products intended for animal feeding (Text with EEA relevance) (2006/576/EC) https://eur-lex.europa.eu/legalcontent/EN/TXT/PDF/?uri=CELEX:02006H0576-20160802\&qid=1572259308626\&from=EN

13 Performance assessment in proficiency tests organised by the EURL mycotoxins \& plant toxins in food and feed $v 1,2019$. EURL mycotoxins \& plant toxins, WFSR Wageningen University \& Research. 


\section{Annex 1 Codification of the samples}

\begin{tabular}{|c|c|c|}
\hline Participants code & Material A* & Material B* \\
\hline РТ9604 & 194 & 161 \\
\hline PT9607 & 584 & 323 \\
\hline PT9609 & 920 & 796 \\
\hline PT9610 & 993 & 743 \\
\hline PT9612 & 746 & 314 \\
\hline PT9613 & 425 & 202 \\
\hline PT9614 & 557 & 467 \\
\hline PT9615 & 702 & 941 \\
\hline PT9619 & 465 & 937 \\
\hline РT9620 & 189 & 525 \\
\hline PT9621 & 383 & 880 \\
\hline PT9622 & 551 & 398 \\
\hline PT9623 & 671 & 100 \\
\hline РT9624 & 112 & 521 \\
\hline PT9625 & 938 & 864 \\
\hline PT9626 & 222 & 526 \\
\hline PT9627 & 486 & 637 \\
\hline
\end{tabular}

* All sample codes start with 2019/mycotoxins/oats/ 


\section{Annex 2 Instruction letter}

WAGENINGEN

UNIVERSITY \& RESEARCH

RIKILT

Contaminants \&

Toxins

sans

AprII 8, 2019

Dear Madam/Sir,

Thank you very much for your interest in the proficiency test for the analysis of the mycotoxins in the feed matrix oats. Hereby I send you a parcel containing two randomly coded samples. Each sample consists of approximately $\mathbf{3 5}$ grams of test material.

Please fill out the accompanying acknowledgement of receipt form and return it immediately upon receipt of the samples, preferably by e-mail (pt.rikilt@wur.nl)

Instructions:

After arrival store the samples in the freezer.

Before analysis, homogenize them according to your laboratory's procedure. Treat the test material as if it was a sample for routine analysis. Report one result and not an average of multiple measurements.

Report all results in $\boldsymbol{\mu g} / \mathbf{k g}$ for the product as received (i.e. no correction moisture is needed). When a mycotoxin is not within your scope, please report 'nt (not tested)' in the web application. Do not use the option 'detected' from the web application. When a mycotoxin is 'not detected' or the result is below your LOQ, report the result as $<\mathrm{LOQ}$-value and specify the value (e.g. $<20 \mu \mathrm{g} / \mathrm{kg}$ ).

- Please use the web application for entering your results

(https://crlwebshop,wur,nl/apex/f?p=307:LOGIN). Information about the use of this web application was sent to you earlier by e-mail.

- The deadline for submitting test-results for this test is May $20^{\text {th }} \mathbf{2 0 1 9}$.

- Your username is:

- Your password is:

- Your lab code to enter this proficiency test is:

- $\quad$ Please inform us about your applied method and detection technique (via the web application).

Please contact me if you have any questions or need any assistance.

With kind regards,

$$
\text { D. Perel oom }
$$

D.P.K.H. Pereboom - de Fauw

Proficiency tests

Pt.rikilt@wur.nl

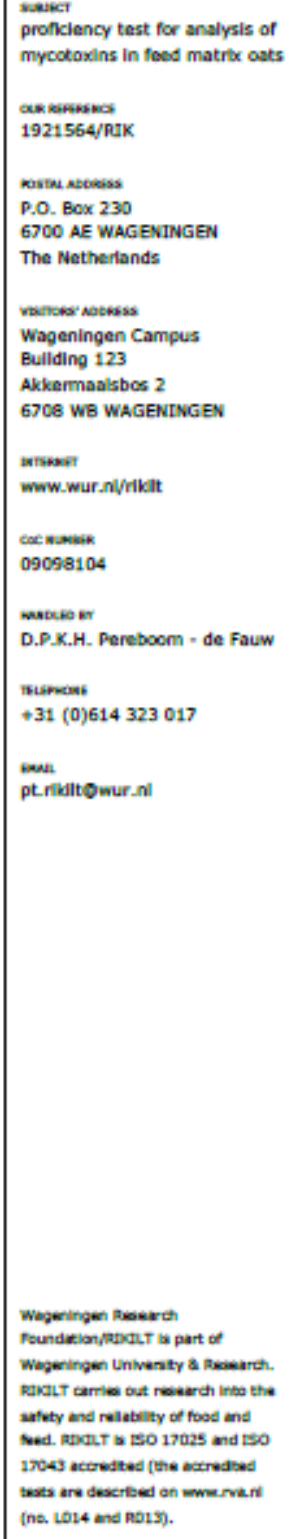




\section{Annex 3 Statistical evaluation of homogeneity data}

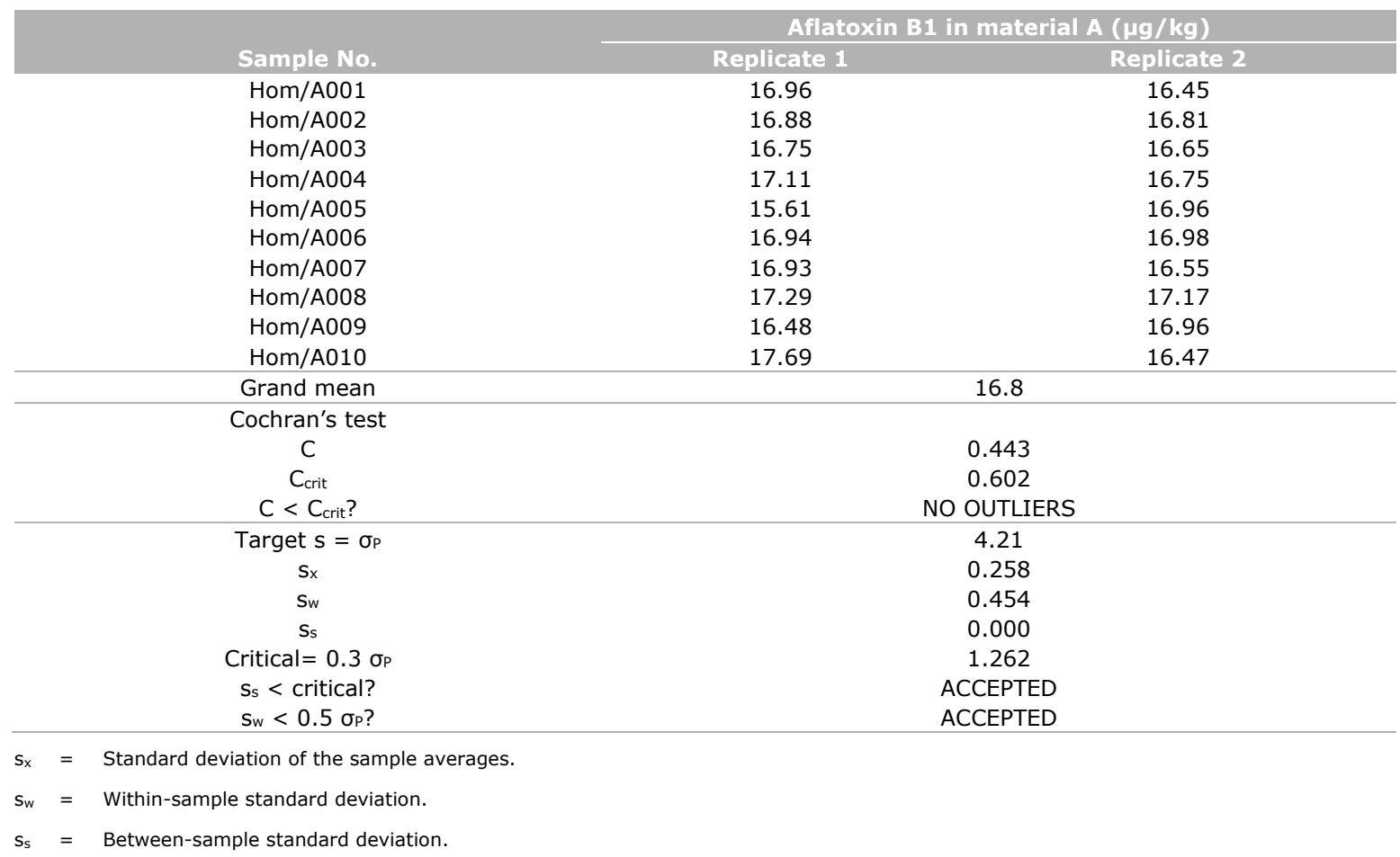

\begin{tabular}{|c|c|c|}
\hline \multirow[b]{2}{*}{ Sample No. } & \multicolumn{2}{|c|}{ 3-Acetyl-Deoxynivalenol in material A ( $\mu \mathrm{g} / \mathrm{kg})$} \\
\hline & Replicate 1 & Replicate 2 \\
\hline Hom/A001 & 565.90 & 616.41 \\
\hline Hom/A002 & 584.89 & 598.43 \\
\hline $\mathrm{Hom} / \mathrm{A004}$ & 574.06 & 555.93 \\
\hline Hom/A005 & 518.27 & 557.42 \\
\hline Hom/A006 & 594.12 & 577.58 \\
\hline Hom/A008 & 576.97 & 549.22 \\
\hline Hom/A009 & 554.41 & 512.49 \\
\hline Hom/A010 & 579.42 & 617.70 \\
\hline Grand mean & \multicolumn{2}{|c|}{567.78} \\
\hline \multicolumn{3}{|l|}{ Cochran's test } \\
\hline $\mathrm{C}$ & \multicolumn{2}{|c|}{0.237} \\
\hline $\mathrm{S}_{\mathrm{x}}$ & \multicolumn{2}{|c|}{24.79} \\
\hline $\mathrm{S}_{\mathrm{w}}$ & \multicolumn{2}{|c|}{23.19} \\
\hline $\mathrm{S}_{\mathrm{s}}$ & \multicolumn{2}{|c|}{18.59} \\
\hline Critical $=0.3 \sigma_{\mathrm{p}}$ & \multicolumn{2}{|c|}{42.58} \\
\hline $\mathrm{S}_{\mathrm{s}}<$ critical? & \multicolumn{2}{|c|}{ ACCEPTED } \\
\hline $\mathrm{s}_{\mathrm{w}}<0.5 \sigma_{\mathrm{p}} ?$ & \multicolumn{2}{|c|}{ ACCEPTED } \\
\hline
\end{tabular}




\begin{tabular}{|c|c|c|}
\hline \multirow[b]{2}{*}{ Sample No. } & \multicolumn{2}{|c|}{ 15-Acetyl-Deoxynivalenol in material A ( $\mu \mathrm{g} / \mathrm{kg})$} \\
\hline & Replicate 1 & Replicate 2 \\
\hline Hom/A001 & 19.38 & 18.90 \\
\hline Hom/A002 & 18.78 & 19.52 \\
\hline Hom/A003 & 19.33 & 17.94 \\
\hline Hom/A004 & 18.33 & 19.56 \\
\hline Hom/A005 & 17.39 & 17.79 \\
\hline Hom/A006 & 19.51 & 19.82 \\
\hline Hom/A007 & 18.86 & 19.70 \\
\hline Hom/A008 & 19.58 & 20.34 \\
\hline Hom/A009 & 18.66 & 19.66 \\
\hline Hom/A010 & 20.82 & 18.92 \\
\hline Grand mean & \multicolumn{2}{|c|}{19.14} \\
\hline Cochran's test & \\
\hline $\mathrm{C}$ & \multicolumn{2}{|c|}{0.349} \\
\hline $\mathrm{C}_{\text {crit }}$ & \multicolumn{2}{|c|}{0.602} \\
\hline $\mathrm{C}<\mathrm{C}_{\text {crit }} ?$ & \multicolumn{2}{|c|}{ NO OUTLIERS } \\
\hline Target $\mathrm{s}=\sigma_{\mathrm{P}}$ & \multicolumn{2}{|c|}{4.78} \\
\hline$S_{x}$ & \multicolumn{2}{|c|}{0.683} \\
\hline $\mathrm{S}_{\mathrm{w}}$ & \multicolumn{2}{|c|}{0.719} \\
\hline $\mathrm{S}_{\mathrm{s}}$ & \multicolumn{2}{|c|}{0.456} \\
\hline Critical $=0.3 \sigma_{p}$ & \multicolumn{2}{|c|}{1.435} \\
\hline $\mathrm{s}_{\mathrm{s}}<$ critical? & \multicolumn{2}{|c|}{ ACCEPTED } \\
\hline $\mathrm{S}_{\mathrm{W}}<0.5 \sigma_{\mathrm{P}} ?$ & \multicolumn{2}{|c|}{ ACCEPTED } \\
\hline
\end{tabular}

\begin{tabular}{|c|c|c|}
\hline \multicolumn{3}{|c|}{ Deoxynivalenol in material A ( $\mu \mathrm{g} / \mathrm{kg})$} \\
\hline Sample No. & Replicate 1 & Replicate 2 \\
\hline Hom/A001 & 3622.39 & 3482.17 \\
\hline Hom/A002 & 3704.33 & 3556.63 \\
\hline Hom/A003 & 3278.92 & 3340.25 \\
\hline Hom/A004 & 3891.11 & 3864.71 \\
\hline Hom/A005 & 3554.09 & 3442.36 \\
\hline Hom/A006 & 3745.54 & 3673.19 \\
\hline Hom/A007 & 3664.93 & 3739.59 \\
\hline Hom/A008 & 3775.61 & 3853.91 \\
\hline Hom/A009 & 3649.23 & 3512.61 \\
\hline Hom/A010 & & \\
\hline Grand mean & \multicolumn{2}{|c|}{3631} \\
\hline \multicolumn{3}{|l|}{ Cochran's test } \\
\hline $\mathrm{C}$ & \multicolumn{2}{|c|}{0.232} \\
\hline $\mathrm{C}_{\text {crit }}$ & \multicolumn{2}{|c|}{0.638} \\
\hline $\mathrm{C}<\mathrm{C}_{\text {crit }} ?$ & \multicolumn{2}{|c|}{ NO OUTLIERS } \\
\hline Target $\mathrm{s}=\sigma_{\mathrm{p}}$ & \multicolumn{2}{|c|}{907.7} \\
\hline $\mathrm{S}_{\mathrm{x}}$ & \multicolumn{2}{|c|}{171.6} \\
\hline $\mathrm{S}_{\mathrm{w}}$ & \multicolumn{2}{|c|}{72.27} \\
\hline $\mathrm{S}_{\mathrm{s}}$ & \multicolumn{2}{|c|}{163.8} \\
\hline Critical $=0.3 \sigma_{P}$ & \multicolumn{2}{|c|}{272.3} \\
\hline $\mathrm{S}_{\mathrm{s}}<$ critical? & \multicolumn{2}{|c|}{ ACCEPTED } \\
\hline $\mathrm{s}_{\mathrm{w}}<0.5 \sigma_{\mathrm{p}} ?$ & \multicolumn{2}{|c|}{ ACCEPTED } \\
\hline
\end{tabular}

\begin{tabular}{|c|c|c|}
\hline \multirow[b]{2}{*}{ Sample No. } & \multicolumn{2}{|c|}{ Deoxynivalenol-3-glucoside in material A $(\mu \mathrm{g} / \mathrm{kg})$} \\
\hline & Replicate 1 & Replicate 2 \\
\hline Hom/A001 & 674.51 & 706.11 \\
\hline Hom/A002 & 690.72 & 665.37 \\
\hline Hom/A003 & 600.46 & 584.58 \\
\hline Hom/A004 & 616.01 & 626.93 \\
\hline Hom/A005 & 613.85 & 711.35 \\
\hline Hom/A006 & 662.16 & 610.90 \\
\hline Hom/A007 & 579.71 & 574.80 \\
\hline Hom/A008 & 639.05 & 623.41 \\
\hline Hom/A009 & 615.70 & 505.27 \\
\hline Hom/A010 & 659.63 & 619.35 \\
\hline Grand mean & \multicolumn{2}{|c|}{628.99} \\
\hline \multicolumn{3}{|l|}{ Cochran's test } \\
\hline $\mathrm{C}$ & \multicolumn{2}{|c|}{0.432} \\
\hline $\mathrm{C}_{\text {crit }}$ & \multicolumn{2}{|c|}{0.602} \\
\hline $\mathrm{C}<\mathrm{C}_{\text {crit }} ?$ & \multicolumn{2}{|c|}{ NO OUTLIERS } \\
\hline Target $\mathrm{s}=\sigma_{\mathrm{p}}$ & \multicolumn{2}{|c|}{157.25} \\
\hline $\mathrm{S}_{\mathrm{x}}$ & \multicolumn{2}{|c|}{42.46} \\
\hline $\mathrm{S}_{\mathrm{w}}$ & \multicolumn{2}{|c|}{37.57} \\
\hline $\mathrm{S}_{\mathrm{s}}$ & \multicolumn{2}{|c|}{33.12} \\
\hline Critical $=0.3 \sigma_{P}$ & \multicolumn{2}{|c|}{47.17} \\
\hline $\mathrm{S}_{\mathrm{s}}<$ critical? & \multicolumn{2}{|c|}{ ACCEPTED } \\
\hline $\mathrm{s}_{\mathrm{w}}<0.5 \sigma_{\mathrm{p}} ?$ & \multicolumn{2}{|c|}{ ACCEPTED } \\
\hline
\end{tabular}




\begin{tabular}{|c|c|c|}
\hline \multirow[b]{2}{*}{ Sample No. } & \multicolumn{2}{|c|}{ Enniatin B in material A $(\mu \mathrm{g} / \mathrm{kg})$} \\
\hline & Replicate 1 & Replicate 2 \\
\hline Hom/A001 & 85.32 & 81.32 \\
\hline Hom/A002 & 87.08 & 78.46 \\
\hline Hom/A003 & 85.97 & 89.31 \\
\hline Hom/A004 & 87.88 & 91.67 \\
\hline Hom/A005 & 87.58 & 81.61 \\
\hline Hom/A006 & 83.82 & 84.69 \\
\hline Hom/A007 & 79.80 & 82.46 \\
\hline Hom/A008 & 88.89 & 86.56 \\
\hline Hom/A009 & 87.25 & 91.50 \\
\hline Hom/A010 & 92.38 & 86.70 \\
\hline Grand mean & \multicolumn{2}{|c|}{86.01} \\
\hline \multicolumn{3}{|l|}{ Cochran's test } \\
\hline $\mathrm{C}$ & \multicolumn{2}{|c|}{0.345} \\
\hline $\mathrm{C}_{\text {crit }}$ & \multicolumn{2}{|c|}{0.602} \\
\hline $\mathrm{C}<\mathrm{C}_{\text {crit }}$ ? & \multicolumn{2}{|c|}{ NO OUTLIERS } \\
\hline Target $\mathrm{s}=\sigma_{\mathrm{P}}$ & \multicolumn{2}{|c|}{21.50} \\
\hline $\mathrm{S}_{\mathrm{x}}$ & \multicolumn{2}{|c|}{3.164} \\
\hline$S_{w}$ & \multicolumn{2}{|c|}{3.278} \\
\hline $\mathrm{S}_{\mathrm{s}}$ & \multicolumn{2}{|c|}{2.154} \\
\hline Critical $=0.3 \sigma_{p}$ & \multicolumn{2}{|c|}{6.451} \\
\hline $\mathrm{S}_{\mathrm{s}}<$ critical? & \multicolumn{2}{|c|}{ ACCEPTED } \\
\hline $\mathrm{s}_{\mathrm{w}}<0.5 \sigma_{\mathrm{p}} ?$ & \multicolumn{2}{|c|}{ ACCEPTED } \\
\hline
\end{tabular}

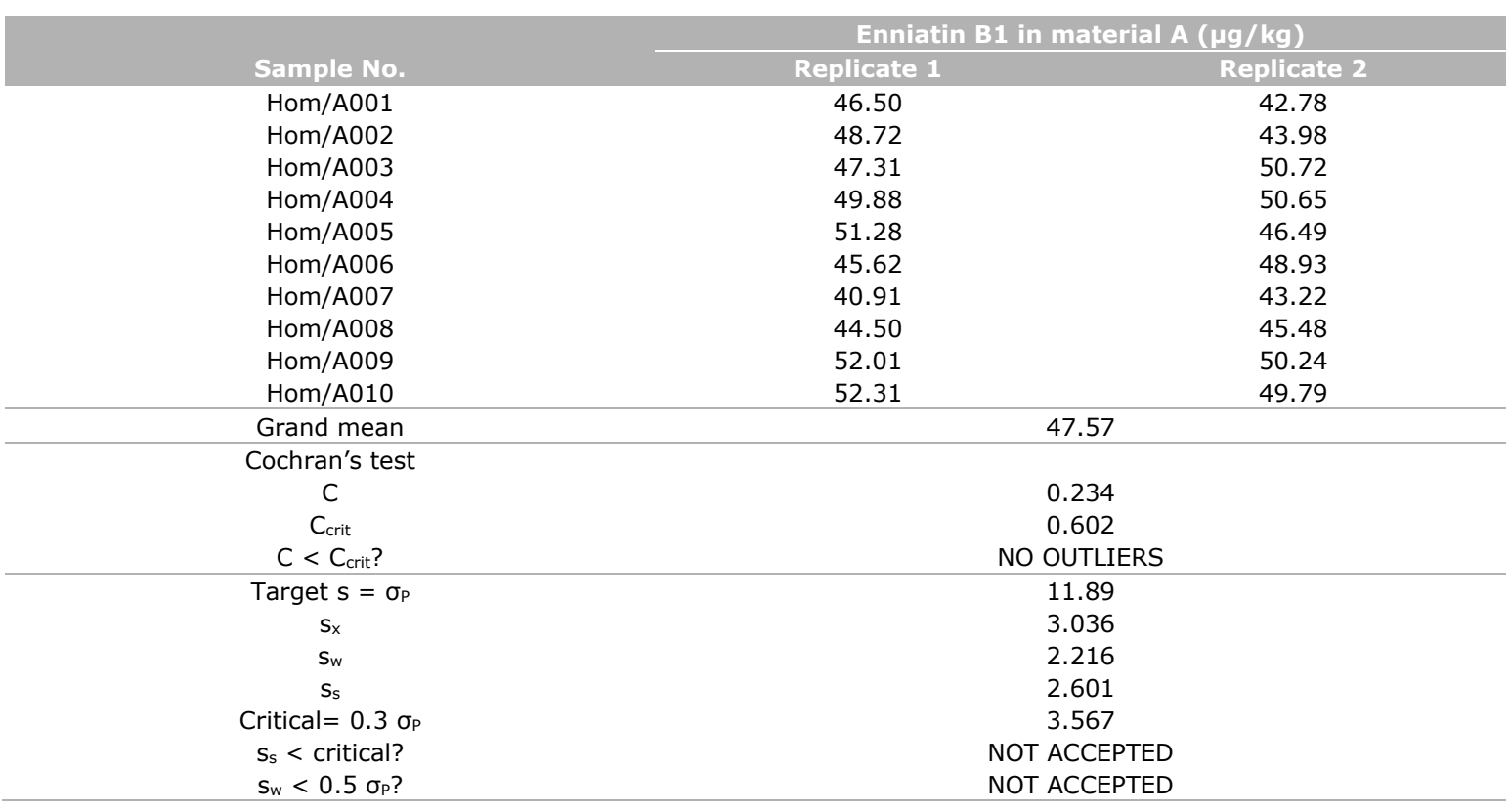

\begin{tabular}{|c|c|c|}
\hline \multirow[b]{2}{*}{ Sample No. } & \multicolumn{2}{|c|}{ HT-2 toxin in material A ( $\mu g / k g)$} \\
\hline & Replicate 1 & Replicate 2 \\
\hline Hom/A001 & 203.66 & 203.17 \\
\hline Hom/A002 & 198.40 & 197.49 \\
\hline Hom/A003 & 203.23 & 200.40 \\
\hline Hom/A004 & 192.75 & 189.16 \\
\hline Hom/A005 & 197.28 & 191.16 \\
\hline Hom/A006 & 190.25 & 208.12 \\
\hline Hom/A007 & 200.81 & 200.75 \\
\hline Hom/A008 & 211.84 & 202.46 \\
\hline Hom/A009 & 197.30 & 188.03 \\
\hline Hom/A010 & 201.01 & 206.13 \\
\hline Grand mean & \multicolumn{2}{|c|}{199.17} \\
\hline \multicolumn{3}{|l|}{ Cochran's test } \\
\hline $\mathrm{C}$ & \multicolumn{2}{|c|}{0.552} \\
\hline $\mathrm{C}_{\text {crit }}$ & \multicolumn{2}{|c|}{0.602} \\
\hline $\mathrm{C}<\mathrm{C}_{\text {crit }} ?$ & \multicolumn{2}{|c|}{ NO OUTLIERS } \\
\hline Target $s=\sigma_{P}$ & \multicolumn{2}{|c|}{49.79} \\
\hline$s_{x}$ & \multicolumn{2}{|c|}{5.234} \\
\hline $\mathrm{S}_{\mathrm{w}}$ & \multicolumn{2}{|c|}{5.380} \\
\hline $\mathrm{S}_{\mathrm{s}}$ & \multicolumn{2}{|c|}{3.594} \\
\hline Critical $=0.3 \sigma_{P}$ & \multicolumn{2}{|c|}{14.938} \\
\hline $\mathrm{s}_{\mathrm{s}}<$ critical? & \multicolumn{2}{|c|}{ ACCEPTED } \\
\hline $\mathrm{S}_{\mathrm{w}}<0.5 \sigma_{\mathrm{p}} ?$ & \multicolumn{2}{|c|}{ ACCEPTED } \\
\hline
\end{tabular}




\begin{tabular}{|c|c|c|}
\hline \multirow[b]{2}{*}{ Sample No. } & \multicolumn{2}{|c|}{ T-2 toxin in material A $(\mu \mathrm{g} / \mathrm{kg})$} \\
\hline & Replicate 1 & Replicate 2 \\
\hline Hom/A001 & 52.62 & 51.64 \\
\hline Hom/A002 & 48.19 & 50.40 \\
\hline Hom/A003 & 51.44 & 55.61 \\
\hline Hom/A004 & 53.48 & 51.95 \\
\hline Hom/A005 & 52.30 & 52.97 \\
\hline Hom/A006 & 48.90 & 54.90 \\
\hline Hom/A007 & 56.89 & 54.56 \\
\hline Hom/A008 & 56.16 & 54.00 \\
\hline Hom/A009 & 53.90 & 50.69 \\
\hline Hom/A010 & 52.13 & 52.36 \\
\hline Grand mean & \multicolumn{2}{|c|}{52.75} \\
\hline Cochran's test & \\
\hline $\mathrm{C}$ & \multicolumn{2}{|c|}{0.437} \\
\hline $\mathrm{C}_{\text {crit }}$ & \multicolumn{2}{|c|}{0.602} \\
\hline $\mathrm{C}<\mathrm{C}_{\text {crit }}$ ? & \multicolumn{2}{|c|}{ NO OUTLIERS } \\
\hline Target $\mathrm{s}=\sigma_{\mathrm{P}}$ & \multicolumn{2}{|c|}{13.19} \\
\hline $\mathrm{S}_{\mathrm{x}}$ & \multicolumn{2}{|c|}{1.776} \\
\hline$S_{w}$ & \multicolumn{2}{|c|}{2.029} \\
\hline $\mathrm{S}_{\mathrm{s}}$ & \multicolumn{2}{|c|}{1.046} \\
\hline Critical $=0.3 \sigma_{p}$ & \multicolumn{2}{|c|}{3.957} \\
\hline $\mathrm{S}_{\mathrm{s}}<$ critical? & \multicolumn{2}{|c|}{ ACCEPTED } \\
\hline $\mathrm{S}_{\mathrm{W}}<0.5 \sigma_{\mathrm{P}} ?$ & \multicolumn{2}{|c|}{ ACCEPTED } \\
\hline
\end{tabular}

\begin{tabular}{|c|c|c|}
\hline \multicolumn{3}{|c|}{ Zearalenone in material A ( $\mu g / k g)$} \\
\hline Sample No. & Replicate 1 & Replicate 2 \\
\hline Hom/A001 & 212.64 & 191.65 \\
\hline Hom/A002 & 215.11 & 215.57 \\
\hline Hom/A003 & 223.51 & 191.28 \\
\hline Hom/A004 & 187.94 & 178.22 \\
\hline Hom/A005 & 197.66 & 204.69 \\
\hline Hom/A006 & 190.31 & 203.57 \\
\hline Hom/A007 & 223.16 & 180.24 \\
\hline Hom/A008 & 185.02 & 173.75 \\
\hline Hom/A009 & 185.48 & 192.98 \\
\hline Hom/A010 & 167.84 & 196.52 \\
\hline Grand mean & \multicolumn{2}{|c|}{195.86} \\
\hline \multicolumn{3}{|l|}{ Cochran's test } \\
\hline $\mathrm{C}$ & \multicolumn{2}{|c|}{0.396} \\
\hline $\mathrm{C}_{\text {crit }}$ & \multicolumn{2}{|c|}{0.602} \\
\hline $\mathrm{C}<\mathrm{C}_{\text {crit }} ?$ & \multicolumn{2}{|c|}{ NO OUTLIERS } \\
\hline Target $s=\sigma_{p}$ & \multicolumn{2}{|c|}{48.96} \\
\hline $\mathrm{S}_{\mathrm{x}}$ & \multicolumn{2}{|c|}{11.93} \\
\hline $\mathrm{S}_{\mathrm{w}}$ & \multicolumn{2}{|c|}{15.24} \\
\hline $\mathrm{S}_{\mathrm{s}}$ & \multicolumn{2}{|c|}{5.12} \\
\hline Critical $=0.3 \sigma_{P}$ & \multicolumn{2}{|c|}{14.69} \\
\hline $\mathrm{S}_{\mathrm{s}}<$ critical? & \multicolumn{2}{|c|}{ ACCEPTED } \\
\hline $\mathrm{s}_{\mathrm{w}}<0.5 \sigma_{\mathrm{p}} ?$ & \multicolumn{2}{|c|}{ ACCEPTED } \\
\hline
\end{tabular}

\begin{tabular}{|c|c|c|}
\hline \multirow[b]{2}{*}{ Sample No. } & \multicolumn{2}{|c|}{ Aflatoxin B1 in material B ( $\mu \mathrm{g} / \mathrm{kg})$} \\
\hline & Replicate 1 & Replicate 2 \\
\hline Hom/B001 & 7.07 & 5.93 \\
\hline Hom/B002 & 6.38 & 6.35 \\
\hline Hom/B003 & 5.89 & 6.35 \\
\hline Hom/B004 & 6.55 & 6.39 \\
\hline Hom/B005 & 6.32 & 7.54 \\
\hline Hom/B006 & 6.33 & 6.65 \\
\hline Hom/B007 & misinjection & misinjection \\
\hline Hom/B008 & 6.35 & 6.19 \\
\hline Hom/B009 & 6.57 & 6.49 \\
\hline Hom/B010 & 6.52 & 7.21 \\
\hline Grand mean & \multicolumn{2}{|c|}{6.504} \\
\hline \multicolumn{3}{|l|}{ Cochran's test } \\
\hline $\mathrm{C}$ & \multicolumn{2}{|c|}{0.408} \\
\hline $\mathrm{C}_{\text {crit }}$ & \multicolumn{2}{|c|}{0.638} \\
\hline $\mathrm{C}<\mathrm{C}_{\text {crit }} ?$ & \multicolumn{2}{|c|}{ NO OUTLIERS } \\
\hline Target $s=\sigma_{P}$ & \multicolumn{2}{|c|}{1.63} \\
\hline $\mathrm{S}_{\mathrm{x}}$ & \multicolumn{2}{|c|}{0.259} \\
\hline $\mathrm{S}_{\mathrm{w}}$ & \multicolumn{2}{|c|}{0.448} \\
\hline $\mathrm{S}_{\mathrm{s}}$ & \multicolumn{2}{|c|}{0.000} \\
\hline Critical $=0.3 \sigma_{P}$ & \multicolumn{2}{|c|}{0.49} \\
\hline $\mathrm{S}_{\mathrm{s}}<$ critical? & \multicolumn{2}{|c|}{ ACCEPTED } \\
\hline $\mathrm{s}_{\mathrm{w}}<0.5 \sigma_{\mathrm{p}} ?$ & \multicolumn{2}{|c|}{ ACCEPTED } \\
\hline
\end{tabular}




\begin{tabular}{|c|c|c|}
\hline \multirow[b]{2}{*}{ Sample No. } & \multicolumn{2}{|c|}{ 3-Acetyl_Deoxynivalenol in material B ( $\mu \mathrm{g} / \mathrm{kg})$} \\
\hline & Replicate 1 & Replicate 2 \\
\hline Hom/B001 & 569.32 & 579.06 \\
\hline Hom/B002 & 566.09 & 588.06 \\
\hline Hom/B003 & 596.76 & 568.37 \\
\hline Hom/B004 & 606.23 & 568.18 \\
\hline Hom/B005 & 608.80 & 611.63 \\
\hline Hom/B006 & 572.40 & 615.03 \\
\hline Hom/B007 & 564.99 & 557.79 \\
\hline Hom/B008 & 546.06 & 545.88 \\
\hline Hom/B009 & 604.77 & 587.56 \\
\hline Hom/B010 & 537.35 & 599.09 \\
\hline Grand mean & \multicolumn{2}{|c|}{579.67} \\
\hline Cochran's test & \\
\hline $\mathrm{C}$ & \multicolumn{2}{|c|}{0.432} \\
\hline $\mathrm{C}_{\text {crit }}$ & \multicolumn{2}{|c|}{0.602} \\
\hline $\mathrm{C}<\mathrm{C}_{\text {crit }}$ ? & \multicolumn{2}{|c|}{ NO OUTLIERS } \\
\hline Target $\mathrm{s}=\sigma_{\mathrm{P}}$ & \multicolumn{2}{|c|}{144.9} \\
\hline $\mathrm{S}_{\mathrm{x}}$ & \multicolumn{2}{|c|}{18.58} \\
\hline$S_{w}$ & \multicolumn{2}{|c|}{21.00} \\
\hline $\mathrm{S}_{\mathrm{s}}$ & \multicolumn{2}{|c|}{11.16} \\
\hline Critical $=0.3 \sigma_{p}$ & \multicolumn{2}{|c|}{43.48} \\
\hline $\mathrm{S}_{\mathrm{s}}<$ critical? & \multicolumn{2}{|c|}{ ACCEPTED } \\
\hline $\mathrm{s}_{\mathrm{w}}<0.5 \sigma_{\mathrm{p}} ?$ & \multicolumn{2}{|c|}{ ACCEPTED } \\
\hline
\end{tabular}

\begin{tabular}{|c|c|c|}
\hline \multicolumn{3}{|c|}{ 15-Acetyl-Deoxynivalenol in material B ( $\mu \mathrm{g} / \mathrm{kg})$} \\
\hline Sample No. & Replicate 1 & Replicate 2 \\
\hline Hom/B001 & 21.89 & 21.16 \\
\hline Hom/B002 & 21.89 & 22.43 \\
\hline Hom/B004 & 20.13 & 21.58 \\
\hline Hom/B005 & 20.46 & 27.12 \\
\hline Hom/B006 & 17.33 & 24.26 \\
\hline Hom/B008 & 21.78 & 20.15 \\
\hline Hom/B009 & 18.64 & 22.46 \\
\hline Hom/B010 & 23.54 & 23.51 \\
\hline Grand mean & \multicolumn{2}{|c|}{21.68} \\
\hline Cochran's test & \\
\hline $\mathrm{C}$ & \multicolumn{2}{|c|}{0.380} \\
\hline $\mathrm{s}_{\mathrm{x}}$ & \multicolumn{2}{|c|}{1.22} \\
\hline $\mathrm{S}_{\mathrm{w}}$ & \multicolumn{2}{|c|}{2.65} \\
\hline $\mathrm{S}_{\mathrm{s}}$ & \multicolumn{2}{|c|}{0.000} \\
\hline Critical $=0.3 \sigma_{P}$ & \multicolumn{2}{|c|}{1.63} \\
\hline $\mathrm{S}_{\mathrm{s}}<$ critical? & \multicolumn{2}{|c|}{ ACCEPTED } \\
\hline $\mathrm{s}_{\mathrm{W}}<0.5 \sigma_{\mathrm{p}} ?$ & \multicolumn{2}{|c|}{ ACCEPTED } \\
\hline
\end{tabular}

\begin{tabular}{|c|c|c|}
\hline \multirow[b]{2}{*}{ Sample No. } & \multicolumn{2}{|c|}{ Deoxynivalenol in material B ( $\mu \mathrm{g} / \mathrm{kg})$} \\
\hline & Replicate 1 & Replicate 2 \\
\hline Hom/B001 & 4091.14 & 3981.28 \\
\hline Hom/B002 & 3926.88 & 4034.11 \\
\hline Hom/B003 & 3273.86 & 3988.25 \\
\hline Hom/B004 & 4038.58 & 4024.94 \\
\hline Hom/B005 & 3865.14 & 3961.16 \\
\hline Hom/B006 & 3239.96 & 3969.49 \\
\hline Hom/B007 & misinjection & misinjection \\
\hline Hom/B008 & 3755.26 & 3816.83 \\
\hline Hom/B009 & 3563.20 & 3748.91 \\
\hline Hom/B010 & 4411.47 & 3898.94 \\
\hline Grand mean & \multicolumn{2}{|c|}{3866} \\
\hline \multicolumn{3}{|l|}{ Cochran's test } \\
\hline $\mathrm{C}$ & \multicolumn{2}{|c|}{0.387} \\
\hline $\mathrm{C}_{\text {crit }}$ & \multicolumn{2}{|c|}{0.638} \\
\hline $\mathrm{C}<\mathrm{C}_{\text {crit }} ?$ & \multicolumn{2}{|c|}{ NO OUTLIERS } \\
\hline Target $\mathrm{s}=\sigma_{\mathrm{P}}$ & \multicolumn{2}{|c|}{966.52} \\
\hline$s_{x}$ & \multicolumn{2}{|c|}{202.9} \\
\hline $\mathrm{S}_{\mathrm{w}}$ & \multicolumn{2}{|c|}{276.54} \\
\hline $\mathrm{S}_{\mathrm{s}}$ & \multicolumn{2}{|c|}{54.15} \\
\hline Critical $=0.3 \sigma_{P}$ & \multicolumn{2}{|c|}{289.96} \\
\hline $\mathrm{s}_{\mathrm{s}}<$ critical? & \multicolumn{2}{|c|}{ ACCEPTED } \\
\hline $\mathrm{S}_{\mathrm{w}}<0.5 \sigma_{\mathrm{p}} ?$ & \multicolumn{2}{|c|}{ ACCEPTED } \\
\hline
\end{tabular}




\begin{tabular}{|c|c|c|}
\hline \multirow[b]{2}{*}{ Sample No. } & \multicolumn{2}{|c|}{ Deoxynivalenol-3-glucoside in material B ( $\mu \mathrm{g} / \mathrm{kg})$} \\
\hline & Replicate 1 & Replicate 2 \\
\hline Hom/B001 & 638.12 & 626.25 \\
\hline Hom/B002 & 639.16 & 635.07 \\
\hline Hom/B003 & 684.61 & 623.81 \\
\hline Hom/B004 & 673.88 & 661.70 \\
\hline Hom/B005 & 688.22 & 613.91 \\
\hline Hom/B006 & 658.80 & 743.43 \\
\hline Hom/B007 & 707.08 & 556.62 \\
\hline Hom/B008 & 681.50 & 617.21 \\
\hline Hom/B009 & 711.20 & 648.10 \\
\hline Hom/B010 & 546.10 & 620.98 \\
\hline Grand mean & \multicolumn{2}{|c|}{648.79} \\
\hline Cochran's test & \\
\hline $\mathrm{C}$ & \multicolumn{2}{|c|}{0.427} \\
\hline $\mathrm{C}_{\text {crit }}$ & \multicolumn{2}{|c|}{0.602} \\
\hline $\mathrm{C}<\mathrm{C}_{\text {crit }}$ ? & \multicolumn{2}{|c|}{ NO OUTLIERS } \\
\hline Target $\mathrm{s}=\sigma_{\mathrm{P}}$ & \multicolumn{2}{|c|}{162.20} \\
\hline $\mathrm{S}_{\mathrm{x}}$ & \multicolumn{2}{|c|}{31.70} \\
\hline$S_{w}$ & \multicolumn{2}{|c|}{51.50} \\
\hline $\mathrm{S}_{\mathrm{s}}$ & \multicolumn{2}{|c|}{0.000} \\
\hline Critical $=0.3 \sigma_{p}$ & \multicolumn{2}{|c|}{48.66} \\
\hline $\mathrm{S}_{\mathrm{s}}<$ critical? & \multicolumn{2}{|c|}{ ACCEPTED } \\
\hline $\mathrm{s}_{\mathrm{w}}<0.5 \sigma_{\mathrm{p}} ?$ & \multicolumn{2}{|c|}{ ACCEPTED } \\
\hline
\end{tabular}

\begin{tabular}{|c|c|c|}
\hline \multicolumn{3}{|c|}{ Enniatin B in material B ( $\mu \mathrm{g} / \mathrm{kg})$} \\
\hline Sample No. & Replicate 1 & Replicate 2 \\
\hline Hom/B001 & 92.66 & 80.67 \\
\hline Hom/B002 & 85.89 & 79.92 \\
\hline Hom/B003 & 83.34 & 84.92 \\
\hline Hom/B004 & 87.45 & 81.88 \\
\hline Hom/B005 & 91.32 & 83.09 \\
\hline Hom/B008 & 81.52 & 79.22 \\
\hline Hom/B009 & 84.46 & 82.13 \\
\hline Hom/B010 & 76.26 & 85.59 \\
\hline Grand mean & \multicolumn{2}{|c|}{83.99} \\
\hline Cochran's test & \\
\hline $\mathrm{C}$ & \multicolumn{2}{|c|}{0.375} \\
\hline $\mathrm{S}_{\mathrm{x}}$ & \multicolumn{2}{|c|}{2.376} \\
\hline $\mathrm{S}_{\mathrm{w}}$ & \multicolumn{2}{|c|}{4.617} \\
\hline $\mathrm{S}_{\mathrm{s}}$ & \multicolumn{2}{|c|}{0.000} \\
\hline Critical $=0.3 \sigma_{P}$ & \multicolumn{2}{|c|}{6.299} \\
\hline $\mathrm{S}_{\mathrm{s}}<$ critical? & \multicolumn{2}{|c|}{ ACCEPTED } \\
\hline $\mathrm{S}_{\mathrm{w}}<0.5 \sigma_{\mathrm{p}} ?$ & \multicolumn{2}{|c|}{ ACCEPTED } \\
\hline
\end{tabular}

\begin{tabular}{|c|c|c|}
\hline \multirow[b]{2}{*}{ Sample No. } & \multicolumn{2}{|c|}{ Enniatin B1 in material B ( $\mu \mathrm{g} / \mathrm{kg}$ ) } \\
\hline & Replicate 1 & Replicate 2 \\
\hline Hom/B001 & 54.78 & 43.70 \\
\hline Hom/B002 & 46.62 & 45.11 \\
\hline Hom/B003 & 47.63 & 46.97 \\
\hline Hom/B004 & 46.61 & 44.36 \\
\hline Hom/B005 & 50.63 & 47.51 \\
\hline Hom/B006 & 47.90 & 47.61 \\
\hline Hom/B007 & misinjection & misinjection \\
\hline Hom/B008 & 42.67 & 46.20 \\
\hline Hom/B009 & 47.72 & 45.68 \\
\hline Hom/B010 & 39.54 & 48.62 \\
\hline Grand mean & \multicolumn{2}{|c|}{46.66} \\
\hline \multicolumn{3}{|l|}{ Cochran's test } \\
\hline $\mathrm{C}$ & \multicolumn{2}{|c|}{0.513} \\
\hline $\mathrm{C}_{\text {crit }}$ & \multicolumn{2}{|c|}{0.638} \\
\hline $\mathrm{C}<\mathrm{C}_{\text {crit }}$ ? & \multicolumn{2}{|c|}{ NO OUTLIERS } \\
\hline Target $\mathrm{s}=\sigma_{\mathrm{p}}$ & \multicolumn{2}{|c|}{11.66} \\
\hline$s_{x}$ & \multicolumn{2}{|c|}{1.860} \\
\hline $\mathrm{S}_{\mathrm{w}}$ & \multicolumn{2}{|c|}{3.647} \\
\hline $\mathrm{S}_{\mathrm{s}}$ & \multicolumn{2}{|c|}{0.000} \\
\hline Critical $=0.3 \sigma_{P}$ & \multicolumn{2}{|c|}{3.499} \\
\hline $\mathrm{s}_{\mathrm{s}}<$ critical? & \multicolumn{2}{|c|}{ ACCEPTED } \\
\hline $\mathrm{s}_{\mathrm{w}}<0.5 \sigma_{\mathrm{p}} ?$ & \multicolumn{2}{|c|}{ ACCEPTED } \\
\hline
\end{tabular}




\begin{tabular}{|c|c|c|}
\hline \multirow[b]{2}{*}{ Sample No. } & \multicolumn{2}{|c|}{ HT-2 toxin in material B ( $\mu \mathrm{g} / \mathrm{kg})$} \\
\hline & Replicate 1 & Replicate 2 \\
\hline Hom/B001 & 75.27 & 67.29 \\
\hline Hom/B002 & 67.09 & 72.88 \\
\hline Hom/B003 & 58.15 & 68.60 \\
\hline Hom/B004 & 65.06 & 60.33 \\
\hline Hom/B005 & 59.13 & 78.07 \\
\hline Hom/B006 & 64.14 & 65.44 \\
\hline Hom/B007 & misinjection & misinjection \\
\hline Hom/B008 & 61.88 & 71.86 \\
\hline Hom/B009 & 63.80 & 68.02 \\
\hline Hom/B010 & 64.11 & 73.50 \\
\hline Grand mean & \multicolumn{2}{|c|}{66.92} \\
\hline Cochran's test & \\
\hline $\mathrm{C}$ & \multicolumn{2}{|c|}{0.451} \\
\hline $\mathrm{C}_{\text {crit }}$ & \multicolumn{2}{|c|}{0.638} \\
\hline $\mathrm{C}<\mathrm{C}_{\text {crit }} ?$ & \multicolumn{2}{|c|}{ NO OUTLIERS } \\
\hline Target $\mathrm{s}=\sigma_{\mathrm{P}}$ & \multicolumn{2}{|c|}{16.73} \\
\hline $\mathrm{S}_{\mathrm{x}}$ & \multicolumn{2}{|c|}{2.974} \\
\hline$S_{w}$ & \multicolumn{2}{|c|}{6.644} \\
\hline $\mathrm{S}_{\mathrm{s}}$ & \multicolumn{2}{|c|}{0.000} \\
\hline Critical $=0.3 \sigma_{p}$ & \multicolumn{2}{|c|}{5.019} \\
\hline $\mathrm{S}_{\mathrm{s}}<$ critical? & \multicolumn{2}{|c|}{ ACCEPTED } \\
\hline $\mathrm{S}_{\mathrm{w}}<0.5 \sigma_{\mathrm{p}} ?$ & \multicolumn{2}{|c|}{ ACCEPTED } \\
\hline
\end{tabular}

\begin{tabular}{|c|c|c|}
\hline \multirow[b]{2}{*}{ Sample No. } & \multicolumn{2}{|c|}{ Zearalenone in material B ( $\mu \mathrm{g} / \mathbf{k g})$} \\
\hline & Replicate 1 & Replicate 2 \\
\hline Hom/B001 & 164.76 & 165.18 \\
\hline Hom/B002 & 155.97 & 150.01 \\
\hline Hom/B003 & 162.36 & 152.69 \\
\hline Hom/B004 & outlier & outlier \\
\hline Hom/B005 & 171.64 & 173.28 \\
\hline Hom/B006 & 162.47 & 159.72 \\
\hline Hom/B007 & 152.01 & 163.89 \\
\hline Hom/B008 & 165.58 & 160.50 \\
\hline Hom/B009 & 176.58 & 164.11 \\
\hline Hom/B010 & 180.31 & 190.67 \\
\hline Grand mean & \multicolumn{2}{|c|}{165.1} \\
\hline \multicolumn{3}{|l|}{ Cochran's test } \\
\hline $\mathrm{C}$ & \multicolumn{2}{|c|}{0.273} \\
\hline $\mathrm{C}_{\text {crit }}$ & \multicolumn{2}{|c|}{0.638} \\
\hline $\mathrm{C}<\mathrm{C}_{\text {crit }}$ ? & \multicolumn{2}{|c|}{ NO OUTLIERS } \\
\hline Target $s=\sigma_{p}$ & \multicolumn{2}{|c|}{41.27} \\
\hline$s_{x}$ & \multicolumn{2}{|c|}{9.83} \\
\hline $\mathrm{S}_{\mathrm{w}}$ & \multicolumn{2}{|c|}{5.62} \\
\hline $\mathrm{S}_{\mathrm{s}}$ & \multicolumn{2}{|c|}{8.99} \\
\hline Critical $=0.3 \sigma_{P}$ & \multicolumn{2}{|c|}{12.38} \\
\hline $\mathrm{s}_{\mathrm{s}}<$ critical? & \multicolumn{2}{|c|}{ ACCEPTED } \\
\hline $\mathrm{s}_{\mathrm{w}}<0.5 \sigma_{\mathrm{p}} ?$ & \multicolumn{2}{|c|}{ ACCEPTED } \\
\hline
\end{tabular}




\section{Annex 4 Statistical evaluation of stability data}

Statistical evaluation for aflatoxin B1 in material A.

\begin{tabular}{|c|c|c|c|}
\hline Storage temperature & $<-70^{\circ} \mathrm{C}$ & $<-18^{\circ} \mathrm{C}$ & 2 days RT \\
\hline Time (days) & 0 & 43 & 43 \\
\hline \multirow[t]{5}{*}{ Calculated amounts $(\mu \mathrm{g} / \mathrm{kg})$} & 16.05 & 16.02 & 15.31 \\
\hline & 15.65 & 15.10 & 16.04 \\
\hline & 16.35 & 15.61 & 15.23 \\
\hline & 15.75 & 15.86 & 15.83 \\
\hline & 15.71 & 15.56 & 16.91 \\
\hline $\mathrm{n}$ & 6 & 6 & 6 \\
\hline st. dev $(\mu \mathrm{g} / \mathrm{kg})$ & 0.342 & 0.573 & 0.671 \\
\hline Difference & & 0.165 & 0.011 \\
\hline $0.3^{*} \sigma_{p}$ & & 1.199 & 1.199 \\
\hline Consequential difference? Diff $<0.3^{*} \sigma_{p}$ & & NO & NO \\
\hline
\end{tabular}

Statistical evaluation for 3-AC-DON in material A.

\begin{tabular}{|c|c|c|c|}
\hline Storage temperature & $<-70^{\circ} \mathrm{C}$ & $<-18^{\circ} \mathrm{C}$ & 2 days $\mathbf{R T}$ \\
\hline Time (days) & 0 & 43 & 43 \\
\hline \multirow[t]{5}{*}{ Calculated amounts $(\mu \mathrm{g} / \mathrm{kg})$} & 596.85 & 616.34 & 575.36 \\
\hline & 567.32 & 544.86 & 578.23 \\
\hline & 533.71 & 624.58 & 574.39 \\
\hline & 587.42 & 577.99 & 566.25 \\
\hline & 597.11 & 540.52 & 571.03 \\
\hline $\mathrm{n}$ & 6 & 6 & 6 \\
\hline st. dev $(\mu \mathrm{g} / \mathrm{kg})$ & 24.07 & 35.025 & 4.319 \\
\hline Difference & & -6.27 & 2.010 \\
\hline $0.3^{*} \sigma_{p}$ & & 43.17 & 43.17 \\
\hline Consequential difference? Diff $<0.3^{*} \sigma_{p}$ & & NO & NO \\
\hline
\end{tabular}

Statistical evaluation for 15-AC-DON in material A.

\begin{tabular}{|c|c|c|c|}
\hline Storage temperature & $<-70^{\circ} \mathrm{C}$ & $<-18^{\circ} \mathrm{C}$ & 2 days $R T$ \\
\hline Time (days) & 0 & 43 & 43 \\
\hline \multirow{4}{*}{ Calculated amounts $(\mu \mathrm{g} / \mathrm{kg})$} & 29.78 & 30.18 & 29.61 \\
\hline & 32.55 & 30.26 & 20.87 \\
\hline & 32.54 & 34.26 & 33.57 \\
\hline & 28.80 & 29.89 & 32.14 \\
\hline $\mathrm{n}$ & 6 & 6 & 6 \\
\hline st. dev $(\mu \mathrm{g} / \mathrm{kg})$ & 1.509 & 1.848 & 4.642 \\
\hline Difference & & -0.525 & 0.946 \\
\hline $0.3^{*} \sigma_{p}$ & & 2.32 & 2.32 \\
\hline Consequential difference? Diff $<0.3^{*} \sigma_{p}$ & & NO & NO \\
\hline
\end{tabular}


Statistical evaluation for DON in material A.

\begin{tabular}{|c|c|c|c|}
\hline Storage temperature & $<-70^{\circ} \mathrm{C}$ & $<-18^{\circ} \mathrm{C}$ & 2 days RT \\
\hline Time (days) & 0 & 43 & 43 \\
\hline \multirow[t]{5}{*}{ Calculated amounts $(\mu \mathrm{g} / \mathrm{kg})$} & 3986.21 & 3992.84 & 3838.54 \\
\hline & 3945.81 & 3766.77 & 3947.20 \\
\hline & 3878.49 & 3885.78 & 3738.05 \\
\hline & 3936.03 & 3867.29 & 3943.09 \\
\hline & 3830.92 & 3790.93 & 4180.56 \\
\hline $\mathrm{n}$ & 6 & 6 & 6 \\
\hline st. dev $(\mu \mathrm{g} / \mathrm{kg})$ & 59.054 & 113.9 & 147.5 \\
\hline Difference & & 12.34 & -20.03 \\
\hline $0.3^{*} \sigma_{\mathrm{P}}$ & & 293 & 293 \\
\hline Consequential difference? Diff $<0.3^{*} \sigma_{p}$ & & NO & NO \\
\hline
\end{tabular}

Statistical evaluation for DON-3G in material A.

\begin{tabular}{|c|c|c|c|}
\hline Storage temperature & $<-70^{\circ} \mathrm{C}$ & $<-18^{\circ} \mathrm{C}$ & 2 days RT \\
\hline Time (days) & 0 & 43 & 43 \\
\hline \multirow[t]{5}{*}{ Calculated amounts $(\mu \mathrm{g} / \mathrm{kg})$} & 530.97 & 601.34 & 518.55 \\
\hline & 528.48 & 479.29 & 534.71 \\
\hline & 483.25 & 519.61 & 507.44 \\
\hline & 515.34 & 577.77 & 506.85 \\
\hline & 574.27 & 557.70 & 516.44 \\
\hline $\mathrm{n}$ & 6 & 6 & 6 \\
\hline st. dev $(\mu \mathrm{g} / \mathrm{kg})$ & 30.9 & 57.4 & 10.7 \\
\hline Difference & & -9.198 & 4.30 \\
\hline $0.3^{*} \sigma_{\mathrm{p}}$ & & 39.2 & 39.2 \\
\hline Consequential difference? Diff $<0.3^{*} \sigma_{p}$ & & NO & NO \\
\hline
\end{tabular}

Statistical evaluation for enniatin B in material A.

\begin{tabular}{|c|c|c|c|}
\hline Storage temperature & $<-70^{\circ} \mathrm{C}$ & $<-18^{\circ} \mathrm{C}$ & 2 days RT \\
\hline Time (days) & 0 & 43 & 43 \\
\hline \multirow[t]{4}{*}{ Calculated amounts $(\mu \mathrm{g} / \mathrm{kg})$} & 83.00 & 83.27 & 74.09 \\
\hline & 79.78 & 74.02 & 69.38 \\
\hline & 82.10 & 77.48 & 80.36 \\
\hline & 78.59 & 80.47 & 81.64 \\
\hline $\mathrm{n}$ & 6 & 6 & 6 \\
\hline st. dev $(\mu \mathrm{g} / \mathrm{kg})$ & 1.63 & 3.60 & 4.90 \\
\hline Difference & & 1.73 & 3.43 \\
\hline $0.3^{*} \sigma_{p}$ & & 6.08 & 6.08 \\
\hline Consequential difference? Diff $<0.3 * \sigma_{p}$ & & NO & NO \\
\hline
\end{tabular}

Statistical evaluation for enniatin B1 in material A.

\begin{tabular}{|c|c|c|c|}
\hline Storage temperature & $<-70^{\circ} \mathrm{C}$ & $<-18{ }^{\circ} \mathrm{C}$ & 2 days RT \\
\hline Time (days) & 0 & 43 & 43 \\
\hline \multirow[t]{4}{*}{ Calculated amounts $(\mu \mathrm{g} / \mathrm{kg})$} & 49.72 & 49.35 & 41.97 \\
\hline & 47.96 & 41.78 & 40.52 \\
\hline & 50.38 & 45.46 & 47.28 \\
\hline & 48.38 & 50.48 & 48.72 \\
\hline $\mathrm{n}$ & 6 & 6 & 6 \\
\hline st. dev $(\mu \mathrm{g} / \mathrm{kg})$ & 0.991 & 4.05 & 3.56 \\
\hline Difference & & 1.64 & 3.66 \\
\hline $0.3^{*} \sigma_{p}$ & & 3.71 & 3.71 \\
\hline Consequential difference? Diff $<0.3^{*} \sigma_{p}$ & & NO & NO \\
\hline
\end{tabular}


Statistical evaluation for $\boldsymbol{H T}-\mathbf{2}$ toxin in material $\boldsymbol{A}$.

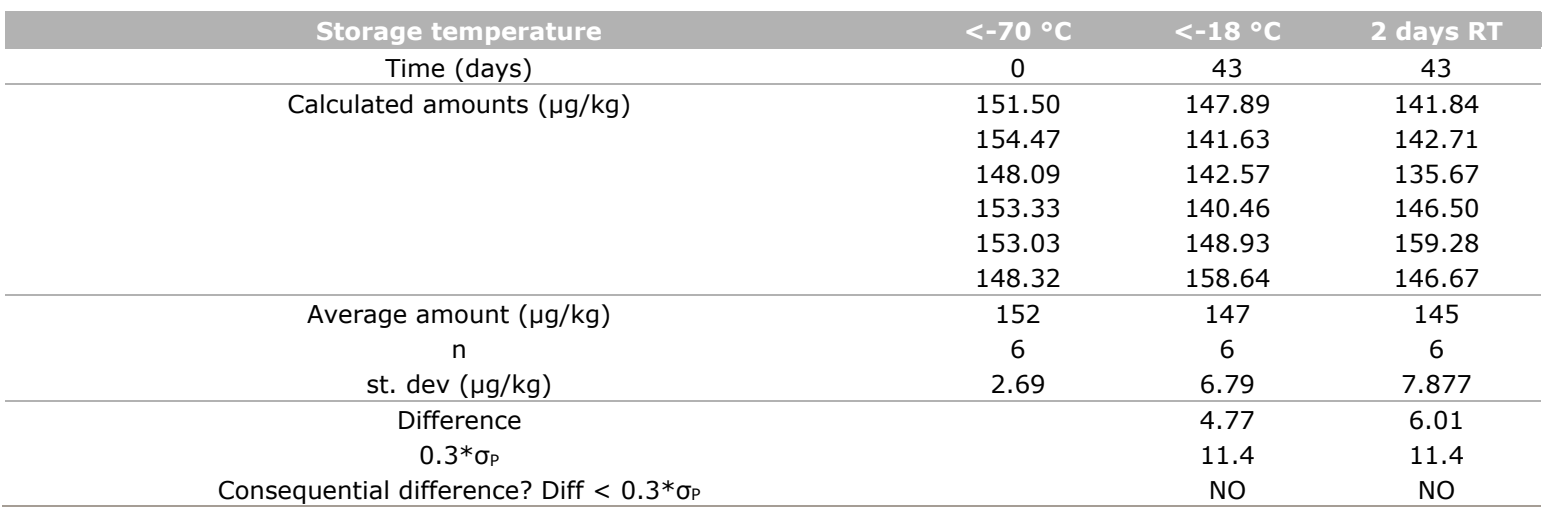

Statistical evaluation for T-2 toxin in material A.

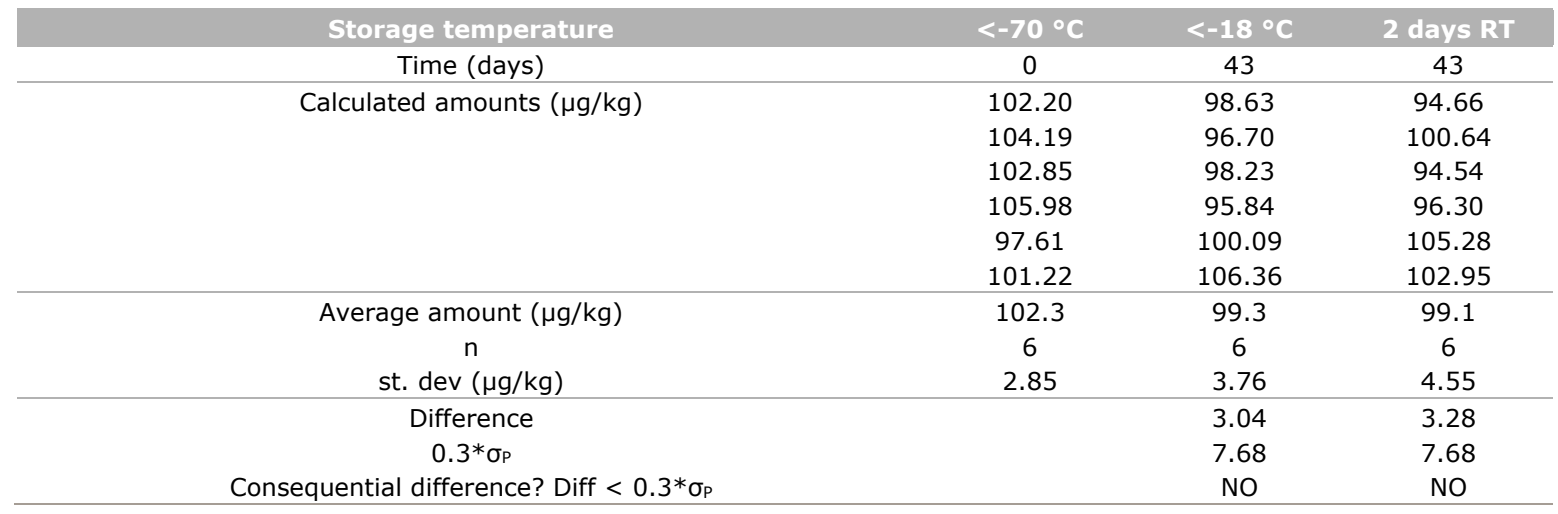

Statistical evaluation for zearalenone in material A.

\begin{tabular}{|c|c|c|c|}
\hline Storage temperature & $<-70^{\circ} \mathrm{C}$ & $<-18^{\circ} \mathrm{C}$ & 2 days $\mathbf{R T}$ \\
\hline Time (days) & 0 & 43 & 43 \\
\hline \multirow[t]{4}{*}{ Calculated amounts $(\mu \mathrm{g} / \mathrm{kg})$} & 262.28 & 262.31 & 250.97 \\
\hline & 275.56 & 253.65 & 252.63 \\
\hline & 270.86 & 256.12 & 281.84 \\
\hline & 259.21 & 274.93 & 278.53 \\
\hline $\mathrm{n}$ & 6 & 6 & 6 \\
\hline st. dev $(\mu \mathrm{g} / \mathrm{kg})$ & 9.38 & 14.8 & 16.4 \\
\hline Difference & & 1.31 & -6.66 \\
\hline $0.3^{*} \sigma_{\mathrm{p}}$ & & 19.7 & 19.7 \\
\hline Consequential difference? Diff $<0.3^{*} \sigma_{p}$ & & NO & NO \\
\hline
\end{tabular}

Statistical evaluation for aflatoxin B in material B.

\begin{tabular}{|c|c|c|c|}
\hline Storage temperature & $<-70^{\circ} \mathrm{C}$ & $<-18{ }^{\circ} \mathrm{C}$ & 2 days RT \\
\hline Time (days) & 0 & 43 & 43 \\
\hline \multirow[t]{4}{*}{ Calculated amounts $(\mu \mathrm{g} / \mathrm{kg})$} & 6.17 & 6.04 & 6.86 \\
\hline & 5.97 & 6.18 & 5.95 \\
\hline & 6.80 & 6.65 & 6.19 \\
\hline & 6.73 & 6.35 & 6.41 \\
\hline $\mathrm{n}$ & 6 & 6 & 6 \\
\hline st. dev $(\mu \mathrm{g} / \mathrm{kg})$ & 0.373 & 0.219 & 0.318 \\
\hline Difference & & 0.179 & 0.111 \\
\hline $0.3^{*} \sigma_{p}$ & & 0.489 & 0.489 \\
\hline Consequential difference? Diff $<0.3^{*} \sigma_{p}$ & & NO & NO \\
\hline
\end{tabular}


Statistical evaluation for $\boldsymbol{H T}-\mathbf{2}$ toxin in material B.

\begin{tabular}{|c|c|c|c|}
\hline Storage temperature & $<-70^{\circ} \mathrm{C}$ & $<-18^{\circ} \mathrm{C}$ & 2 days RT \\
\hline Time (days) & 0 & 43 & 43 \\
\hline \multirow[t]{4}{*}{ Calculated amounts $(\mu \mathrm{g} / \mathrm{kg})$} & 50.41 & 46.54 & 47.32 \\
\hline & 50.37 & 42.85 & 48.49 \\
\hline & 67.58 & 46.57 & 41.93 \\
\hline & 50.12 & 44.89 & 43.01 \\
\hline $\mathrm{n}$ & 6 & 5 & 6 \\
\hline st. dev $(\mu \mathrm{g} / \mathrm{kg})$ & 0.8 .21 & 1.81 & 3.11 \\
\hline Difference & & 8.34 & 7.93 \\
\hline $0.3^{*} \sigma_{\mathrm{p}}$ & & 4.05 & 4.05 \\
\hline Consequential difference? Diff $<0.3^{*} \sigma_{p}$ & & YES & YES \\
\hline
\end{tabular}

Statistical evaluation for T-2 toxin in material B.

\begin{tabular}{|c|c|c|c|}
\hline Storage temperature & $<-70^{\circ} \mathrm{C}$ & $<-18^{\circ} \mathrm{C}$ & 2 days $R T$ \\
\hline Time (days) & 0 & 43 & 43 \\
\hline \multirow[t]{5}{*}{ Calculated amounts $(\mu \mathrm{g} / \mathrm{kg})$} & 18.9 & 17.8 & 18.1 \\
\hline & 17.8 & 17.4 & 18.0 \\
\hline & 16.2 & outlier & 19.1 \\
\hline & 19.9 & 18.5 & 16.7 \\
\hline & 18.6 & 16.8 & 17.5 \\
\hline $\mathrm{n}$ & 6 & 6 & 6 \\
\hline st. dev $(\mu \mathrm{g} / \mathrm{kg})$ & 1.89 & 1.02 & 0.81 \\
\hline Difference & & 0.8 & 1.0 \\
\hline $0.3^{*} \sigma_{\mathrm{p}}$ & & 1.41 & 1.41 \\
\hline Consequential difference? Diff $<0.3^{*} \sigma_{p}$ & & NO & NO \\
\hline
\end{tabular}




\section{Annex 5 Overview of the applied methods}

\begin{tabular}{|c|c|c|c|c|}
\hline Lab & Compound & Sample purification & Internal standard & Detection technique \\
\hline PT9604 & all & Immunoaffinity & no & $\begin{array}{l}\text { Fluorescentie - } \\
\text { Fumonisin/zearalenon/aflatoxin/ochratoxin } \\
\text { UV - Vomitoxin }\end{array}$ \\
\hline PT9607 & & Extractie met acetonitril/water/mierenzuurmengsel & $\begin{array}{l}\text { isotoop gelabelde } \\
\text { mycotoxines }\end{array}$ & triple quadrupool massaspectrometer \\
\hline PT9608 & DON-3G & $\begin{array}{l}25 \mathrm{~g} \text { sample }+100 \mathrm{ml} \text { Acetonitril/Water/Acetic acid }(79 / 20 / 1) ; 120 \text { min stirring no clean up only dilution } \\
1: 10 \text { "Dilute \& Shoot" }\end{array}$ & $\begin{array}{l}\text { fully } 13 \text { C-labeld analogs } \\
\text { of each mycotoxin } \\
\text { (Biopure/RomerLabs) }\end{array}$ & $\begin{array}{l}\text { LC-MS/MS LC-QqQ ESI Electro Spray } \\
\text { Ionisation } 2 \text { MRMs/compound } \\
\text { (identification criteria according to Hans } \\
\text { Mol) }\end{array}$ \\
\hline PT9610 & & $\begin{array}{l}\text { shake with solvent (ACN/H2O/FA:80:20:0.1) } \\
\text { centrifuge } \\
\text { filter: Oasis Prime HLB } \\
\text { Evaporate and reconstitute with ACN/H2O (16:84) }\end{array}$ & $\begin{array}{l}13 \mathrm{C} \text { internal standard } \\
\text { for every analyte. }\end{array}$ & MS-MS \\
\hline PT9611 & AFLA & add $\mathrm{NaCl}$, add extraction solvent $\mathrm{MeOH} / \mathrm{H} 2 \mathrm{O}(80 / 20)$, shake, filtration, clean up by IAC & & LC-FLD \\
\hline PT9611 & DON, ZEN, HT2, T2 & add extraction solvent $\mathrm{ACN} / \mathrm{H} 20(80 / 20)$, shake, dilute & $\begin{array}{l}\text { DON-C13, ZAN, HT2- } \\
\text { C13, T2-C13 }\end{array}$ & LC-MS/MS \\
\hline PT9611 & ENN & add extraction solvent $\mathrm{ACN} / \mathrm{H} 2 \mathrm{O}(80 / 20)$, shake, dilute & & LC-MS/MS \\
\hline PT9611 & OTA & add $\mathrm{NaHCO}$, add extraction solvent $\mathrm{MeOH} / \mathrm{H} 2 \mathrm{O}(80 / 20)$, shake, clean up by IAC & & LC-FLD \\
\hline PT9612 & AFLA & 5g sample. Extraction with methanol/water. Clean-up with immunoaff. column & No & FLD \\
\hline PT9612 & DON & $2.5 \mathrm{~g}$ sample. extraction with water. Clean up with immunoaff. column & No & UV detection \\
\hline PT9612 & OTA & $5 \mathrm{~g}$ sample. extraction with $40 \mathrm{ml}$ acetonitrile/water. Clean-up with immunoaff. column & No & FLD \\
\hline PT9612 & $\mathrm{T} 2, \mathrm{HT} 2$ & $\begin{array}{l}\text { 10g sample. Extraction with methanol/water 90/10. Dilution of filtrate with water. pH7.4 Clean up with } \\
\text { immunoaff column. Derivatiz. with DMAP and 1-AN }\end{array}$ & No & FLD \\
\hline PT9612 & $\begin{array}{l}\text { ZEN, DON relatives, } \\
\text { ENN }\end{array}$ & $\begin{array}{l}5 \mathrm{~g} \text { sample. Extraction with } 50 \mathrm{ml} \text { acetonitrile / water }(90 / 10) \text {. Shaking mashine. Filtration. } 10 \mathrm{ml} \text { filtrate is } \\
\text { diluted with } 40 \mathrm{ml} \text { of water. } 10 \mathrm{mldiluted} \text { filtrate is passed through a immunoaffinity column. Washing, } \\
\text { elution with methanol, evaporation and reconstit }\end{array}$ & No & Fluorescence detection \\
\hline
\end{tabular}




\begin{tabular}{|c|c|c|c|c|}
\hline Lab & Compound & Sample purification & Internal standard & Detection technique \\
\hline PT9613 & & $\begin{array}{l}-5 \mathrm{~g} \text { sample }+10 \mathrm{~mL} \mathrm{H} 2 \mathrm{O} \text { (soaking time } 1 \text { hour) }-10 \mathrm{~mL} \text { acidified acetonitrile }(0.1 \% \text { formic acid) -manual } \\
\text { shaking } 2 \text { minute -add } 6.5 \mathrm{~g} \text { Quechers mixture -manual shaking } 2 \text { minuts -Centrifuge at } 5000 \mathrm{~g} 5 \text { minuts - } \\
\text { Filter and inject }\end{array}$ & no internal standard & LC-MS/MS \\
\hline PT9614 & & ACN/water no clean-up & several & LCMSMS \\
\hline PT9616 & & Different for each parameter & No & UPLC/MS/MS \\
\hline PT9617 & & Inmunoafinity column & Not used & LC-MS/MS \\
\hline PT9618 & & $\begin{array}{l}\text { Extraction solvent: } 80 \% \text { acetonitrile in water } 5 \text { gram oat feed, } 20 \mathrm{ml} \text { solvent. Clean-up: pass through "Bond } \\
\text { Elut mycotoxin" SPE-column. } 2 \mathrm{ml} \text { cleaned extracts is evaporated and dissolved in } 1 \mathrm{ml} 25 \% \text { acetonitrile in } \\
\text { water. }\end{array}$ & $\begin{array}{l}\text { None. Only instrument } \\
\text { suitability standard } \\
\text { (zearalanone) added to } \\
\text { each sample. }\end{array}$ & $\begin{array}{l}\text { LC-Q-Orbitrap (model: Thermo Q- } \\
\text { Exactive) in tSIM-ddMS2 mode. }\end{array}$ \\
\hline PT9620 & & HPLC-ACN $1 \%$ FA shake & IS Myc & LC-MSMS \\
\hline PT9621 & & Shake with acetonitrile/water, centrifuge and filter & $\begin{array}{l}13 \mathrm{C} \text { labelled stds for } \\
\text { each analyte }\end{array}$ & LCMSMS \\
\hline PT9622 & & AcN/Acetic acid/H2) no clean up & $\begin{array}{l}\text { Isotopic labelled } \\
\text { standards }\end{array}$ & LCMSMS \\
\hline PT9623 & & Extraction with acified acetonitril/water & $\begin{array}{l}13 \mathrm{C} \text { for each } \\
\text { component }\end{array}$ & MSMS \\
\hline PT9624 & & QUEChERS & no IS & LC-MS/MS \\
\hline PT9625 & & Extraction by shaking with a mixture of acetonitrile and aqueous formic acid solution & $\begin{array}{l}13 C 15 \text { Deoxynivalenol } \\
13 C 17 \text { Aflatoxin } B 1 \\
13 C 200 \text { chratoxin A }\end{array}$ & MS detection \\
\hline PT9627 & $\begin{array}{l}\text { AFLA, DON } \\
\text { relatives, ENN }\end{array}$ & Extraction solvent: C3H6O:H2O 85:15 Clean-up: IAC & External calibration & FLD \\
\hline PT9627 & $\begin{array}{l}\text { DON, DON-3-G, T2, } \\
\text { HT2, ZEN }\end{array}$ & Extraction solvent: ACN:H2O 84:16 Clean-up: SPE & External calibration & LC MSMS \\
\hline PT9627 & OTA & Extraction solvent: $\mathrm{MeOH}: \mathrm{H} 2 \mathrm{O}$ 50:50 Clean-up: IAC & External calibration & FLD \\
\hline PT9627 & $\mathrm{T} 2, \mathrm{HT} 2$ & Extraction solvent: ACN:H2O 84:16 Clean-up: SPE & External calibration & LC MSMS \\
\hline PT9627 & ZEN & Extraction solvent: ACN:H2O 84:16 Clean-up: SPE & External calibration & LC MSMS \\
\hline
\end{tabular}




\section{Annex 6 Results material A}

\begin{tabular}{|c|c|c|c|c|c|c|}
\hline \multirow[b]{2}{*}{$\begin{array}{l}\text { Lab } \\
\text { code }\end{array}$} & \multicolumn{2}{|c|}{$\begin{array}{c}15-A C-D O N \\
\text { CV: } 161 \mu g / k g \\
\text { u: } 38 \mu \mathrm{g} / \mathrm{kg} \\
\sigma_{\mathrm{p}}: 40 \mu \mathrm{g} / \mathrm{kg} \\
\text { robust } \sigma: 67 \mu \mathrm{g} / \mathrm{kg}\end{array}$} & $\begin{array}{c}\text { 3-AC-DON } \\
\text { CV: } 613 \mu \mathrm{g} / \mathrm{kg} \\
\text { u: } 26 \mu \mathrm{gg} / \mathrm{kg} \\
\sigma_{\mathrm{p}}: 153 \mu \mathrm{g} / \mathrm{kg} \\
\text { robust } \sigma: 56 \mu \mathrm{g} / \mathrm{kg} \\
\end{array}$ & $\begin{array}{c}\text { DON-3G } \\
\text { CV: } 1143 \mu \mathrm{g} / \mathrm{kg} \\
\text { u: } 181 \mu \mathrm{g} / \mathrm{kg} \\
\sigma_{\mathrm{p}}: 286 \mu \mathrm{g} / \mathrm{kg} \\
\text { robust o: } 290 \mu \mathrm{gg} / \mathrm{kg}\end{array}$ & \multicolumn{2}{|c|}{$\begin{array}{c}\text { DON } \\
\text { CV: } 4174 \mu \mathrm{g} / \mathrm{kg} \\
\text { u: } 176 \mu \mathrm{g} / \mathrm{kg} \\
\sigma_{\mathrm{p}}: 1044 \mu \mathrm{g} / \mathrm{kg} \\
\text { robust } \sigma: 629 \mu \mathrm{gg} / \mathrm{kg}\end{array}$} \\
\hline & $\begin{array}{c}\text { Result } \\
\text { ( } \mu \mathrm{g} / \mathrm{kg})\end{array}$ & $\mathrm{z}_{\mathrm{a}}$-score & $\begin{array}{l}\text { Result } \quad z_{a}^{\prime} \text {-score } \\
(\mu g / k g)\end{array}$ & $\begin{array}{c}\text { Result } \quad Z_{a} \text {-score } \\
(\mu g / k g)\end{array}$ & $\begin{array}{c}\text { Result } \\
(\mu g / k g)\end{array}$ & $\mathrm{Z}_{\mathrm{a}}$-score \\
\hline PT9604 & & NO & & NO & 4557 & 0.37 \\
\hline PT9607 & & STATISTICAL & & STATISTICAL & 4036 & -0.13 \\
\hline PT9608 & 93.6 & EVALUATION & 0.12 & EVALUATION & 4277 & 0.10 \\
\hline PT9609 & & POSSIBLE & & POSSIBLE & $\mathrm{FN}$ & \\
\hline PT9610 & & & & & 2572 & -1.54 \\
\hline PT9611 & 250 & TOO & -0.87 & TOO & 3874 & -0.29 \\
\hline PT9612 & & LITTLE & & LITTLE & 4666.4 & 0.47 \\
\hline PT9613 & & RESULTS & & RESULTS & 3886.78 & -0.28 \\
\hline PT9614 & 494 & & -0.83 & & 4610 & 0.42 \\
\hline PT9615 & \multicolumn{3}{|c|}{422.9 for the sum of $15-A c-D O N$ and $3-A c-D O N$} & & 3657.6 & -0.50 \\
\hline PT9616 & & & & & 3009 & -1.12 \\
\hline \multicolumn{7}{|l|}{ PT9617 } \\
\hline PT9618 & \multicolumn{3}{|c|}{1330.5 for the sum of $15-A c-D O N$ and 3-Ac-DON } & & 4249.8 & 0.07 \\
\hline \multicolumn{7}{|l|}{ PT9619 } \\
\hline PT9620 & nd & & -1.29 & 1413 & 3509 & -0.64 \\
\hline PT9621 & nd & & 0.33 & 569 & 4539 & 0.35 \\
\hline PT9622 & & & & & 3860 & -0.30 \\
\hline PT9623 & & & & & 4332 & 0.15 \\
\hline PT9624 & 135.84 & & 654.44 & 1087.1 & 5680.16 & 1.44 \\
\hline PT9625 & nd & & & & 6458 & 2.19 \\
\hline PT9626 & 136 & & 0.26 & & 4170 & 0.00 \\
\hline PT9627 & & & & & 3300 & -0.84 \\
\hline PT9628 & & & & & 6860 & 2.57 \\
\hline \multicolumn{7}{|c|}{$\mathrm{CV} \quad=$ consensus value. } \\
\hline \multicolumn{7}{|c|}{$=$ uncertainty of consensus value. } \\
\hline$=\mathrm{n}$ & t detected & & & & & \\
\hline
\end{tabular}




\begin{tabular}{|c|c|c|c|c|c|c|}
\hline \multirow[b]{2}{*}{$\begin{array}{l}\text { Lab } \\
\text { code }\end{array}$} & \multicolumn{2}{|c|}{$\begin{array}{c}\text { Aflatoxin B1 } \\
\text { CV: } 25 \mu g / k g \\
\text { u: } 1.5 \mu g / k g \\
\sigma_{p}: 6.2 \mu g / k g \\
\text { robust o: } 5.5 \mu g / k g\end{array}$} & $\begin{array}{c}\text { Enniatin B } \\
\text { CV: } 121 \mu g / k g \\
\text { u: } 28 \mu g / k g \\
\sigma_{p}: 30 \mu g / k g \\
\text { robust } 0: 46 \mu g / k g \\
\end{array}$ & $\begin{array}{c}\text { Enniatin B1 } \\
\text { CV: } 65 \mu g / k g \\
\text { u: } 19.7 \mu g / k g \\
\sigma_{p}: 16.2 \mu g / k g \\
\text { robust o: } 31 \mu g / k g \\
\end{array}$ & \multicolumn{2}{|c|}{$\begin{array}{c}\text { Zearalenone } \\
\text { CV: } 293 \mu g / k g \\
\text { u: } 11.3 \mu g / k g \\
\sigma_{p}: 73 \mu g / k g \\
\text { robust o: } 41 \mu g / k g\end{array}$} \\
\hline & $\begin{array}{c}\text { Result } \\
(\mu g / k g)\end{array}$ & $\mathrm{z}_{\mathrm{a}}$-score & $\begin{array}{c}\text { Result } \quad z_{a} \text {-score } \\
(\mu g / k g)\end{array}$ & $\begin{array}{c}\text { Result } \quad z_{a} \text {-score } \\
(\mu g / k g)\end{array}$ & $\begin{array}{l}\text { Result } \\
(\mu g / k g)\end{array}$ & $\mathrm{z}_{\mathrm{a}}$-score \\
\hline РT9604 & 16.2 & -1.37 & NO & NO & 253 & -0.54 \\
\hline PT9607 & 26.96 & 0.37 & STATISTICAL & STATISTICAL & 317 & 0.34 \\
\hline РT9608 & 29.3 & 0.75 & EVALUATION & EVALUATION & 314 & 0.29 \\
\hline РT9609 & 31 & 1.03 & POSSIBLE & POSSIBLE & 290 & -0.03 \\
\hline РT9610 & 29 & 0.70 & & & 231 & -0.84 \\
\hline РT9611 & 18.9 & -0.94 & TOO & TOO & 309 & 0.23 \\
\hline РT9612 & 25.2 & 0.08 & LITTLE & LITTLE & 288.3 & -0.06 \\
\hline PT9613 & 24 & -0.11 & RESULTS & RESULTS & 292.06 & -0.01 \\
\hline РT9614 & 29 & 0.70 & & & 289 & -0.05 \\
\hline РT9615 & 24.1 & -0.09 & & & 283.4 & -0.12 \\
\hline РT9616 & 13.3 & -1.84 & & & & \\
\hline РT9617 & 29 & 0.70 & & & 177 & -1.58 \\
\hline РT9618 & & & 117.4 & 100.4 & 271.4 & -0.29 \\
\hline РT9619 & 18.75 & -0.96 & & & & \\
\hline РT9620 & 25.35 & 0.11 & 75 & 35.4 & 273 & -0.27 \\
\hline РT9621 & 25 & 0.05 & & & 284 & -0.12 \\
\hline РT9622 & 26.7 & 0.33 & & & 331 & 0.53 \\
\hline PT9623 & 27.7 & 0.49 & & & 376 & 1.14 \\
\hline PT9624 & 27.81 & 0.51 & 123.54 & 70.92 & 363.84 & 0.98 \\
\hline РT9625 & 21.5 & -0.51 & & & 270.1 & -0.31 \\
\hline РT9626 & 19.3 & -0.87 & & & 360 & 0.92 \\
\hline РT9627 & 12.4 & -1.99 & & & 200 & -1.26 \\
\hline PT9628 & 33.0 & 1.35 & & & 692 & 5.46 \\
\hline
\end{tabular}




\begin{tabular}{|c|c|c|c|c|c|c|}
\hline \multirow[b]{2}{*}{$\begin{array}{l}\text { Lab } \\
\text { code }\end{array}$} & \multicolumn{2}{|c|}{$\begin{array}{c}\text { T-2 toxin } \\
\text { CV: } 133 \mu g / k g \\
\text { u: } 7.1 \mu g / k g \\
\sigma_{p}: 33 \mu g / k g \\
\text { robust o: } 25 \mu g / k g\end{array}$} & \multicolumn{2}{|c|}{$\begin{array}{c}\text { HT-2 toxin } \\
\text { CV: } 185 \mu g / \mathrm{kg} \\
\text { u: } 12.1 \mu \mathrm{gg} / \mathrm{kg} \\
\sigma_{\mathrm{p}}: 46 \mu \mathrm{gg} / \mathrm{kg} \\
\text { robust o: } 42 \mu \mathrm{gg} / \mathrm{kg}\end{array}$} & \multicolumn{2}{|c|}{$\begin{array}{c}\text { Sum of T-2 and HT-2 toxin } \\
\text { CV: } 319 \mu g / k g \\
\text { u: } 17.9 \mu g / k g \\
\sigma_{p}: 80 \mu g / k g \\
\text { robust } \sigma: 62 \mu g / k g\end{array}$} \\
\hline & $\begin{array}{c}\text { Result } \\
\text { ( } \mu g / k g)\end{array}$ & & $\begin{array}{l}\text { Result } \\
(\mu g / k g)\end{array}$ & $z_{a}^{\prime}$-score & $\begin{array}{c}\text { Result } \\
(\mu g / k g)\end{array}$ & $\mathrm{z}_{\mathrm{a}}$-score \\
\hline \multicolumn{7}{|l|}{ РT9604 } \\
\hline РТ9607 & 150 & 0.50 & 197 & 0.25 & 347 & 0.35 \\
\hline РT9608 & 148 & 0.44 & 218 & 0.70 & 366 & 0.58 \\
\hline РT9609 & 110 & -0.70 & 78 & -2.32 & 188 & -1.65 \\
\hline РТ9610 & 122 & -0.34 & 259 & 1.59 & 381 & 0.77 \\
\hline РT9611 & 151 & 0.53 & 194 & 0.18 & 345 & 0.32 \\
\hline РT9612 & 80.5 & -1.58 & 137 & -1.05 & 217.5 & -1.28 \\
\hline PT9613 & 170.69 & 1.12 & 137.06 & -1.04 & 307.75 & -0.15 \\
\hline РT9614 & 126 & -0.22 & 184 & -0.03 & 310 & -0.12 \\
\hline РТ9615 & 156.2 & 0.69 & 220.6 & 0.76 & 376.8 & 0.72 \\
\hline \multicolumn{7}{|l|}{ РT9616 } \\
\hline \multicolumn{7}{|l|}{ РT9617 } \\
\hline РT9618 & 144.6 & 0.34 & 201.8 & 0.35 & 346.4 & 0.34 \\
\hline \multicolumn{7}{|l|}{ РT9619 } \\
\hline PT9620 & 221 & 2.63 & 231 & 0.98 & 452 & 1.66 \\
\hline PT9621 & 127 & -0.19 & 208 & 0.49 & 335 & 0.20 \\
\hline РT9622 & 138 & 0.14 & 187 & 0.03 & 325 & 0.07 \\
\hline PT9623 & 146 & 0.38 & 228 & 0.92 & 374 & 0.68 \\
\hline PT9624 & 120.75 & -0.38 & 193.09 & 0.16 & 313.84 & -0.07 \\
\hline РT9625 & 87.3 & -1.38 & 130.2 & -1.19 & 217.5 & -1.28 \\
\hline РT9626 & 136 & 0.08 & 178 & -0.16 & 314 & -0.07 \\
\hline РT9627 & 26.0 & -3.22 & 71.1 & -2.47 & 97.1 & -2.78 \\
\hline PT9628 & 109 & -0.73 & 162 & -0.51 & 271 & -0.61 \\
\hline
\end{tabular}


3-acetyl-Deoynivalenol in material A

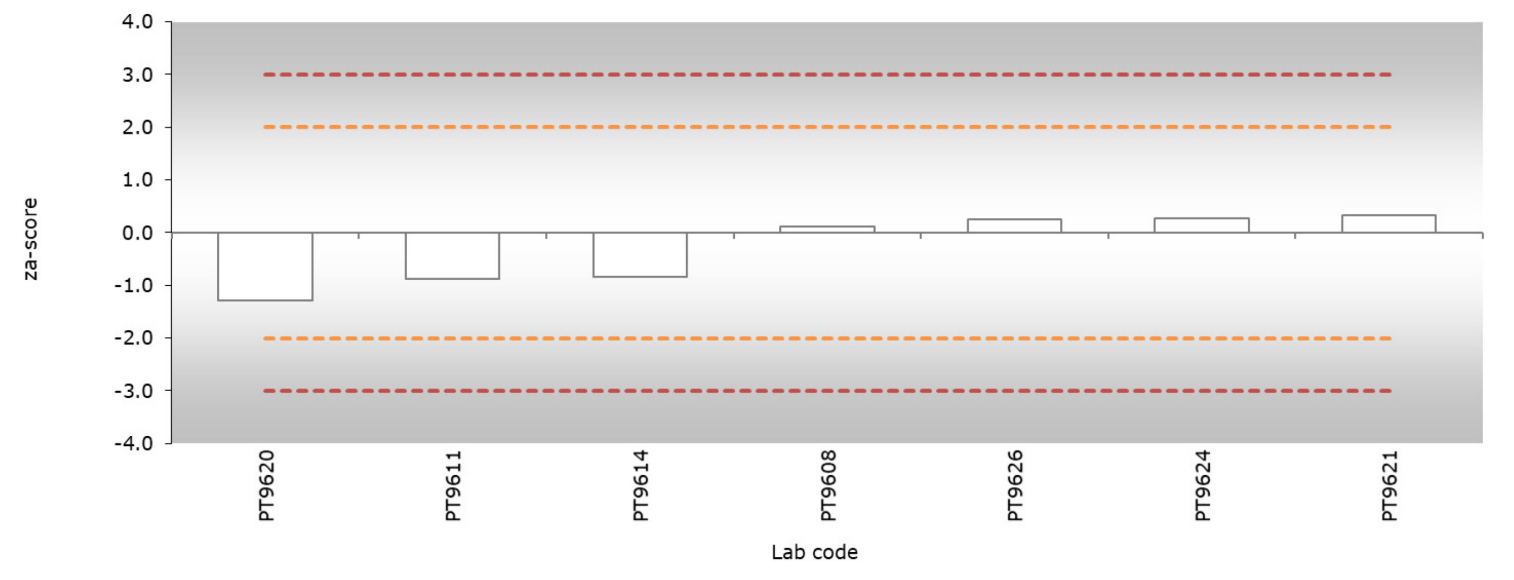

Figure a Graphical representation of the $z_{a}$-scores for 3-acetyl-deoxynivalenol in material $A$. The $X \pm 2 \sigma_{P}$ lines (dotted) are calculated according to equation I in §3.4.

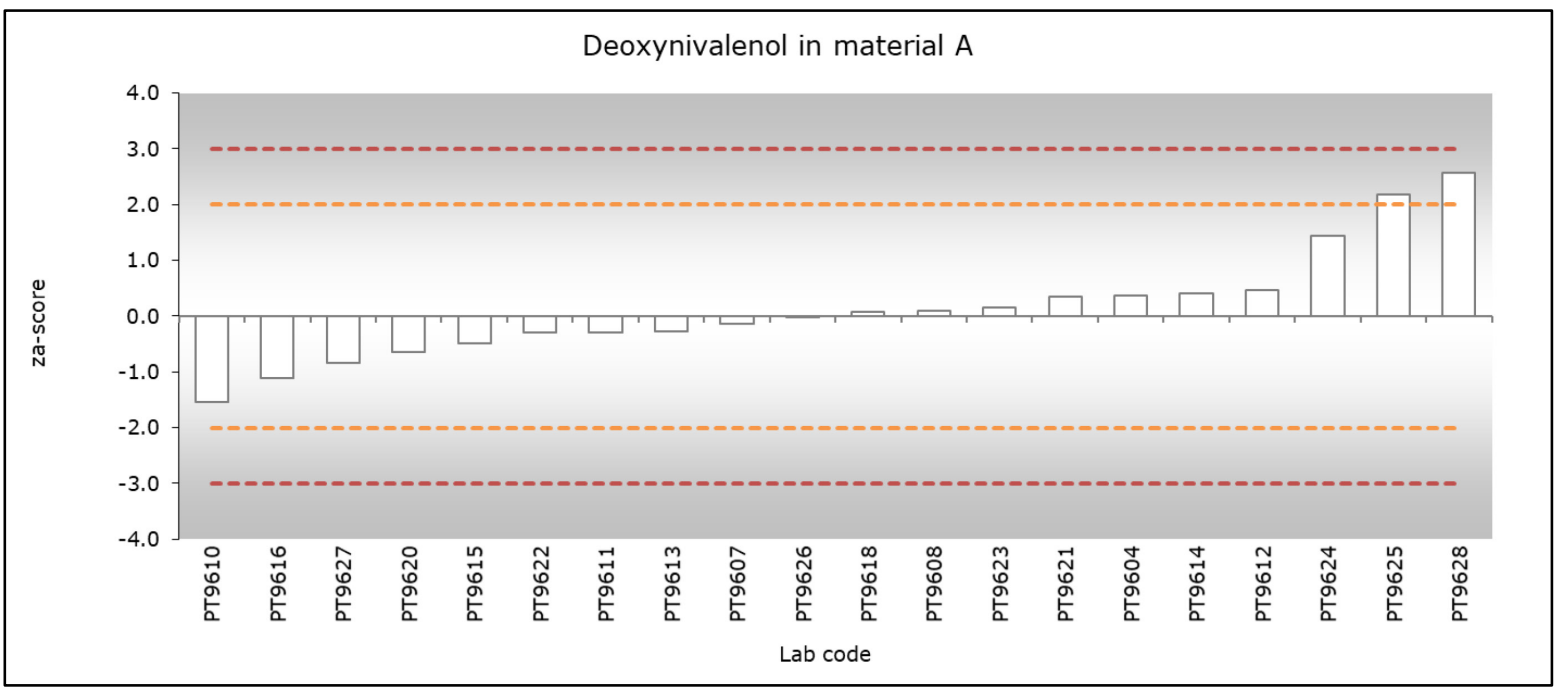

Figure $\boldsymbol{b} \quad$ Graphical representation of the $z_{a}$-scores for deoxynivalenol in material $A$. The $X \pm 2 \sigma_{P}$ lines (dotted) are calculated according to equation I in \$3.4.

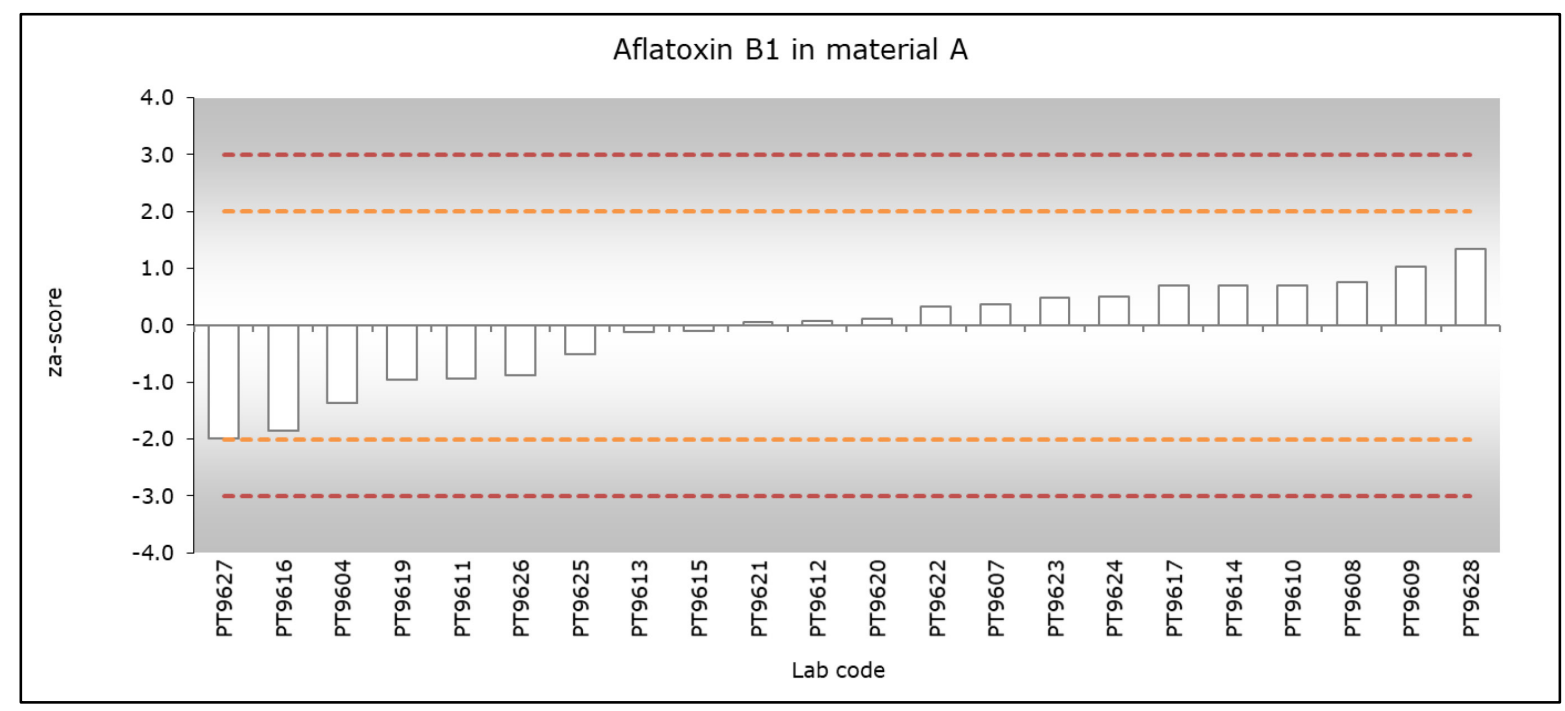

Figure $\boldsymbol{c} \quad$ Graphical representation of the $z_{a}$-scores for aflatoxin $B 1$ in material $A$. The $X \pm 2 \sigma_{P}$ lines (dotted) are calculated according to equation I in \$3.4. 
Zearalenone in material $\mathrm{A}$

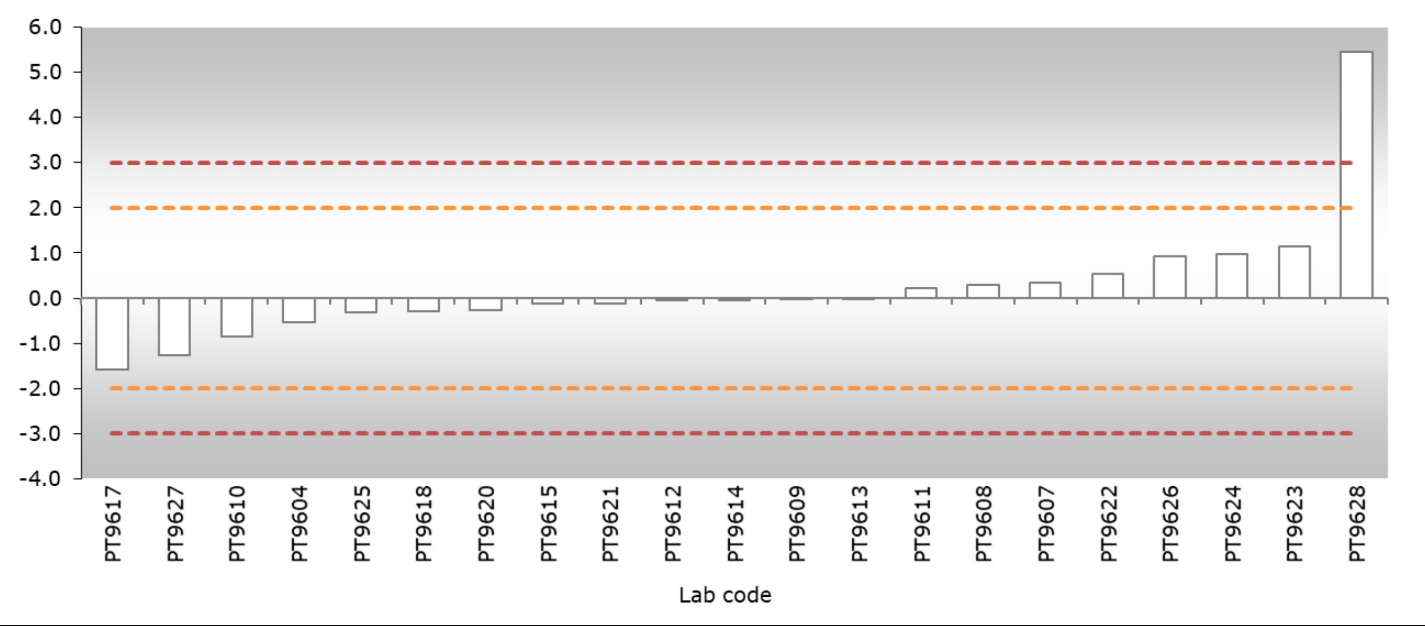

Figure d Graphical representation of the $z_{a}$-scores for zearalenone in material $A$. The $X \pm 2 \sigma_{P}$ lines (dotted) are calculated according to equation I in $\S 3.4$.

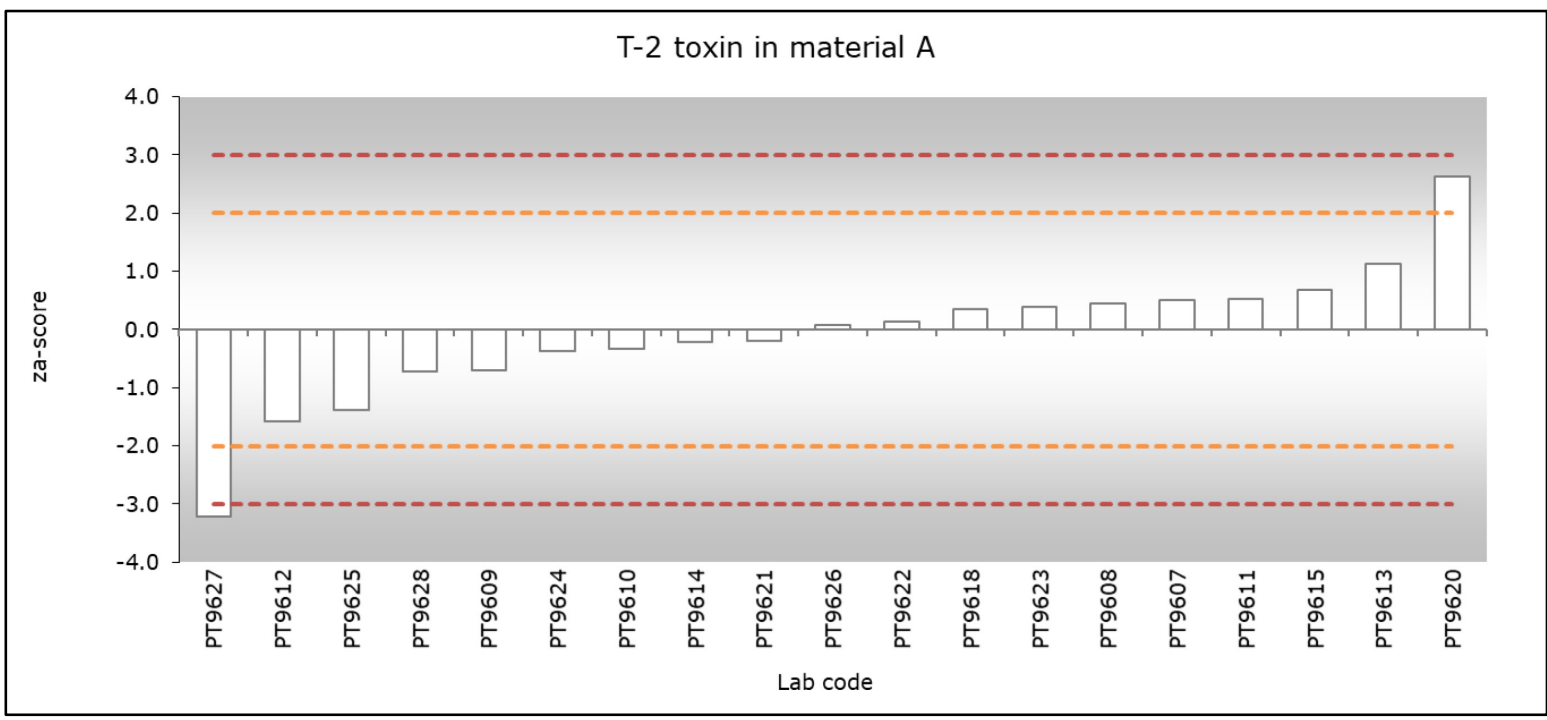

Figure e Graphical representation of the $z_{a}$-scores for $T$-2 toxin in material $A$. The $X \pm 2 \sigma_{P}$ lines (dotted) are calculated according to equation I in §3.4.

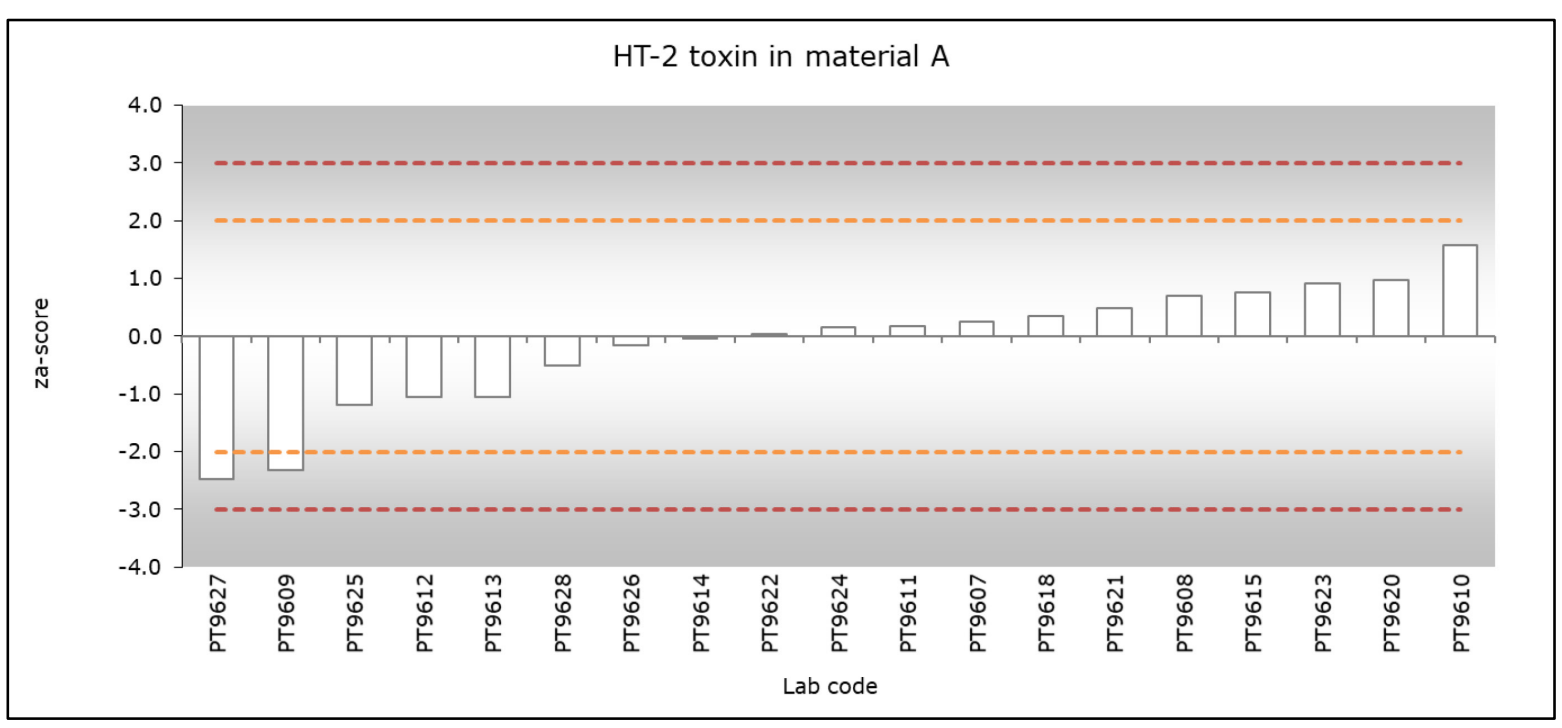

Figure $\boldsymbol{f} \quad$ Graphical representation of the $z_{a}$-scores for HT-2 toxin in material A. The $X \pm 2 \sigma_{P}$ lines (dotted) are calculated according to equation I in $\$ 3.4$. 
Sum of T-2 and HT-2 toxin in material A

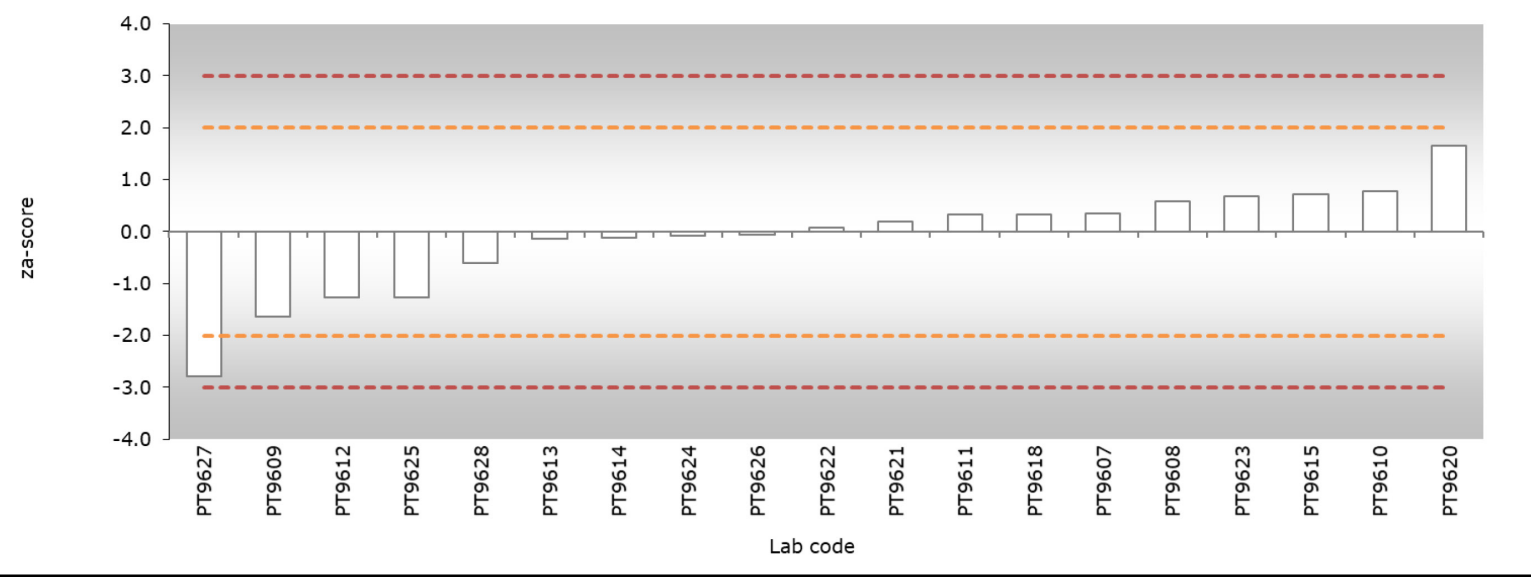

Figure g Graphical representation of the $z_{a}$-scores for the sum of T-2 and HT-2 toxin in material A. The $X \pm 2 \sigma_{p}$ lines (dotted) are calculated according to equation I in \$3.4. 


\section{Annex 7 Results material B}

\begin{tabular}{|c|c|c|c|c|c|c|}
\hline \multirow[b]{2}{*}{$\begin{array}{l}\text { Lab } \\
\text { code }\end{array}$} & \multicolumn{2}{|c|}{$\begin{array}{c}\text { 15-Acetyl-DON } \\
\text { CV: } 152 \mu \mathrm{gg} / \mathrm{kg} \\
\text { u: } 27 \mu \mathrm{gg} / \mathrm{kg} \\
\sigma_{\mathrm{p}}: 38 \mu \mathrm{g} / \mathrm{kg} \\
\text { robust o: } 48 \mu \mathrm{gg} / \mathrm{kg}\end{array}$} & $\begin{array}{c}\text { 3-Acetyl-DON } \\
\text { CV: } 645 \mu g / k g \\
\text { u: } 33 \mu \mathrm{g} / \mathrm{kg} \\
\text { op: } 110 \mu \mathrm{g} / \mathrm{kg} \\
\text { robust o: } 69 \mu \mathrm{\mu g} / \mathrm{kg}\end{array}$ & $\begin{array}{l}\text { DON-3-glucoside } \\
\text { CV: } 1144 \mu \mathrm{\mu g} / \mathrm{kg} \\
\text { u: } 261 \mu \mathrm{g} / \mathrm{kg} \\
\text { op: } 286 \mu \mathrm{g} / \mathrm{kg} \\
\text { robust } 0: 418 \mu \mathrm{kg} / \mathrm{kg}\end{array}$ & \multicolumn{2}{|c|}{$\begin{array}{c}\text { DON } \\
\text { CV: } 4268 \mu \mathrm{g} / \mathrm{kg} \\
\text { u: } 209 \mu \mathrm{g} / \mathrm{kg} \\
\sigma_{\mathrm{p}}: 549 \mu \mathrm{g} / \mathrm{kg} \\
\text { robust } \sigma: 729 \mu \mathrm{gg} / \mathrm{kg}\end{array}$} \\
\hline & $\begin{array}{l}\text { Result } \\
(\mu \mathrm{g} / \mathrm{kg})\end{array}$ & $\mathrm{z}_{\mathrm{a}}$-score & $\begin{array}{c}\text { Result } \quad z_{a} \text {-score } \\
(\mu g / k g)\end{array}$ & $\begin{array}{cc}\text { Result } & z_{a} \text {-score } \\
(\mu g / k g) & \end{array}$ & $\begin{array}{c}\text { Result } \\
(\mu \mathrm{gg} / \mathrm{kg})\end{array}$ & $\mathbf{z}^{\prime} \mathrm{a}$-score \\
\hline PT9604 & & NO & & NO & 4530 & 0.45 \\
\hline PT9607 & & STATISTICAL & & STATISTICAL & 3909 & -0.61 \\
\hline PT9608 & 106 & EVALUATION & 0.23 & EVALUATION & 4249 & -0.03 \\
\hline PT9609 & & POSSIBLE & & POSSIBLE & $\mathrm{FN}$ & \\
\hline PT9610 & & & & & 2627 & -2.79 \\
\hline PT9611 & 240 & TOO & -1.53 & TOO & 3460 & -1.38 \\
\hline PT9612 & & LITTLE & & LITTLE & 4747.2 & 0.82 \\
\hline PT9613 & & RESULTS & & RESULTS & 3968.75 & -0.51 \\
\hline PT9614 & 514 & & -1.24 & & 4790 & 0.89 \\
\hline PT9615 & \multicolumn{3}{|c|}{471.4 for the sum of $15-A c-D O N$ and $3-A c-D O N$} & & 3826.6 & -0.50 \\
\hline \multicolumn{7}{|l|}{ PT9616 } \\
\hline \multicolumn{7}{|l|}{ PT9617 } \\
\hline PT9618 & \multicolumn{3}{|c|}{1300 for the sum of $15-A c-D O N$ and $3-A c-D O N$} & & 4330.5 & 0.07 \\
\hline \multicolumn{7}{|l|}{ PT9619 } \\
\hline PT9620 & nd & & -1.94 & 1517 & 3386 & -1.50 \\
\hline PT9621 & nd & & 0.55 & 726 & 4436 & 0.29 \\
\hline PT9622 & & & & & 4530 & 0.45 \\
\hline PT9623 & & & & & 4300 & 0.05 \\
\hline PT9624 & 135.73 & & 674.54 & 1015.82 & 5614.24 & 2.29 \\
\hline PT9625 & nd & & & & 5682 & 2.41 \\
\hline PT9626 & 130 & & 0.61 & & 4160 & -0.18 \\
\hline PT9627 & & & & & 3180 & -1.85 \\
\hline PT9628 & & & & & 5591 & 2.25 \\
\hline \multicolumn{7}{|c|}{$\mathrm{CV} \quad=$ consensus value } \\
\hline \multicolumn{7}{|c|}{$=$ uncertainty of consensus value } \\
\hline nd $\quad=n$ & t detected & & & & & \\
\hline
\end{tabular}




\begin{tabular}{|c|c|c|c|c|c|c|}
\hline \multirow[b]{2}{*}{$\begin{array}{l}\text { Lab } \\
\text { code }\end{array}$} & \multicolumn{2}{|c|}{$\begin{array}{c}\text { Aflatoxin B1 } \\
\text { CV: } 10.3 \mu g / k g \\
\text { u: } 0.43 \mu g / k g \\
\sigma_{p}: 2.6 \mu g / k g \\
\text { robust } 0: 1.6 \mu g / k g\end{array}$} & $\begin{array}{c}\text { Enniatin B } \\
\text { CV: } 115 \mu g / k g \\
\text { u: } 25 \mu g / k g \\
\sigma_{p}: 29 \mu g / k g \\
\text { robust o: } 39 \mu \mathrm{g} / \mathrm{kg}\end{array}$ & $\begin{array}{c}\text { Enniatin B1 } \\
\text { CV: } 65 \mu \mathrm{gg} / \mathrm{kg} \\
\text { u: } 22 \mu \mathrm{g} / \mathrm{kg} \\
\sigma_{\mathrm{p}}: 16.2 \mu \mathrm{kg} / \mathrm{kg} \\
\text { robust } 0: 35 \mu \mathrm{g} / \mathrm{kg}\end{array}$ & \multicolumn{2}{|c|}{$\begin{array}{c}\text { Zearalenone } \\
\mathrm{CV}: 289 \mu \mathrm{gg} / \mathrm{kg} \\
\text { u: } 10.2 \mu \mathrm{gg} / \mathrm{kg} \\
\sigma_{\mathrm{p}}: \mathbf{7 2 \mu \mathrm { kg }} \\
\text { robust } 0: 38 \mu \mathrm{g} / \mathrm{kg}\end{array}$} \\
\hline & $\begin{array}{l}\text { Result } \\
(\mu \mathrm{g} / \mathrm{kg})\end{array}$ & $\mathrm{z}_{\mathrm{a}}$-score & $\begin{array}{c}\text { Result } \quad z_{a} \text {-score } \\
(\mu g / k g)\end{array}$ & $\begin{array}{l}\text { Result } \quad z_{a} \text {-score } \\
(\mu g / k g)\end{array}$ & $\begin{array}{l}\text { Result } \\
\text { ( } \mu g / k g)\end{array}$ & $\mathrm{z}_{\mathrm{a}}$-score \\
\hline PT9604 & 6.7 & -1.40 & NO & NO & 314 & 0.35 \\
\hline PT9607 & 11.09 & 0.31 & STATISTICAL & STATISTICAL & 285 & -0.05 \\
\hline PT9608 & 11.5 & 0.47 & EVALUATION & EVALUATION & 313 & 0.34 \\
\hline РT9609 & 11 & 0.27 & POSSIBLE & POSSIBLE & 280 & -0.12 \\
\hline РT9610 & 12 & 0.66 & & & 258 & -0.42 \\
\hline РT9611 & 7.9 & -0.93 & TOO & TOO & 299 & 0.15 \\
\hline РT9612 & 10.8 & 0.20 & LITTLE & LITTLE & 292.9 & 0.06 \\
\hline РT9613 & 10.11 & -0.07 & RESULTS & RESULTS & 285.17 & -0.05 \\
\hline РT9614 & 12.6 & 0.89 & & & 293 & 0.06 \\
\hline PT9615 & 10.5 & 0.08 & & & 283 & -0.08 \\
\hline РT9616 & & & & & 178 & -1.53 \\
\hline PT9617 & 12 & 0.66 & & & 172 & -1.62 \\
\hline PT9618 & & & 115.3 & 110.3 & 275.7 & -0.18 \\
\hline PT9619 & 7.98 & -0.90 & & & & \\
\hline PT9620 & 9.8 & -0.19 & 74.2 & 31.4 & 274 & -0.20 \\
\hline PT9621 & 10 & -0.12 & & & 280 & -0.12 \\
\hline PT9622 & 10.4 & 0.04 & & & 311 & 0.31 \\
\hline РT9623 & 11.3 & 0.39 & & & 390 & 1.41 \\
\hline РT9624 & 11.59 & 0.50 & 115.56 & 69.74 & 322.73 & 0.47 \\
\hline PT9625 & 9.3 & -0.39 & & & 259 & -0.41 \\
\hline РT9626 & 6.3 & -1.55 & & & 364 & 1.05 \\
\hline PT9627 & 5.45 & -1.88 & & & 194 & -1.31 \\
\hline РT9628 & 10.6 & 0.12 & & & 389 & 1.39 \\
\hline
\end{tabular}




\begin{tabular}{|c|c|c|c|c|c|c|}
\hline \multirow[b]{2}{*}{$\begin{array}{l}\text { Lab } \\
\text { code }\end{array}$} & \multicolumn{2}{|c|}{$\begin{array}{c}\text { T-2 Toxin } \\
\text { CV: } 24 \mu \mathrm{g} / \mathrm{kg} \\
\text { u: } 0.74 \mu \mathrm{gg} / \mathrm{kg} \\
\sigma_{\mathrm{p}}: 6.1 \mu \mathrm{g} / \mathrm{kg} \\
\text { robust } 0: 2.4 \mu \mathrm{g} / \mathrm{kg}\end{array}$} & \multicolumn{2}{|c|}{$\begin{array}{c}\text { HT-2 Toxin } \\
\text { CV: } 61 \mu \mathrm{g} / \mathrm{kg} \\
\text { u: } 2.7 \mu \mathrm{gg} \\
\sigma_{\mathrm{p}}: 15.2 \mu \mathrm{kg} / \mathrm{kg} \\
\text { robust o: } 9.2 \mu \mathrm{gg} / \mathrm{kg}\end{array}$} & \multicolumn{2}{|c|}{$\begin{array}{l}\text { Sum of T-2 and HT-2 Toxin } \\
\qquad \begin{array}{l}\text { CV: } 83 \mu g / k g \\
\text { u: } 4.3 \mu g / k g \\
\sigma_{p}: 21 \mu g / k g \\
\text { robust } \sigma: 15.0 \mu g / k g\end{array}\end{array}$} \\
\hline & $\begin{array}{c}\text { Result } \\
(\mu \mathrm{g} / \mathrm{kg})\end{array}$ & & $\begin{array}{c}\text { Result } \\
\text { ( } \mu g / k g)\end{array}$ & zai-score & $\begin{array}{c}\text { Result } \\
\text { ( } \mu \mathrm{g} / \mathrm{kg})\end{array}$ & $z_{a}$-score \\
\hline \multicolumn{7}{|l|}{ РT9604 } \\
\hline PT9607 & 23.35 & -0.16 & 61.37 & 0.04 & 84.72 & 0.07 \\
\hline PT9608 & 25.5 & 0.19 & 68.4 & 0.51 & 93.9 & 0.51 \\
\hline РT9609 & $<20$ & & 47 & -0.77 & 47 & -1.74 \\
\hline РT9610 & 24 & -0.05 & 90 & 1.93 & 114 & 1.47 \\
\hline PT9611 & 23 & -0.22 & 53 & -0.43 & 76 & -0.35 \\
\hline PT9612 & $<50.0$ & & $<50.0$ & & & \\
\hline РT9613 & 27 & 0.44 & 36.31 & -1.37 & 63.31 & -0.96 \\
\hline РT9614 & 22.8 & -0.25 & 62.1 & 0.09 & 84.9 & 0.08 \\
\hline РT9615 & 31.5 & 1.18 & 69.8 & 0.60 & 101.3 & 0.87 \\
\hline РT9616 & 22.6 & -0.28 & 56 & -0.26 & 78.6 & -0.23 \\
\hline \multicolumn{7}{|l|}{ РT9617 } \\
\hline PT9618 & 26.2 & 0.31 & 61.5 & 0.05 & 87.7 & 0.21 \\
\hline \multicolumn{7}{|l|}{ PT9619 } \\
\hline PT9620 & 78.9 & 8.98 & 65.4 & 0.31 & 144.3 & 2.93 \\
\hline РT9621 & 21 & -0.55 & 64 & 0.22 & 85 & 0.08 \\
\hline PT9622 & 23.9 & -0.07 & 62.8 & 0.14 & 86.7 & 0.16 \\
\hline РT9623 & 24 & -0.05 & 64 & 0.22 & 88 & 0.23 \\
\hline РT9624 & 21.53 & -0.46 & 64.82 & 0.27 & 86.35 & 0.15 \\
\hline РT9625 & 47 & 3.73 & FN (LOD 15) & & 47 & -1.74 \\
\hline PT9626 & 23 & -0.22 & 69.1 & 0.55 & 92.1 & 0.42 \\
\hline PT9627 & FN $(<10)$ & & 23.8 & -2.07 & $23.8^{*}$ & -2.86 \\
\hline РT9628 & nd, $<42$ & & 47.1 & -0.76 & 47.1 & -1.74 \\
\hline
\end{tabular}

* taken into account the instability of HT-2 toxin this z-score would still be questionable. 
3-acetyl-Deoxynivalenol in material B

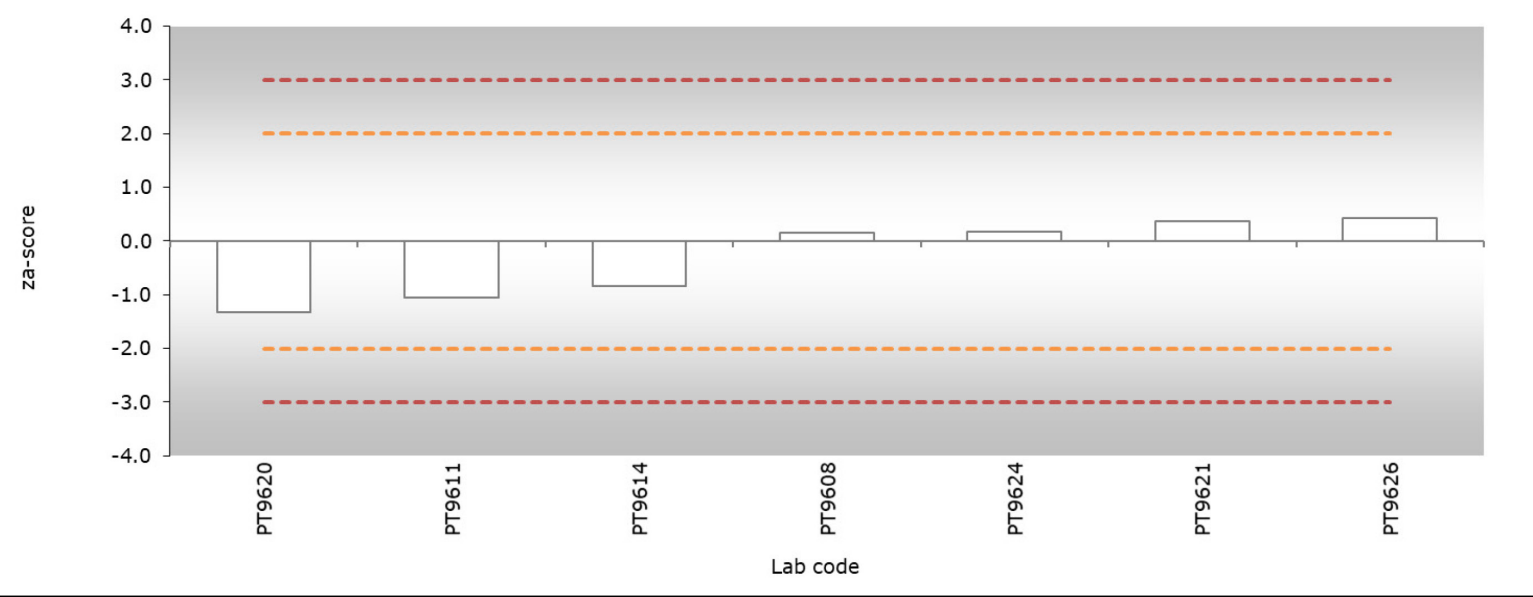

Figure a Graphical representation of the $z_{a}$-scores for 3-acetyl-deoxynivalenol in material $B$. The $X \pm 2 \sigma_{p}$ lines (dotted) are calculated according to equation I in §3.4.

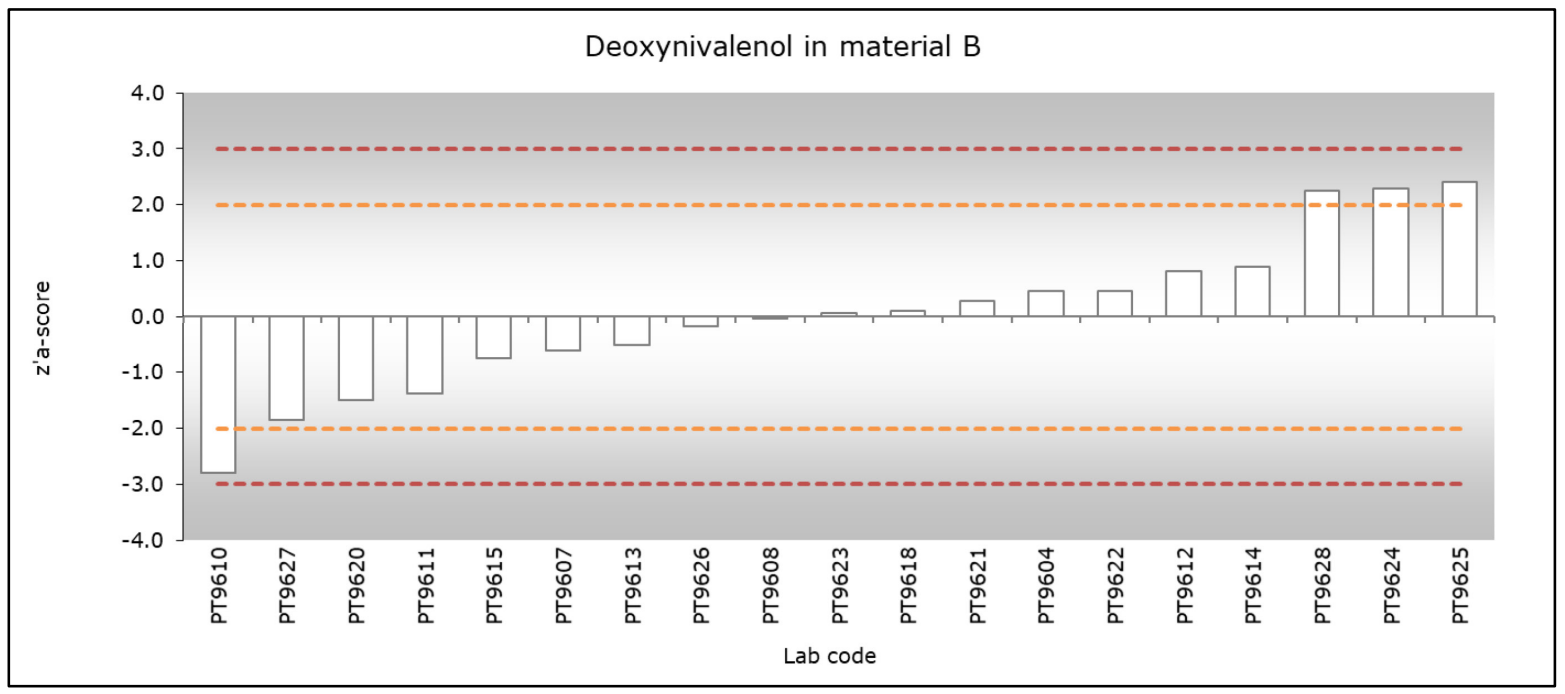

Figure $\boldsymbol{b} \quad$ Graphical representation of the $z^{\prime}{ }_{a}$-scores for deoxynivalenol in material $B$. The $X \pm 2 \sigma_{P}$ lines (dotted) are calculated according to equation II in $\$ 3.4$.

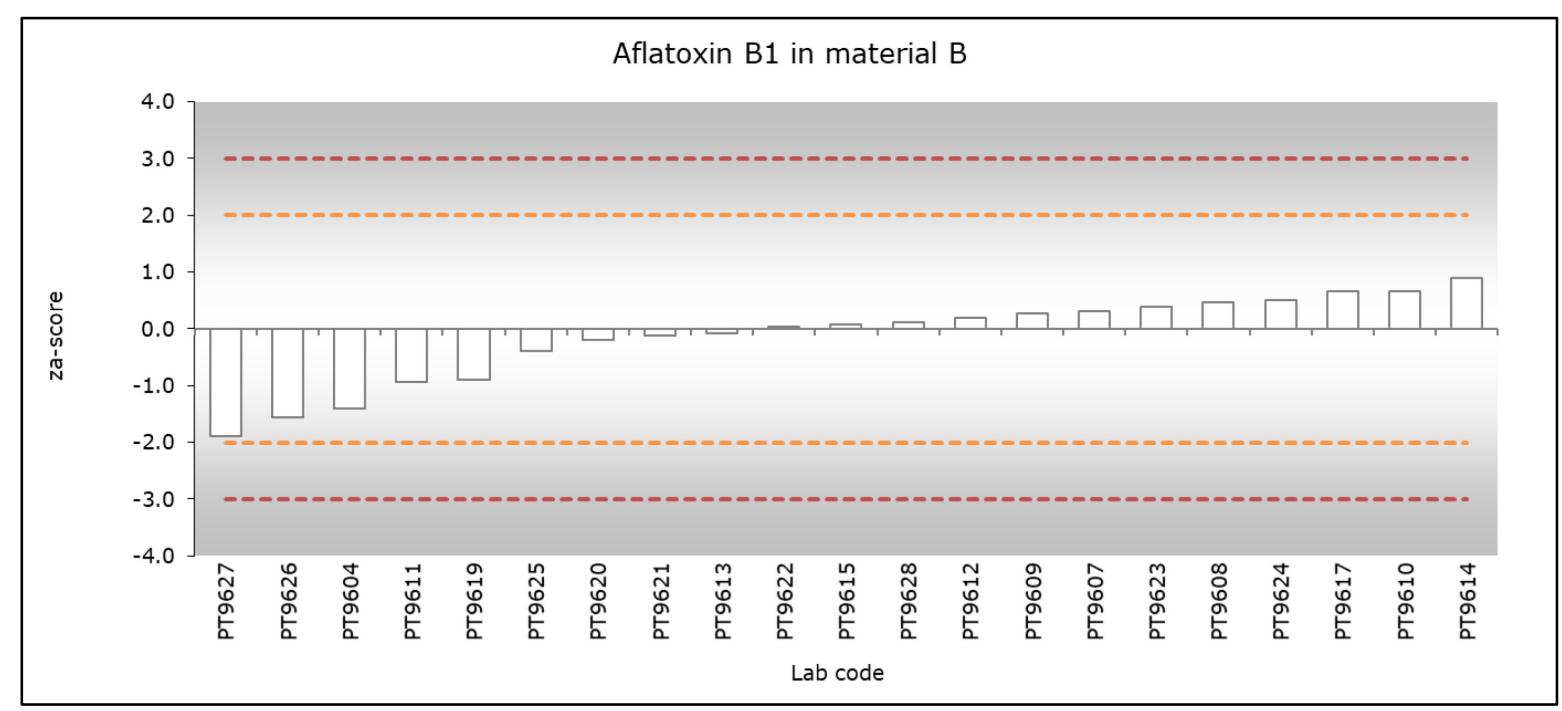

Figure $\boldsymbol{c} \quad$ Graphical representation of the $z_{a}$-scores for aflatoxin $B 1$ in material $B$. The $X \pm 2 \sigma_{P}$ lines (dotted) are calculated according to equation I in $\$ 3.4$. 
Zearalenone in material $\mathrm{B}$

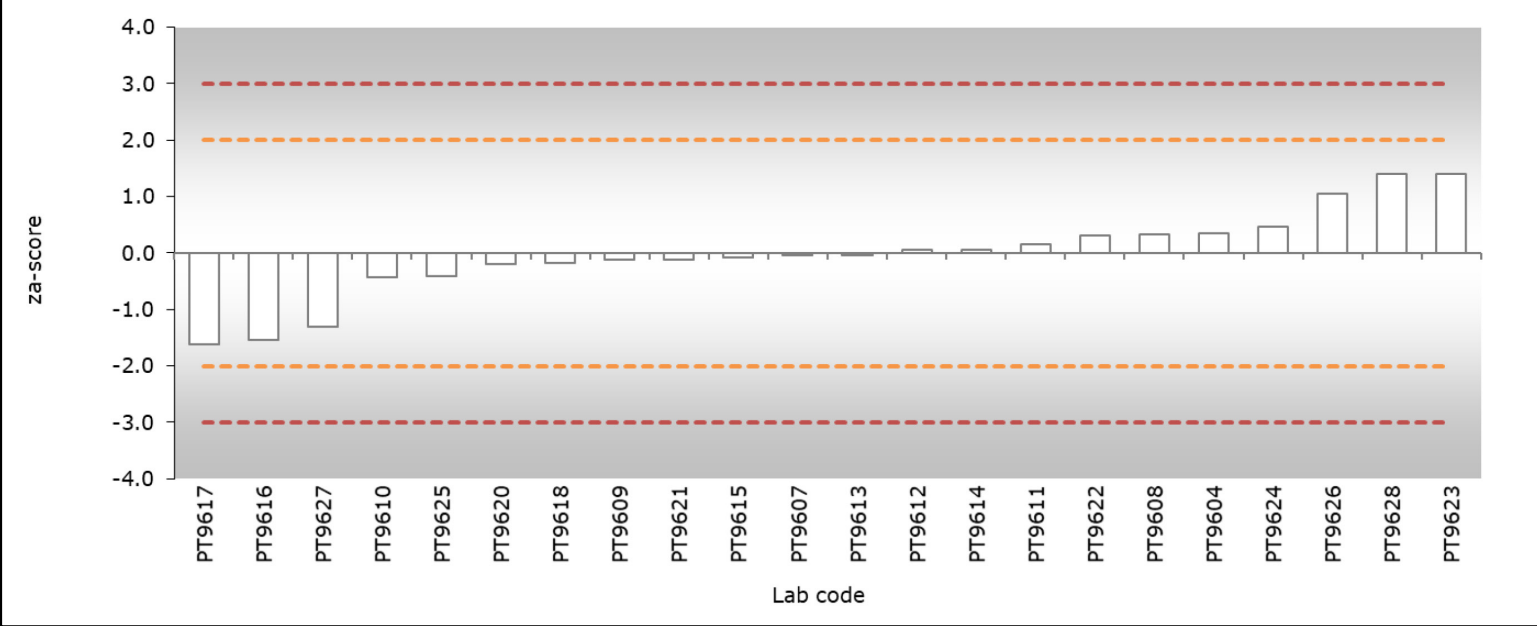

Figure d Graphical representation of the $z_{a}$-scores for zearalenone in material $B$. The $X \pm 2 \sigma_{p}$ lines (dotted) are calculated according to equation I in $\$ 3.4$.

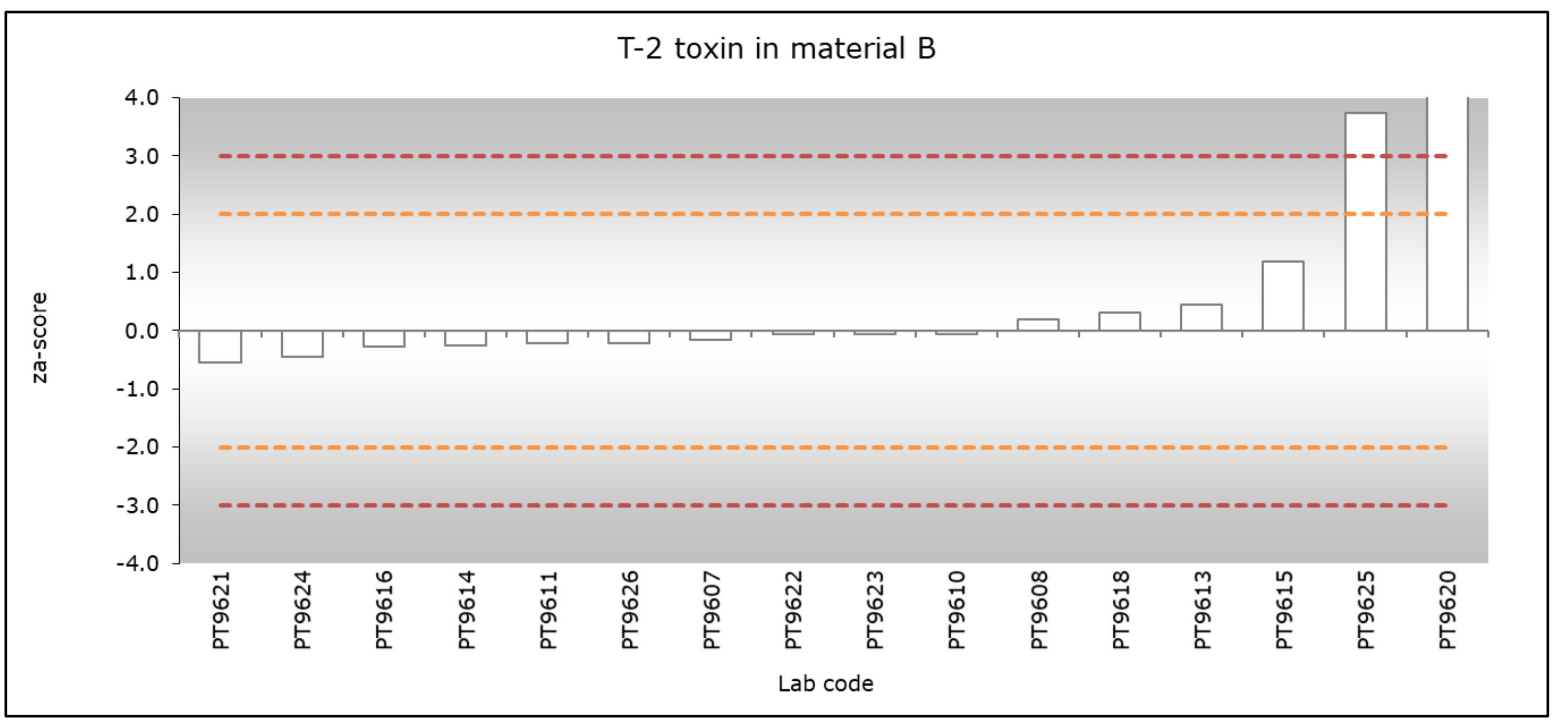

Figure e Graphical representation of the $z_{a}$-scores for $T-2$ toxin in material $B$. The $X \pm 2 \sigma_{P}$ lines (dotted) are calculated according to equation I in $\$ 3.4$.

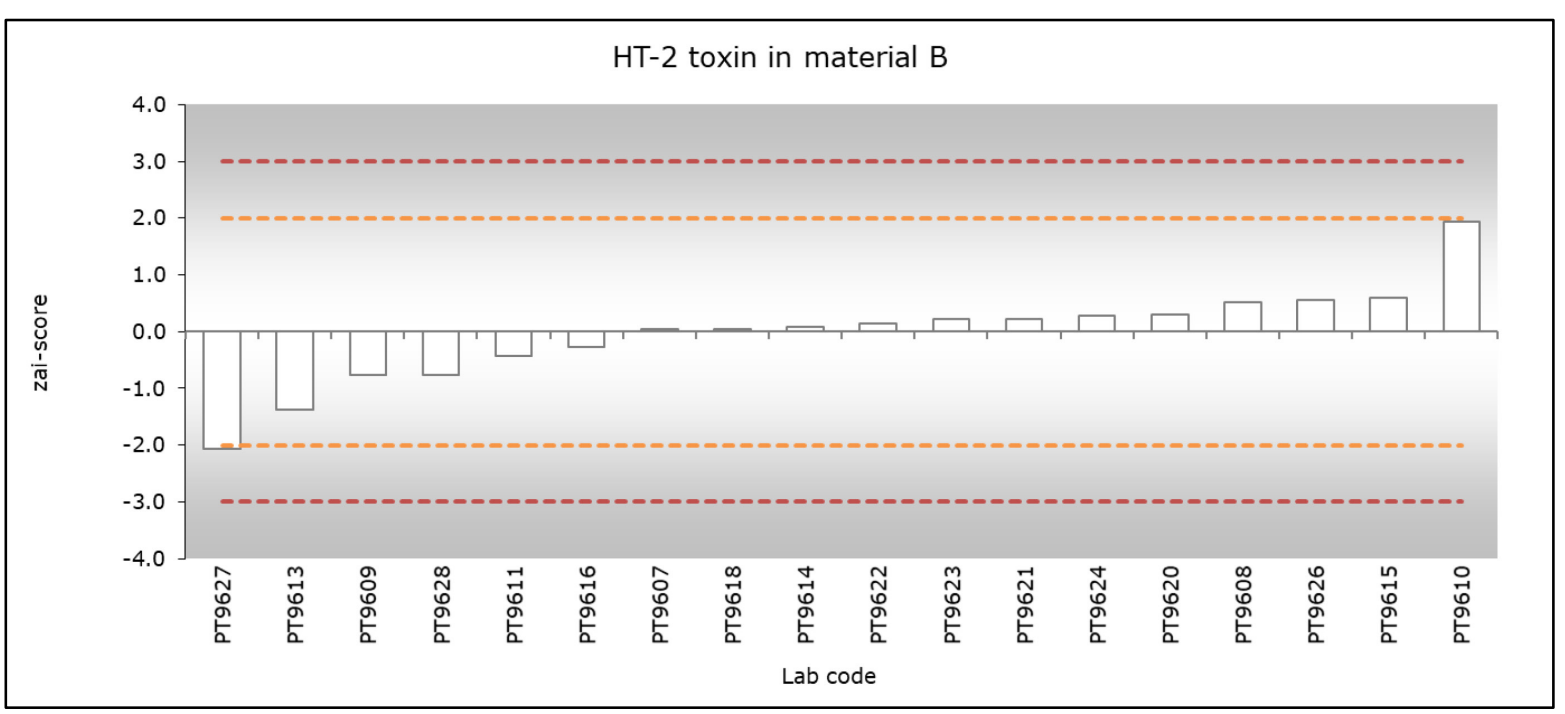

Figure $\boldsymbol{f} \quad$ Graphical representation of the $z_{a}$-scores for HT-2 toxin in material $B$. The $X \pm 2 \sigma_{p}$ lines (dotted) are calculated according to equation III in \$3.4. 


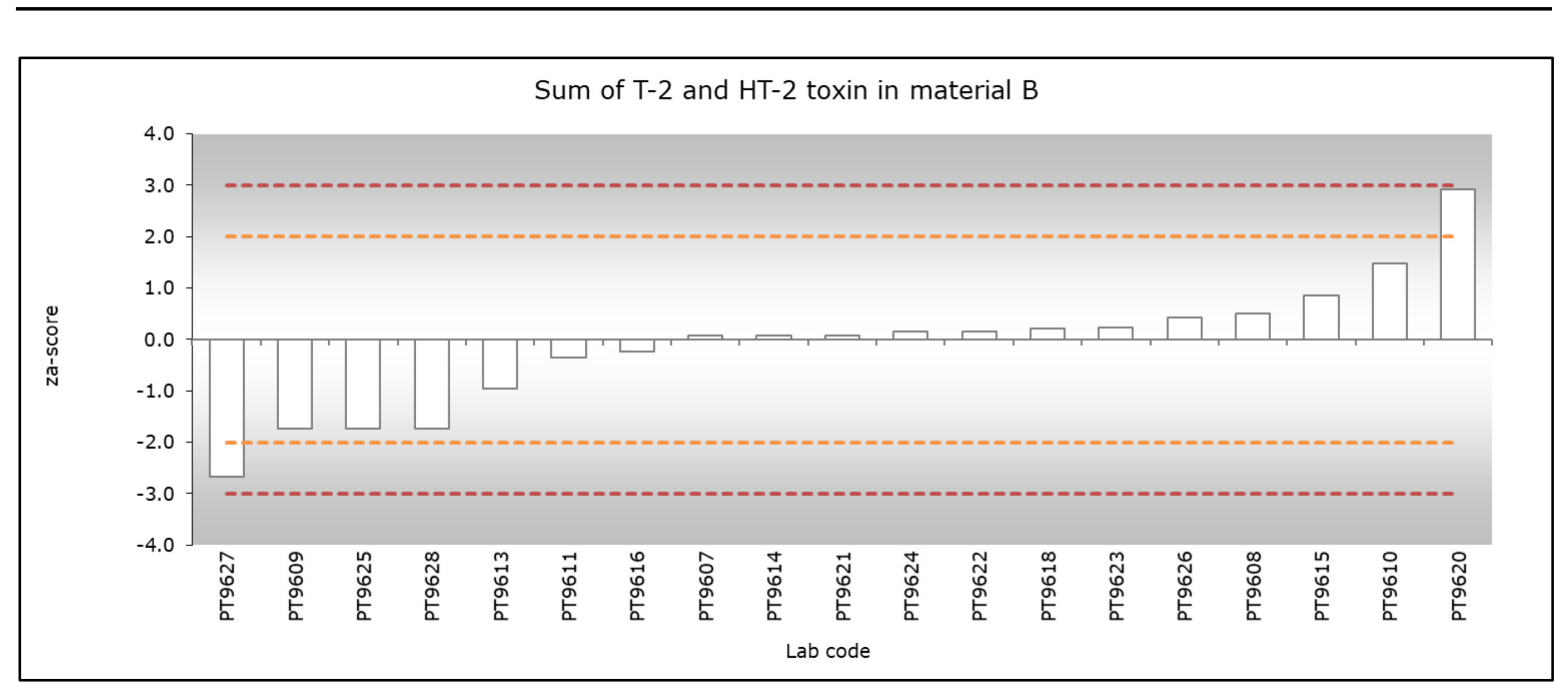

Figure $g$ Graphical representation of the $z_{a}$-scores for the sum of T-2 and HT-2 toxin in material $B$. The $X \pm 2 \sigma_{P}$ lines (dotted) are calculated according to equation I in §3.4. 


\section{Annex 8 False positive and false negative results}

False negative results

\begin{tabular}{ccc} 
Lab code & Material & Compound missed \\
PT9609 & A & DON \\
\hline PT9609 & B & DON \\
\hline PT9625 & B & HT-2 toxin \\
\hline PT9627 & B & T-2 toxin \\
\hline
\end{tabular}

\section{False positive results}

\begin{tabular}{ccc} 
Lab code & Material & Compound detected \\
PT9627 & A & $2.8 \mu \mathrm{g} / \mathrm{kg}$ ochratoxin A \\
\hline PT9627 & B & $3.5 \mu \mathrm{g} / \mathrm{kg}$ ochratoxin A \\
\hline
\end{tabular}




\section{Annex 9 Overview performance per laboratory}

\begin{tabular}{lc} 
Laboratory code & Performance \\
PT9604 & 6 out of 14 satisfactory results \\
\hline PT9607 & 12 out of 14 satisfactory results \\
\hline PT9608 & 14 out of 14 satisfactory results, optimal performance \\
\hline PT9609 & 11 out of 14 satisfactory results, 1 questionable result \\
\hline PT9610 14 satisfactory results, 1 questionable result, 1 qualitative result, 2 false negative results \\
\hline PT9611 & 14 out of 14 satisfactory results, optimal performance \\
\hline PT9612 & 9 out of 14 satisfactory results, two qualitative results \\
\hline PT9613 & 12 out of 14 satisfactory results \\
\hline PT9614 & 14 out of 14 satisfactory results, optimal performance \\
\hline PT9615 & 12 out of 14 satisfactory results \\
\hline PT9616 & 6 out of 14 satisfactory results \\
\hline PT9617 & 4 out of 14 satisfactory results \\
\hline PT9618 & 10 out of 14 satisfactory results \\
\hline PT9619 & 2 out of 14 satisfactory results \\
\hline PT9620 & 11 out of 14 satisfactory results, 2 questionable results, 1 unsatisfactory result \\
\hline PT9621 & 14 out of 14 satisfactory results, optimal performance \\
\hline PT9622 & 12 out of 14 satisfactory results \\
\hline PT9623 & 12 out of 14 satisfactory results \\
\hline PT9624 & 8 out of 14 satisfactory results, 2 questionable and 1 unsatisfactory result \\
\hline PT9625 14 satisfactory results, 2 questionable results, 1 unsatisfactory result, 1 false negative result \\
\hline PT9626 & 14 out of 14 satisfactory results, optimal performance \\
\hline PT9627 & two false positive results \\
\hline PT9628 14 satisfactory results, 4 questionable resuls, 1 unsatisfactory result, 1 false negative and
\end{tabular}


Wageningen Food Safety Research

P.O. Box 230

6700 AE Wageningen

The Netherlands

T +31 (0)317480256

www.wur.eu/food-safety-research

WFSR report 2019.012
The mission of Wageningen University \& Research is "To explore the potential of nature to improve the quality of life". Under the banner Wageningen University \& Research, Wageningen University and the specialised research institutes of the Wageningen Research Foundation have joined forces in contributing to finding solutions to important questions in the domain of healthy food and living environment. With its roughly 30 branches, 5,000 employees and 10,000 students, Wageningen University \& Research is one of the leading organisations in its domain. The unique Wageningen approach lies in its integrated approach to issues and the collaboration between different disciplines. 



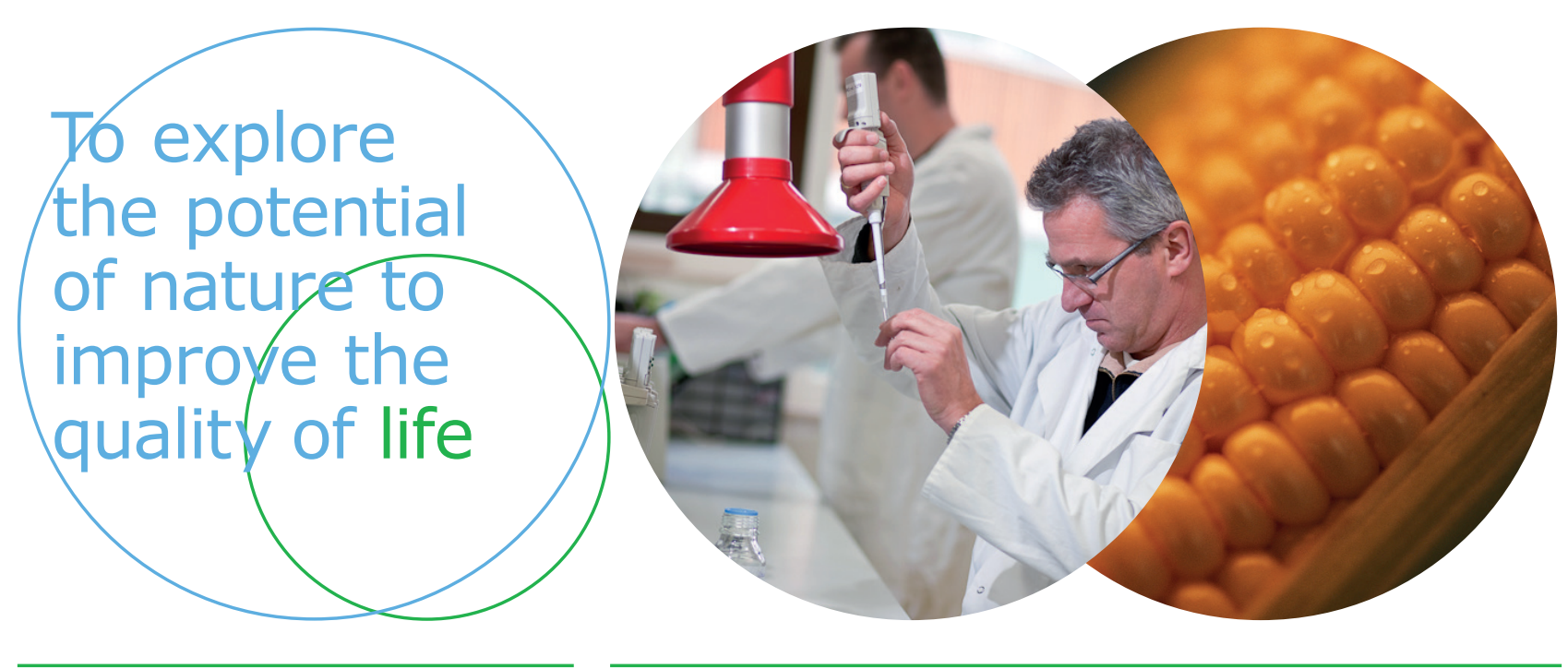

Wageningen Food Safety Research P.O. Box 230

6700 AE Wageningen

The Netherlands

T +31 (0)317480256

www.wur.eu/food-safety-research

WFSR report 2019.012
The mission of Wageningen University \& Research is "To explore the potential of nature to improve the quality of life". Under the banner Wageningen University $\&$ Research, Wageningen University and the specialised research institutes of the Wageningen Research Foundation have joined forces in contributing to inding solutions to important questions in the domain of healthy food and living environment. With its roughly 30 branches, 5,000 employees and 10,000 students, Wageningen University \& Research is one of the leading organisations in its domain. The unique Wageningen approach lies in its integrated approach to issues and the collaboration between different disciplines. 